Supplement of Ocean Sci., 11, 743-757, 2015

http://www.ocean-sci.net/11/743/2015/

doi:10.5194/os-11-743-2015-supplement

(C) Author(s) 2015. CC Attribution 3.0 License.

(c) (1)

Ocean Science

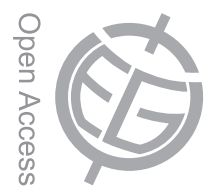

Supplement of

\title{
Transport of volume, heat, and salt towards the Arctic in the Faroe Current 1993-2013
}

\section{B. Hansen et al.}

Correspondence to: B. Hansen (bogihan@hav.fo)

The copyright of individual parts of the supplement might differ from the CC-BY 3.0 licence. 


\section{Contents}

1 Introduction

2 Material and methods

2.1 CTD data

2.2 ADCP data

2.2.1 Vertical extrapolation of ADCP profiles

2.2.2 ADCP temperature

2.3 Drifter data

2.4 Altimetry data

2.4.1 EOF modes

2.4.2 Calibrating the altimetry data

2.4.3 The average surface velocity

3 The velocity field

3.1 Eastward surface velocity

3.2 Vertical variation of the eastward velocity

4 The temperature and salinity fields

4.1 Average temperature and salinity fields

4.2 The depth of the $4^{\circ} \mathrm{C}$ isotherm

4.3 Bottom temperature at ADCP site NE

4.4 The northern surface boundary of Atlantic water

4.5 Atlantic water temperature

4.6 Simulating the temperature distribution

4.7 Atlantic water salinity

4.8 Simulating the salinity distribution

5 Volume transport

5.1 Combining altimetry surface velocity with ADCP velocity profile

5.2 Combining altimetry surface velocity with geostrophic velocity profile

5.3 Total volume transport

5.4 Volume transport of Atlantic water

5.5 Comparison of old and new transport estimates

6 Transport of heat and salt

6.1 Relative heat transport

6.2 Salt transport

References

Appendix A

Appendix B 


\section{Introduction}

This document provides supplementary details on the Atlantic inflow branch to the Nordic Seas that flows between Iceland and Faroes across the Iceland-Faroe Ridge (Figure 1.1, left panel) and is termed IF-inflow. This branch continues as the Faroe Current, transporting Atlantic water towards the Arctic. In the document, we supply details on the in situ observational material gathered over a long period (Figure 1.1, right panel) and their integration with satellite altimetry data to provide time series of volume, heat and salt transport.
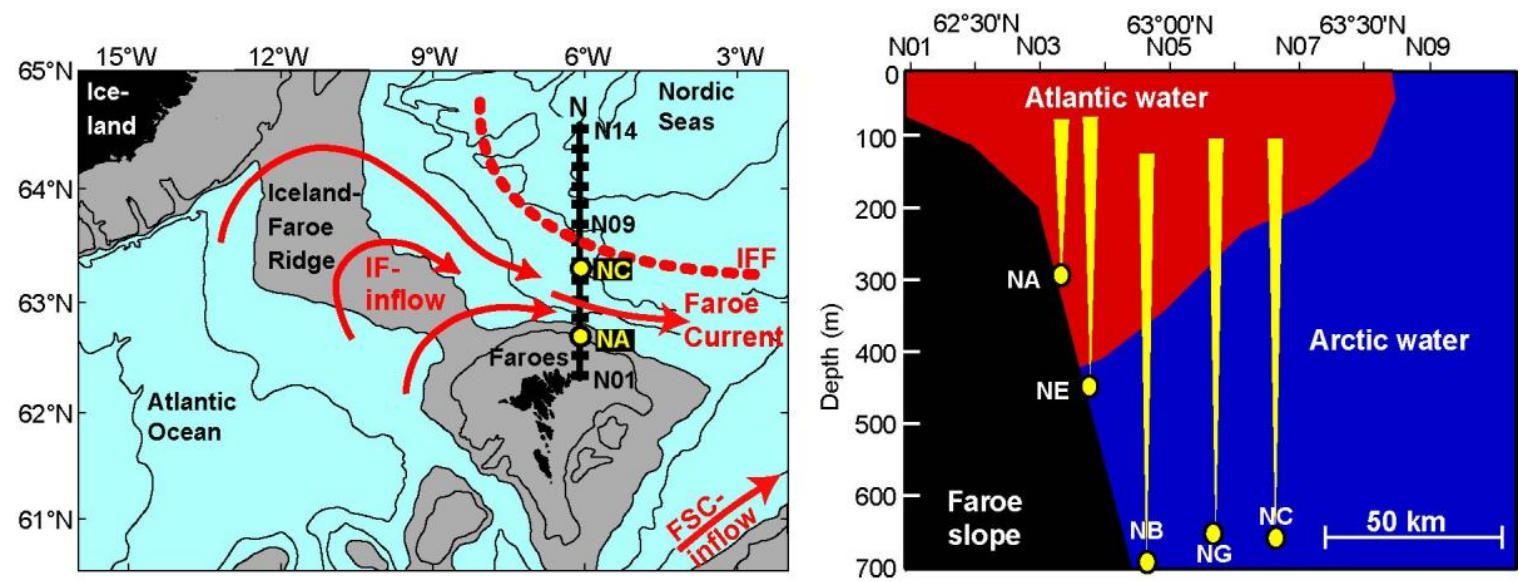

Figure 1.1 Left panel: The region between Iceland and the Scottish shelf with grey areas shallower than $500 \mathrm{~m}$. The two main Atlantic inflow branches are indicated by red arrows. The Iceland-Faroe inflow (IFinflow) crosses the Iceland-Faroe Ridge, meets colder waters, termed Arctic water, in the Iceland-Faroe Front (IFF), and flows north of Faroes in the Faroe Current. The black line extending northwards from the Faroe shelf is the observational section with CTD standard stations N01 to N14 indicated by black rectangles. Yellow circles indicate the innermost (NA) and the outermost (NC) ADCP mooring site on the section. Right panel: typical water mass distribution on the section, location of CTD stations N01 to N09 and of ADCP sites NA, NE, NB, NG, and NC with yellow cones indicating sound beams. 


\section{Material and methods}

By far most of the observational data considered in this report is along a section, section $\mathrm{N}$, extending northwards from the Faroe shelf along longitude $6.083^{\circ} \mathrm{W}\left(6^{\circ} 05^{\prime} \mathrm{W}\right)$. Since the late $1980 \mathrm{~s}$, regular CTD cruises have been carried out along the section on 14 standard stations, labeled N01 to N14. In the mid1990s, efforts were initiated to maintain an array of moored ADCPs (Acoustic Doppler Current Profilers). The data from these CTD and ADCP measurements form the main in-situ data set, but the AVISO data set also includes altimetry data along a line following longitude $6.125^{\circ} \mathrm{W}\left(6^{\circ} 07.5^{\prime} \mathrm{W}\right)$, which is so close that we consider it to be along the same section. We are mainly interested in the southernmost part of the section, which is dominated by Atlantic water and Figure 2.1 illustrates the instrumentation in this part. For completeness, we also include data on drifters that have passed through the section.

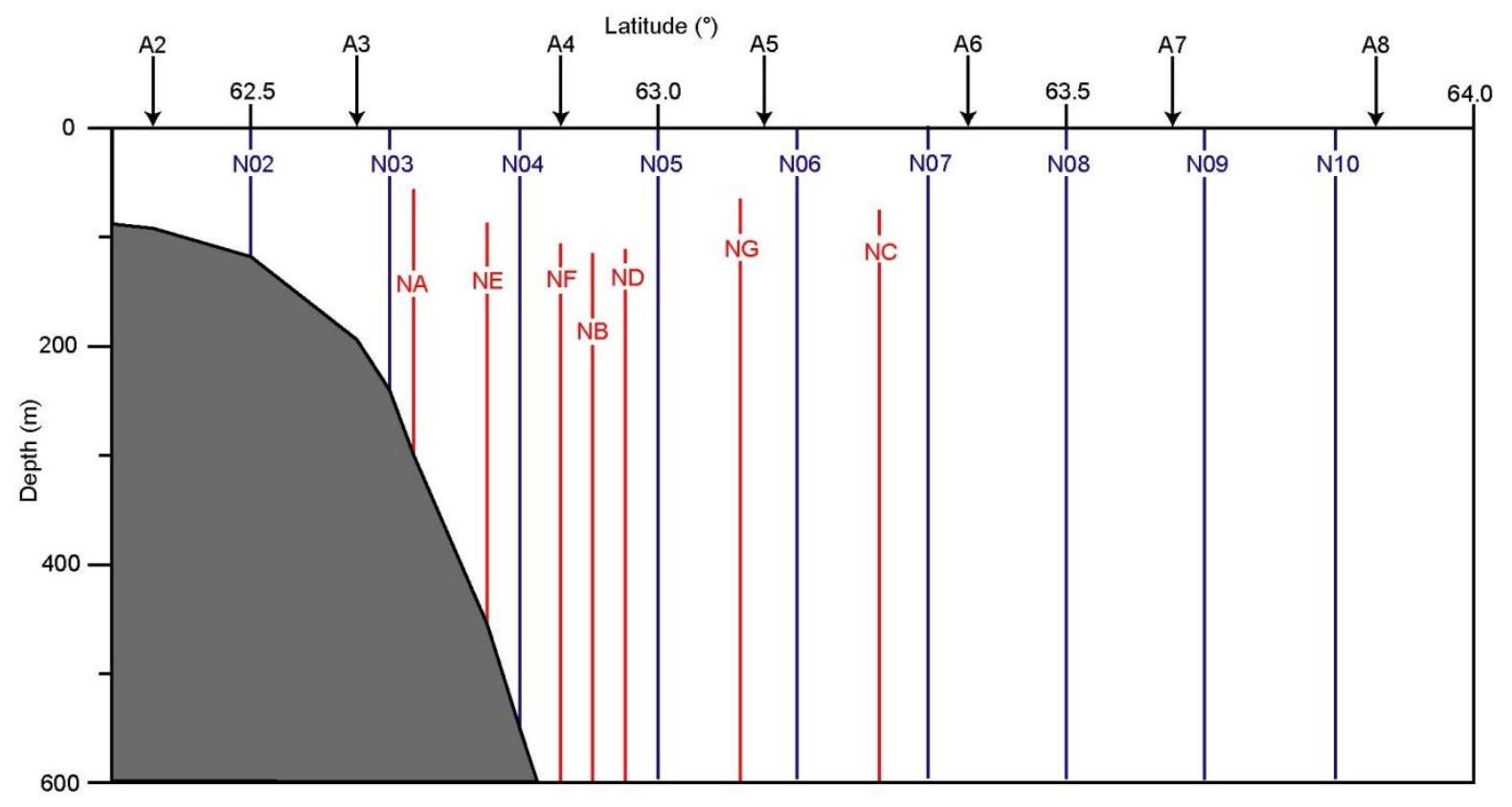

Figure 2.1 The observational section along $6.083^{\circ} \mathrm{W}$. CTD standard stations N02 to N10 are marked by blue lines. ADCP profiles are marked by red lines that extend up to the depth, at which $50 \%$ of the daily averaged profiles are valid. Altimetry points $\mathrm{A}_{2}$ to $\mathrm{A}_{8}$ along $6.125^{\circ} \mathrm{W}$ are marked by black arrows. See Appendix A for details.

\subsection{CTD data}

Fourteen standard stations, labeled N01 to N14, are located equidistantly along the section following $6.083^{\circ} \mathrm{W}$ with a separation of 10 nautical miles from $\mathrm{N} 01$ at $62.333^{\circ} \mathrm{N}$ to $\mathrm{N} 14$ at $64.5^{\circ} \mathrm{N}(\mathrm{N} 14$ is at longitude $\left.6.000^{\circ} \mathrm{W}\right)$. Typically, the section has been occupied on 4 cruises each year since 1988 although bad weather and other conditions have prevented complete coverage in some cases. We use quality controlled and calibrated CTD data averaged to meter intervals with a main focus on data between stations N02 and N11, which contain that part of the section through which the Atlantic water passes. Different instrument models have been used and different calibration procedures. Thus, the CTD data have different quality in different periods and, depending on the use, we have selected different subsets. For the highest quality requirements, especially as regards salinity, we use data from 1997, onwards. 


\subsection{ADCP data}

Between January 1996 and May 2014, ADCPs have been moored at seven different sites along the section (Table 2.2.1). Each site is labelled by a two-letter code beginning with "N". At two sites (NF and ND), only single deployments were made. The other sites (Figure 1.1, right panel) have had repeated deployments, with moorings usually deployed in summer one year and recovered the year after. Thus, there are typically gaps of 2-4 weeks every summer.

Table 2.2.1 Main characteristics of the measurements at the seven ADCP sites

\begin{tabular}{|c|c|c|c|c|c|c|c|}
\hline \multicolumn{2}{|c|}{ Site Latit } & Depth & \multicolumn{4}{|c|}{ Period } & \multirow{2}{*}{$\frac{\text { Days }}{6311}$} \\
\hline $\mathrm{NA}$ & $62.70^{\circ} \mathrm{N}$ & 300 & Jan & 1996 & - May & 2014 & \\
\hline $\mathrm{NE}$ & $62.79^{\circ} \mathrm{N}$ & 455 & Jul & 2000 & - May & 2011 & 2729 \\
\hline $\mathrm{NF}$ & $62.88^{\circ} \mathrm{N}$ & 700 & Jul & 2000 & - Jun & 2001 & 343 \\
\hline NB & $62.92^{\circ} \mathrm{N}$ & 925 & Jun & 1997 & - May & 2014 & 5775 \\
\hline $\mathrm{ND}$ & $62.96^{\circ} \mathrm{N}$ & 1280 & Nov & 1997 & - Jun & 1998 & 213 \\
\hline NG & $63.10^{\circ} \mathrm{N}$ & 1815 & Jul & 2000 & - May & 2014 & 4436 \\
\hline $\mathrm{NC}$ & $63.27^{\circ} \mathrm{N}$ & 1730 & Jun & 1996 & - Jun & 2000 & 1400 \\
\hline
\end{tabular}
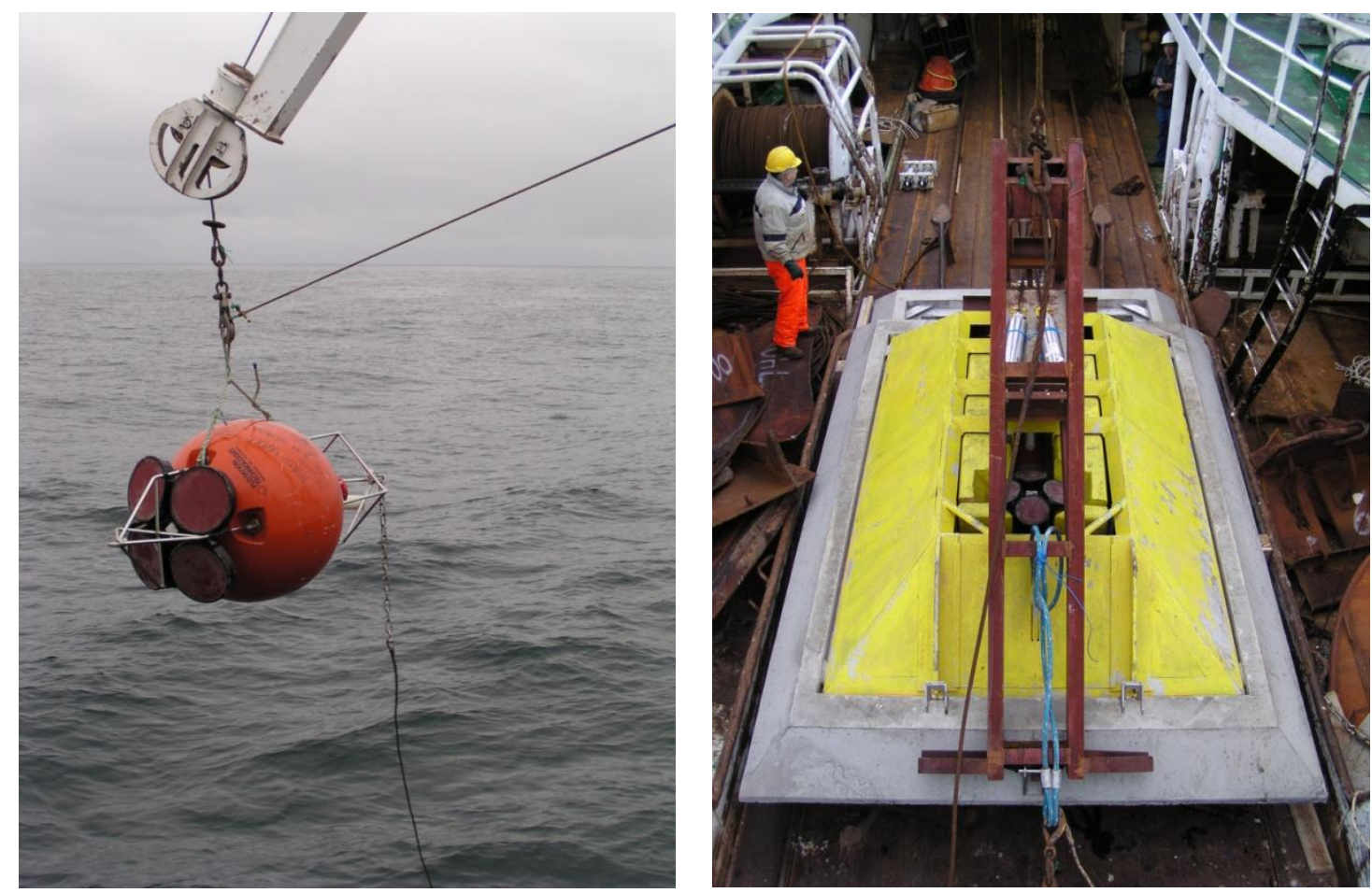

Figure 2.2.1 Left photo: A $75 \mathrm{kHz}$ RDI Broadband ADCP in a Flotation Technology buoy about to be deployed in the top of a traditional mooring. Right photo: A $150 \mathrm{kHz}$ RDI Broadband ADCP in a buoyant aluminium frame (yellow), mounted on a concrete anchor, ready to be lowered to the bottom attached to a special deployment frame (brown).

Except for these gaps, sites NA and NB, have been continuously occupied since summer 1997. NC was occupied from summer 1997 to summer 2000, after which it was replaced by NG. NE was occupied from summer 2000 to summer 2011, but from summer 2001 to summer 2004, it was turned upside down so that only temperature, not velocity data were available. The best ADCP coverage has been with all four "long- 
term" sites $(\mathrm{NA}+\mathrm{NE}+\mathrm{NB}+\mathrm{NG})$ occupied, from summer 2000 to summer 2001 and from summer 2004 to summer 2011. In addition, there are periods with three of these (NA+NB+NC or $\mathrm{NA}+\mathrm{NB}+\mathrm{NG})$ occupied.

At most sites, the ADCPs have been deployed in the top of traditional moorings (Figure 2.2.1, left panel) at sufficient depth to prevent loss from fishing gear. At the shallow sites NA and NE, it has been necessary to put the ADCPs into protective buoyant frames attached to concrete anchors with acoustic releases that were lowered to the bottom (Figure 2.2.1, right panel). The ADCPs have typically pinged every 20 minutes (single pings). After extensive editing and quality control, the data have been averaged to daily values, which are used here.

In addition to velocity profile, the ADCPs have recorded the ambient temperature at the instrument. For the traditional moorings (Figure 2.2.1, left panel), this is in deep cold water and of little use for our purpose. At sites NA and NE, however, the instruments have recorded the bottom temperature at locations where Atlantic water occurs at least some of the time. The ADCP temperature sensors have not been recalibrated and from experience (Hansen and Østerhus, 2007), they are not very accurate. At site NE, the same instrument (sn 1244) was used throughout and so, the bias should be fairly constant. At site NA, on the other hand, the instrument was changed in summer 1999.

\subsection{Drifter data}

From the NOAA surface drifter database (www.aoml.noaa.gov), we downloaded all drifters in the region, noted as having kept the drogue. The tracks clearly illustrate the main core of the Faroe Current (Figure 2.3.1, left panel). The 6-hourly positions were averaged to daily positions, from which daily velocities were determined. Averaging all velocities for a drifter while it was between $6.625^{\circ} \mathrm{W}$ and $5.625^{\circ} \mathrm{W}$, we estimated the eastward velocity of each drifter as it passed the altimetry line $\left(6.125^{\circ} \mathrm{W}\right)$ and plotted it against the latitude where it crossed the altimetry line (Figure 2.3.1, right panel).

It was hoped that this information could be used to calibrate the altimetry data, especially in the northernmost part of the section where we do not have sufficient ADCP coverage. The extreme velocities (Figure 2.3.1, right panel) and high scatter did, however, make this attempt unrealistic.
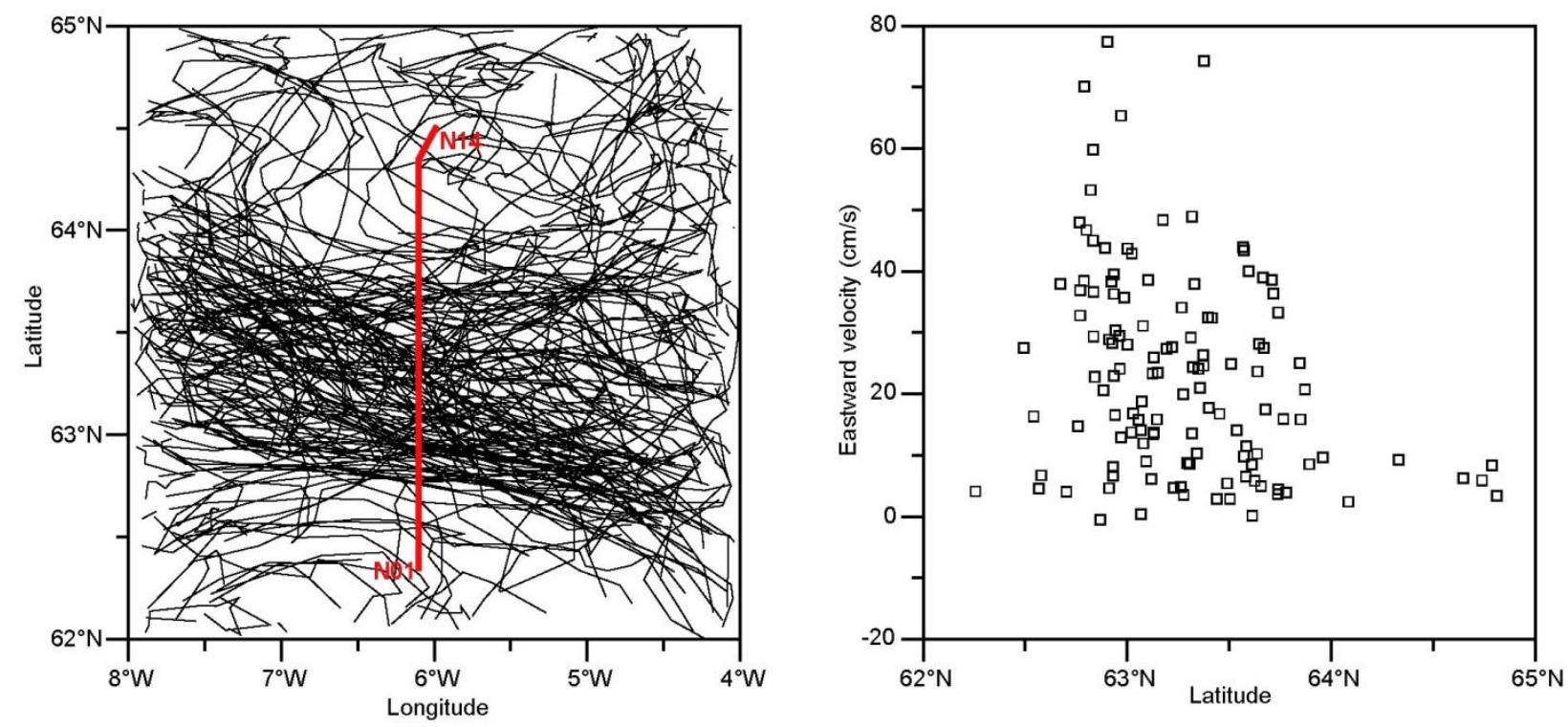

Figure 2.3.1 Left panel: track of drifters passing through the region (note that latitude and longitude are not plotted to the same scale). The CTD standard section is indicated by the red line. Right panel: Eastward velocity of individual drifters as they passed through the altimetry line (along $6.125^{\circ} \mathrm{W}$ ). 


\subsection{Altimetry data}

Daily averaged altimetry was selected from the global gridded $\left(0.25^{\circ} \times 0.25^{\circ}\right)$ sea level anomaly (SLA) field available from "http://www.aviso.altimetry.fr" at daily intervals. SLA values were selected for 8 grid points, which we label $\mathrm{A}_{1}$ to $\mathrm{A}_{8}$, along $6.125^{\circ} \mathrm{W}=6^{\circ} 07.5^{\prime} \mathrm{W}$ from $62.125^{\circ} \mathrm{N}$ to $63.875^{\circ} \mathrm{N}$ :

$$
H_{k}\left(t_{i}\right) \quad k=1-8 \quad i=1-7791 \quad\left(t_{i}=1\right. \text { Jan1993-1May2014) }
$$

\subsubsection{EOF modes}

An Empirical Orthogonal Function analysis (EOF) revealed that the EOF modes were completely dominated by the first two modes, explaining 95\% of the variance with $87 \%$ in the first mode (Figure 2.4.1, left panel).
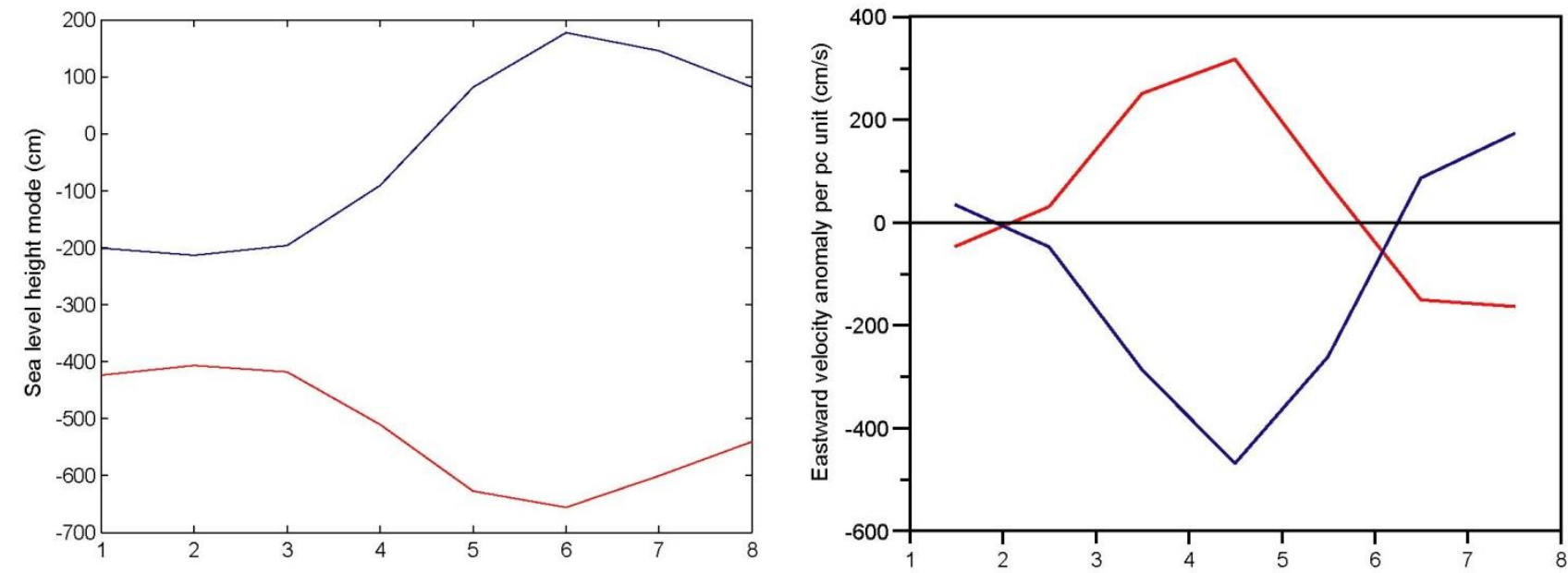

Figure 2.4.1 Left panel: EOF modes $M A_{k}{ }^{l}$ and $M A_{k}^{2}$ for SLA using daily averaged slh along one row of altimetry points (longitude $6.125^{\circ} \mathrm{W}$ ) from point $\mathrm{A}_{1}$ to point $\mathrm{A}_{8}$. Right panel: Derived surface velocity modes (Eq. 2.4.5) from altimetry $M U_{k}{ }^{l}$ and $M U_{k}{ }^{2}$. Mode 1 (expl.: 0.873 ): red and Mode 2 (expl.: 0.077): blue.

Let $u(y, 0, t)$ be the eastward velocity in the surface $(z=0)$ at time $t$ and north location $y$ and let $h(y, t)$ be the absolute surface elevation. Then geostrophy implies:

$$
u(y, 0, t)=-\frac{g}{f} \frac{\partial h(y, t)}{\partial y}
$$

The absolute surface elevation at altimetry gridpoint $A_{k}$ may be seen as the altimetry value plus an offset, which should not vary in time: $h\left(y_{k}, t\right)=H_{k}(t)+H_{k}{ }^{0}$. From Eq. (2.4.1), we get that the horizontally averaged surface velocity between grid points $A_{k}$ and $A_{k+1}$ is:

$$
U_{k}(0, t)=\frac{g}{f \cdot L} \cdot\left[\left(H_{k}(t)+H_{k}^{0}\right)-\left(H_{k+1}(t)+H_{k+1}^{0}\right)\right]
$$

We now split the horizontally averaged surface velocity up into its temporal average $\left\langle U_{k}(0, t)\right\rangle$ and the variable anomaly from that: $U_{k}(0, t)=U_{k}^{V}(t)+\left\langle U_{k}(0, t)\right\rangle$ and the sea level: $h\left(y_{k}, t\right)=H_{k}^{V}(t)+\left\langle H_{k}(t)\right\rangle+H_{k}^{0}$. Geostrophy then splits up into two separate equations:

$$
U_{k}^{V}(0, t)=\frac{g}{f \cdot L} \cdot\left[H_{k}^{V}(t)-H_{k+1}^{V}(t)\right] \text { and }\left\langle U_{k}(0, t)\right\rangle=\frac{g}{f \cdot L} \cdot\left[\left(\left\langle H_{k}(t)\right\rangle-\left\langle H_{k+1}(t)\right\rangle\right)+\left(H_{k}^{0}-H_{k+1}^{0}\right)\right]
$$

From the EOF analysis, the sea level anomaly is well approximated by two modes:

$$
H_{k}^{V}(t)=M A_{k}^{1} \cdot P C_{1}(t)+M A_{k}^{2} \cdot P C_{2}(t)
$$


Geostrophy then implies:

$$
U_{k}^{V}(0, t)=\frac{g}{f \cdot L} \cdot\left[M A_{k}^{1}-M A_{k+1}^{1}\right] \cdot P C_{1}(t)+\frac{g}{f \cdot L} \cdot\left[M A_{k}^{2}-M A_{k+1}^{2}\right] \cdot P C_{2}(t) \equiv M U_{k}^{1} \cdot P C_{1}(t)+M U_{k}^{2} \cdot P C_{2}(t)
$$

The two surface velocity modes $M U_{k}{ }^{l}$ and $M U_{k}^{2}$ are shown in Figure 2.4.1 (right panel).
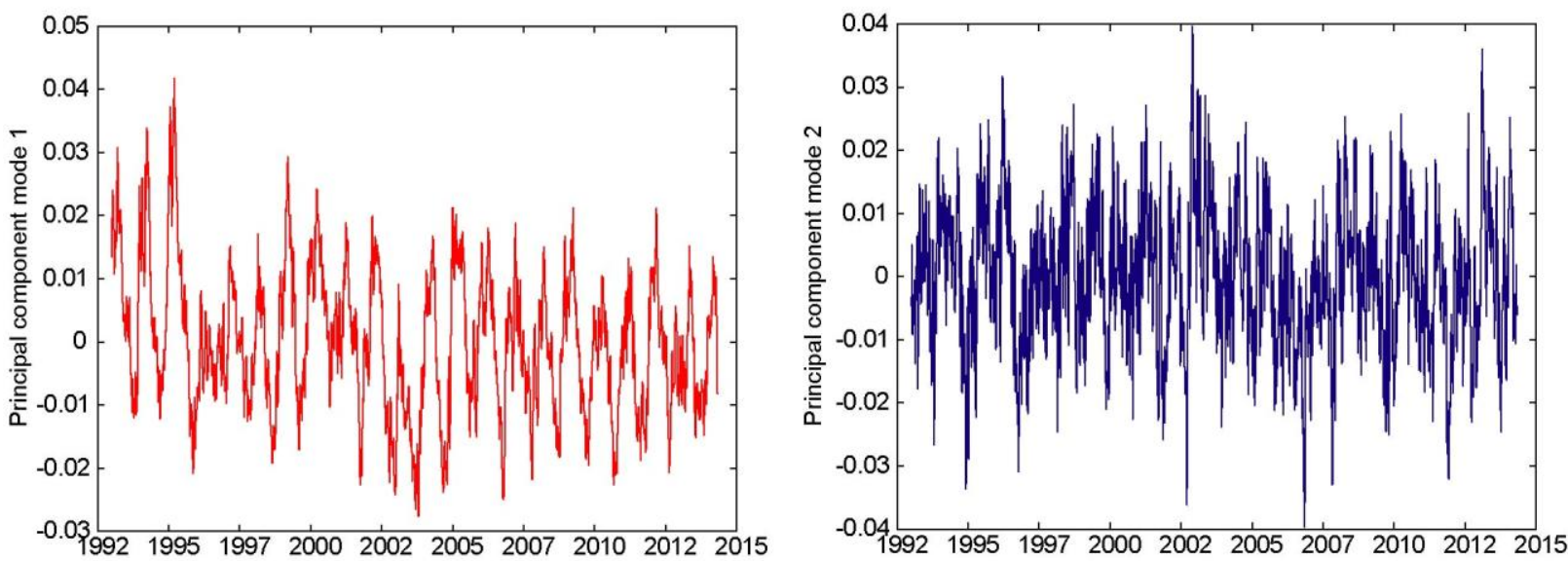

Figure 2.4.2 Principal components for altimetry EOF mode $1\left(P C_{1}\right.$, left panel, red $)$ and mode $2\left(P C_{2}\right.$, right panel, blue) using daily averaged SLA along a row of altimetry points at longitude $6.125^{\circ} \mathrm{W}$.

\subsubsection{Calibrating the altimetry data}

We again split the absolute surface elevation at altimetry gridpoint $A_{k}$ into the altimetry value plus an offset, which does not vary in time: $h\left(y_{k}, t\right)=H_{k}(t)+H_{k}{ }^{0}$. Geostrophy then implies that the horizontally averaged surface velocity between grid points $A_{k}$ and $A_{k+1}$ is:

$$
U_{k}(0, t)=\frac{g}{f \cdot L} \cdot\left[\left(H_{k}(t)+H_{k}^{0}\right)-\left(H_{k+1}(t)+H_{k+1}^{0}\right)\right]=\frac{g}{f \cdot L} \cdot\left[H_{k}^{0}-H_{k+1}^{0}\right]+\frac{g}{f \cdot L} \cdot\left[H_{k}(t)-H_{k+1}(t)\right]=U_{k}^{0}+U_{k}^{A}(t)
$$

where $U_{k}^{A}(t)$ is the velocity generated from raw altimetry values and $U_{k}^{0}$ is the offset to add in order to get the real horizontally averaged surface velocity. If we average over a certain time interval, we get:

$$
\left\langle U_{k}(0, t)\right\rangle=U_{k}^{0}+\left\langle U_{k}^{A}(t)\right\rangle \Rightarrow U_{k}^{0}=\left\langle U_{k}(0, t)\right\rangle-\left\langle U_{k}^{A}(t)\right\rangle=\left\langle U_{k}(0, t)\right\rangle-\frac{g}{f \cdot L} \cdot\left\langle H_{k}(t)-H_{k+1}(t)\right\rangle
$$

We have used this last equation to determine $U_{k}^{0}$ in two different ways. The first method compares extrapolated ADCP surface velocity with altimetry. The second method compares geostrophic profiles with altimetry. In Table 2.4.1, we have used average surface velocities from the long-term ADCP sites to represent $\left\langle U_{k}(0, t)\right\rangle$ and from Eq. (2.4.7) to calculate corresponding values for $U_{k}{ }^{0}$ for $\mathrm{k}=3$ and 4.

Table 2.4.1 Average extrapolated ADCP eastward surface velocity $\left\langle U_{k}(0, t)\right\rangle$, anomaly of altimetry surface

\begin{tabular}{|c|c|c|c|c|}
\hline Alt.interv & Site & $\begin{array}{c}\left\langle U_{k}(0, t)>\right. \\
\mathrm{cm} / \mathrm{s}\end{array}$ & $\begin{array}{l}\left\langle U_{k}^{A}(t)>\right. \\
\mathrm{cm} / \mathrm{s}\end{array}$ & $\begin{array}{c}U_{k}^{0} \\
\mathrm{~cm} / \mathrm{s}\end{array}$ \\
\hline $\mathrm{A}_{3}-\mathrm{A}_{4}$ & $\mathrm{NA}$ & 18.2 & -0.3 & 18.5 \\
\hline$A_{3}-A_{4}$ & $\mathrm{NE}$ & 25.3 & 0.2 & 25.1 \\
\hline$A_{4}-A_{5}$ & NB & 22.3 & -0.5 & 22.7 \\
\hline$A_{4}-A_{5}$ & NG & 11.8 & -0.5 & 12.4 \\
\hline
\end{tabular}
velocity during the ADCP averaging period $\left\langle U_{k}^{A}(t)\right\rangle$, and altimetry offset $U_{k}^{0}$, defined by Eq. (2.4.6), for altimetry intervals $\mathrm{A}_{3}-\mathrm{A}_{4}$ and $\mathrm{A}_{4}-\mathrm{A}_{5}$. 
North of altimetry point $\mathrm{A}_{5}$, we do not have any long-term ADCP sites that can be extrapolated all the way to the surface and there we have to rely on geostrophic velocity profiles. Using all the CTD data from section N, 1993-2013, we have calculated average geostrophic velocity profiles referenced to the surface (Figure 2.4.3). For the interval between standard stations $\mathrm{j}$ and $\mathrm{j}+1$, we denote this as $\Psi_{j}(z, t)$.

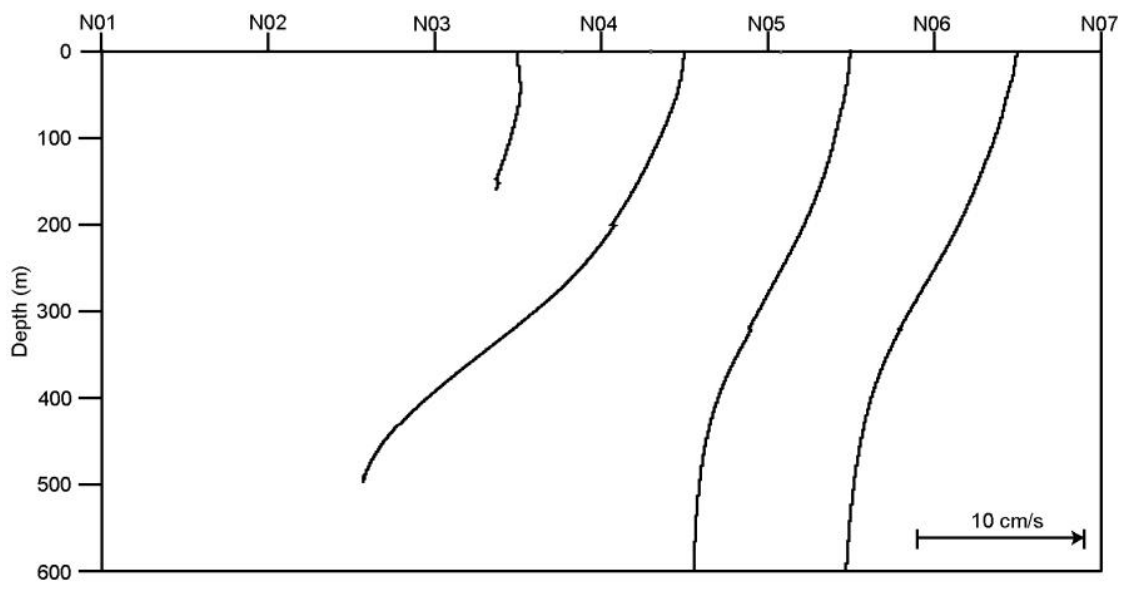

Figure 2.4.3 Average geostrophic profiles between each pair of neighbouring standard stations N03 to N07. The surface expressions of the geostrophic profiles are located in the middle of the associated station pairs.

Geostrophy only gives the velocity shear, not absolute velocity values but, if we know the correct velocity $U_{j}\left(z_{\text {ref }}, t\right)$ at some reference depth $z_{\text {ref }}$, averaged between stations $\mathrm{j}$ and $\mathrm{j}+1$, then the correct surface velocity is:

$$
U_{j}(0, t)=U_{j}\left(z_{r e f}, t\right)+\Psi_{j}(0, t)-\Psi_{j}\left(z_{\text {ref }}, t\right)
$$

if there is geostrophic balance. By averaging, this leads to:

$$
U_{k}^{0}=\left\langle U_{j}\left(z_{r e f}, t\right)+\Psi_{j}(0, t)-\Psi_{j}\left(z_{r e f}, t\right)\right\rangle-\frac{g}{f \cdot L} \cdot\left\langle H_{k}(t)-H_{k+1}(t)\right\rangle
$$

At site NB, the average velocity decreases down to $\sim 500 \mathrm{~m}$ and we use that as reference depth. Table 2.4 .2 shows average eastward velocity at this depth for the deepwater sites as well as the standard deviation:

Table 2.4.2 Average and standard deviation of eastward velocity at 500m for three deep ADCP sites.

\begin{tabular}{lrrr}
\hline Site & $\begin{array}{c}\mathrm{N} \\
\text { Days }\end{array}$ & $\begin{array}{r}\text { Avg } \\
\mathrm{cm} / \mathrm{s}\end{array}$ & $\begin{array}{r}\text { Std } \\
\mathrm{cm} / \mathrm{s}\end{array}$ \\
\hline NB & 5892 & 1.8 & 9.2 \\
NG & 4436 & 1.9 & 4.6 \\
NC & 1517 & 0.4 & 3.6
\end{tabular}

It would be nice if the deepwater velocities were coherent over large parts of the section so that we could use the long time series at NB throughout the deep parts of the section. The correlation coefficient between eastward velocity at $500 \mathrm{~m}$ at $\mathrm{NB}$ and $\mathrm{NG}$ is, however, negligible $(\mathrm{R}=-0.08, \mathrm{~N}=4415)$ and similarly between NB and NC $(\mathrm{R}=-0.15, \mathrm{~N}=1133)$. Thus, we can either use the $500 \mathrm{~m}$ values at $\mathrm{NG}$ and $\mathrm{NC}$, if they were deployed, or assume zero eastward velocity at $500 \mathrm{~m}$. In Table 2.4.3, we have tried both alternatives. The assumption of close to zero velocity at $500 \mathrm{~m}$ north of $\mathrm{NC}$ is consistent with the average value for NC in Table 2.4.2, especially when we note that when averaging over $\sim 81$ values (Table 2.4.3), a standard deviation of $3.6 \mathrm{~cm} / \mathrm{s}$ implies a standard error of $3.6 / 9=0.4 \mathrm{~cm} / \mathrm{s}$. The associated values for $U_{k}{ }^{0}$ were determined by averaging according to Eq. (2.4.9). 
Table 2.4.3 Correlation coefficients $(\mathrm{R})$ between geostrophic surface velocity between two stations and altimetric surface velocity between two grid points and associated values for $U_{k}^{0}\left(\mathrm{in} \mathrm{cm} \cdot \mathrm{s}^{-1}\right)$. N is the number of geostrophic profiles. The geostrophic surface velocity for each profile is adjusted by adding a reference velocity at $500 \mathrm{~m}$ depth (the $500 \mathrm{~m}$-offset), which is either assumed to be zero or from concurrent measurements at ADCP site NG or NC. "Res" (Restricted) means that we only used those ADCP velocities that were less than one standard deviation from the mean, whereas "All" means that all ADCP measurements at $500 \mathrm{~m}$ depth were used. The $U_{k}^{0}$ values are derived from averages similar to Table 2.4.1. The best estimates (highest correlation coefficient R) for each combination of station and grid point pairs are in red.

\begin{tabular}{|c|c|c|c|c|c|c|c|c|c|c|}
\hline \multirow[b]{2}{*}{ St.stat. } & \multirow[b]{2}{*}{ Alt.int } & \multicolumn{3}{|c|}{$500 \mathrm{~m}$-offset $=0$} & \multicolumn{5}{|c|}{ 500m-offset from ADCPs } & \multirow[b]{2}{*}{$U_{k}^{0}$} \\
\hline & & $\mathrm{N}$ & $\mathrm{R}$ & $U_{k}^{0}$ & $\mathrm{U}$ at 50 & $00 \mathrm{~m}$ & & $\mathrm{~N}$ & $\mathrm{R}$ & \\
\hline $\mathrm{N05-N06}$ & $A_{4}-A_{5}$ & 85 & 0.36 & 9.5 & $\mathrm{All} \mathrm{NG}$ & & & 47 & 0.42 & 10.0 \\
\hline N0 5-N06 & $A_{5}-A_{6}$ & 85 & 0.45 & 8.3 & All NG & & & 47 & 0.45 & 7.9 \\
\hline N06-N07 & $A_{5}-A_{6}$ & 84 & 0.47 & 9.0 & All NG & or & $\mathrm{NC}$ & 63 & 0.51 & 10.2 \\
\hline N0 $7-\mathrm{N} 08$ & $A_{5}-A_{6}$ & 85 & 0.24 & 10.6 & Res NG & or & $\mathrm{NC}$ & 49 & 0.30 & 12.3 \\
\hline N07-N08 & $\mathrm{A}_{6}-\mathrm{A}_{7}$ & 85 & 0.56 & 10.4 & Res NG & or & $\mathrm{NC}$ & 49 & 0.62 & 11.7 \\
\hline N08-N09 & $A_{6}-A_{7}$ & 84 & 0.48 & 8.8 & Res NG & or & $\mathrm{NC}$ & 51 & 0.44 & 10.8 \\
\hline N08-N09 & $A_{7}-A_{8}$ & 84 & 0.68 & 9.5 & Res NG & or & $\mathrm{NC}$ & 51 & 0.61 & 11.6 \\
\hline N09-N10 & $A_{7}-A_{8}$ & 84 & 0.38 & 1.7 & Res NG & or & $\mathrm{NC}$ & 51 & 0.30 & 3.7 \\
\hline N10-N11 & $A_{7}-A_{8}$ & 82 & 0.24 & -0.4 & & & & & & \\
\hline
\end{tabular}

For the N05-N06 interval, the best (but not very good) results were found by using the 500m velocity at ADCP NG (which is almost midway between N05 and N06). Between N06 and N07, we used the 500m velocity at both NG and NC. This also was done between N07 and N08, but there, we only used those ADCP velocities that were less than one standard deviation from the mean (Res=Restricted). Outside of N08, it seemed best to ignore the ADCP values, i.e. assume zero reference velocity.

\subsubsection{The average surface velocity}

Figure 2.4.4 illustrates our choice of $U_{k}^{0}$ for the various altimetry intervals and the material on which it is based. The $U_{k}{ }^{0}$ values for the four long-term ADCP sites are indicated by rectangles. ADCPs NF and ND are too short and too deep to allow reliable extrapolation to the surface. At $200 \mathrm{~m}$ depth, the average eastward velocity at NF was $18.5 \mathrm{~cm} / \mathrm{s}$, whereas the simultaneous values at the same depth were $20.5 \mathrm{~cm} / \mathrm{s}$ at NE and $16.5 \mathrm{~cm} / \mathrm{s}$ at NB. The circle labeled NF in Figure 2.4.4 is located on the assumption that the surface velocities at these three sites have the same relationship.

South of site NA, we do not have good in-situ observations of current velocities. The drifter data were considered, but we only found a negligible correlation between eastward drifter velocity as it passed the altimetry line (Figure 2.3.1, right panel) and altimetry-based surface velocity. Thus, they cannot be combined with altimetry data to estimate average velocities. A few short traditional current meter moorings have been deployed before the altimetry period. They cannot give any precise estimates, but indicate that the average eastward velocity is between 6 and $10 \mathrm{~cm} / \mathrm{s}$ close to N02 (Larsen et al., 2008).

The dashed line in Figure 2.4.4 connects the mean of these two values linearly with the values at the long-term ADCP sites. From this, we can determine average values of $U_{k}^{0}$ for altimetry intervals $\mathrm{A}_{3}-\mathrm{A}_{4}$ and $\mathrm{A}_{4}-\mathrm{A}_{5}$ (red line in Figure 2.4.4 and Table 2.4.4). A smoother horizontal variation, drawn by hand (full black line in Figure 2.4.4), may look more realistic, but the associated change in $U_{k}^{0}$ would only be $\sim 1 \%$. For interval $\mathrm{A}_{5}-\mathrm{A}_{6}$, we combine the $U_{k}^{0}$ values for ADCP NG with geostrophy and north of this, we use the average geostrophic values (Table 2.4.3). 


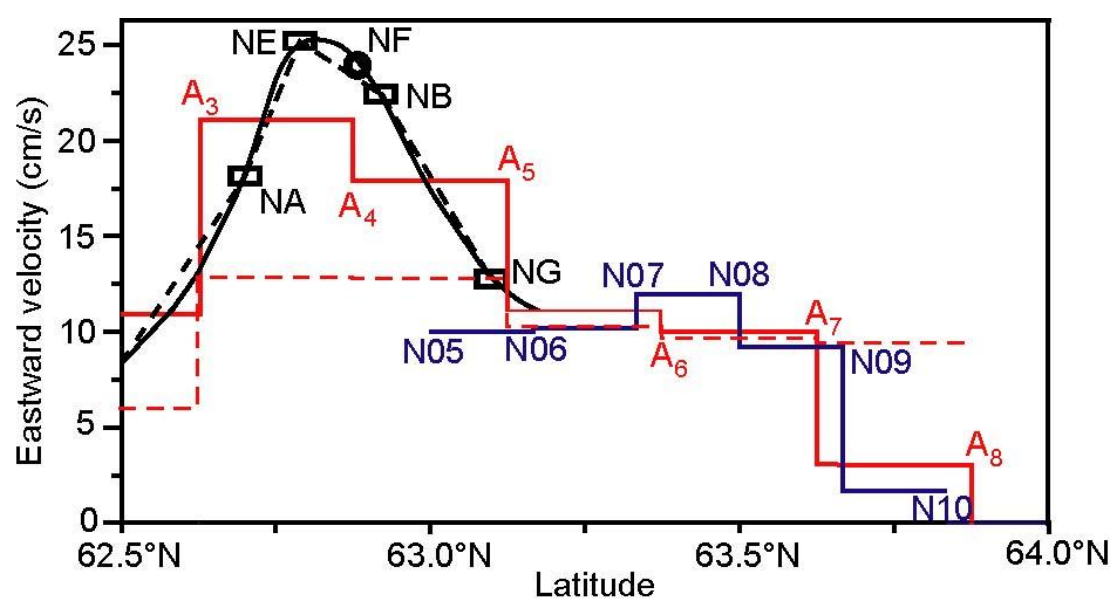

Figure 2.4.4 Values for the altimetry offset $U_{k}^{0}$ (continuous red line) plotted together with altimetrycorrected (Table 2.4.1) average values for surface velocity from the four long-term ADCP sites (rectangles) and surface velocity from average geostrophy (Table 2.4.3) (blue line). Dashed and full black lines show two different ways to interpolate between ADCP sites. The dashed red line shows the values that we would have got for $U_{k}^{0}$ if we had used the ADT data set from AVISO instead of using the in situ observations.

The procedure using our in situ observations to calibrate the altimetry is complicated and introduces uncertainties. Instead, we could have chosen to use the mean dynamic topography (MDT). We would then have used the data set containing absolute dynamic topography (ADT), also supplied by AVISO, instead of the SLA data set. The dashed red line in Figure 2.4.4 shows the values for $U_{k}^{0}$ that this would imply. The surface current with this choice is seen to be broader and weaker. On average between $A_{2}$ and $A_{8}$, this would give a reduction of $18 \%$. More importantly, there would be much weaker flow between $\mathrm{A}_{3}$ and $\mathrm{A}_{5}$ where the Atlantic water layer is deep and most of the transport occurs. We therefore prefer to use the $U_{k}^{0}$ values that are based on our in situ observations (Table 2.4.4). Together with the SLA data set, they allow us to calculate horizontally averaged eastward surface velocities in each altimetry interval from point $\mathrm{A}_{2}$ to $\mathrm{A}_{8}$ for every day since 1 January 1993.

Table 2.4.4 Calibration values $U_{k}^{0}$ for each altimetry interval from point $\mathrm{A}_{2}$ to $\mathrm{A}_{8}$ based on ADCP data and geostrophic profiles. The value for $\mathrm{A}_{2}-\mathrm{A}_{3}$ is only valid for the northern half of the interval, which is used in calculating volume transport.

\begin{tabular}{lcccccc}
\hline Altimetry interval: & $\mathrm{A}_{2}-\AA_{3}$ & $\mathrm{~A}_{3}-\AA_{4}$ & $\AA_{4}-\AA_{5}$ & $\AA_{5}-\AA_{6}$ & $A_{6}-\AA_{7}$ & $A_{7}-\AA_{8}$ \\
Values for $U_{k}{ }^{0}(\mathrm{~cm} / \mathrm{s}):$ & 11 & 21 & 18 & 11 & 10 & 3
\end{tabular}




\section{The velocity field}

Once the altimetry data have been calibrated, using ADCPs and geostrophy, we can produce eastward surface velocity values for each altimetry interval for every day from 1993, onwards, although we expect more reliable values, if we average over longer periods. To get the full velocity field, the vertical variation has to be included, for which we again will need both ADCP and geostrophic profiles.

\subsection{Eastward surface velocity}

The two altimetry intervals with the strongest mean flow $\left(\mathrm{A}_{3}-\mathrm{A}_{4}\right.$ and $\left.\mathrm{A}_{4}-\mathrm{A}_{5}\right)$ have a clear seasonal signal with maximum flow in winter. Farther north, the seasonal variation is not clear (Figure 3.1.1).
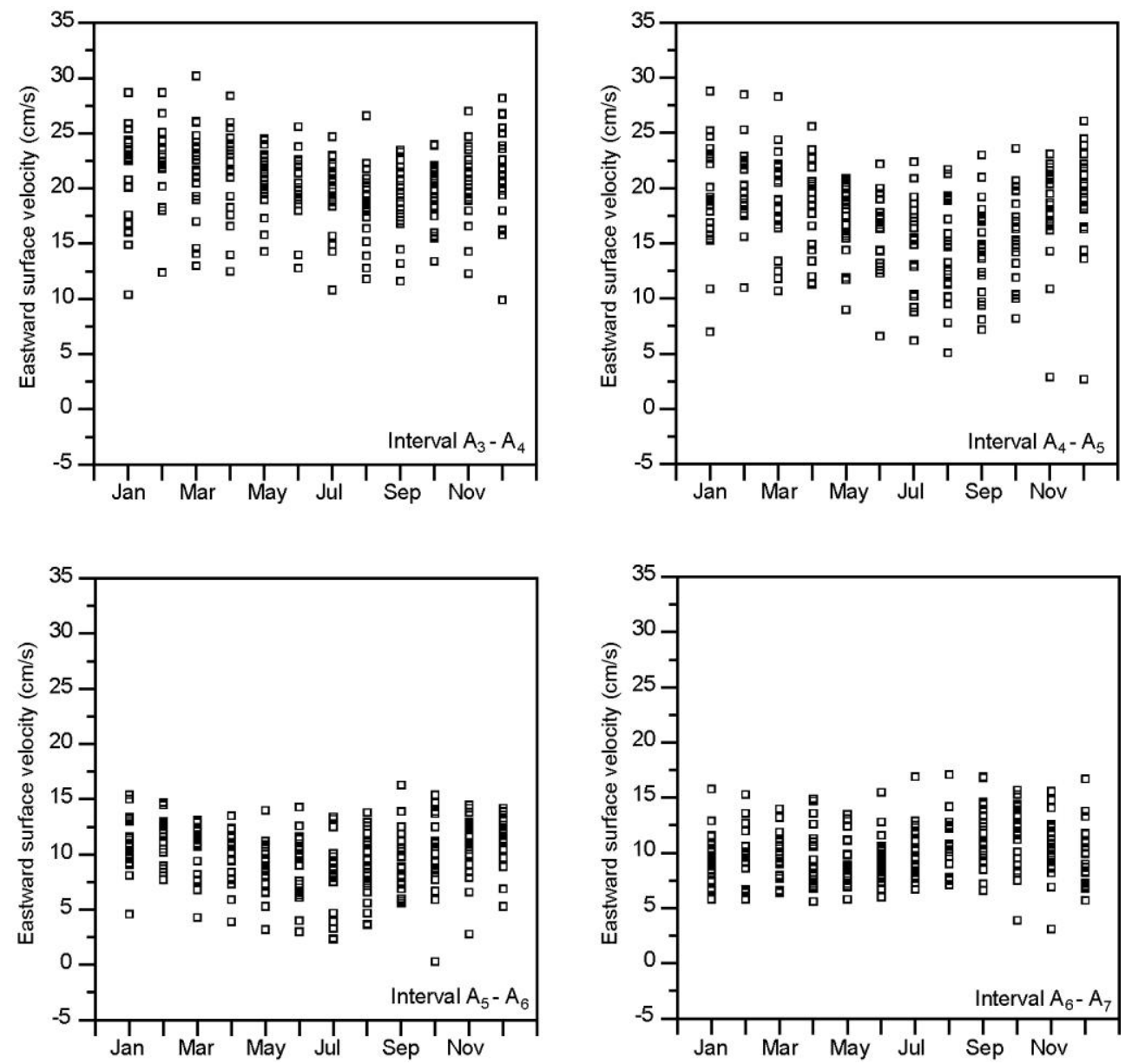

Figure 3.1.1 Horizontally averaged eastward surface velocity in four altimetry intervals based on 91 days running mean of calibrated altimetry, sampled every 30 days.

The basic assumption of geostrophy requires correspondence between temporal variations in surface velocity determined from Altimetry and from ADCPs assuming that the extrapolation of ADCP data to the surface is reliable and that the surface velocity variations at the ADCP site are representative for the whole altimetry interval. We would therefore expect positive correlation coefficients between these two surface velocity estimates, especially if the data are averaged over more than a day. At first glance, the correpondence is not very impressive (Table 3.1.1). 
From Table 3.1.1, correlation coefficients increase with averaging period, as expected, but are not exceptionally high. For altimetry interval $\mathrm{A}_{2}-\mathrm{A}_{3}$, NA is best correlated with $\mathrm{R}=0.62$ for 29 days averaging. For interval $\mathrm{A}_{3}-\mathrm{A}_{4}, \mathrm{NE}$ and NB have similar correlation coefficients, and are much better correlated than NA. For interval $A_{4}-A_{5}, N B$ is best, with $N G$ on second place. In the best case - Altimetry interval $A_{3}-A_{4}$ versus ADCP NE - the explained variance is less than $60 \%\left(0.77^{2}\right)$ and even this is somewhat misleading, since the regression coefficient is 1.8 and there is a large offset.

Table 3.1.1 Correlation coefficients between eastward surface velocity from altimetry in three intervals and ADCPs that are within or close to the altimetry intervals.

\begin{tabular}{lrrrrrr}
\hline & \multicolumn{3}{c}{ Altimetry } & interval & $\mathrm{A}_{2}-\mathrm{A}_{3}$ & \multicolumn{2}{l}{ versus } \\
& ADCP $\mathrm{NA}$ & $\mathrm{ADCP}$ & $\mathrm{NE}$ & \multicolumn{2}{c}{ ADCP } & $\mathrm{NB}$ \\
Average & $\mathrm{N}$ & $\mathrm{R}$ & $\mathrm{N}$ & $\mathrm{R}$ & $\mathrm{N}$ & $\mathrm{R}$ \\
\hline 1 day: & 6297 & 0.42 & 2729 & 0.42 & 5762 & 0.06 \\
7 days: & 886 & 0.57 & 384 & 0.54 & 824 & 0.08 \\
29 days: & 200 & 0.62 & 87 & 0.44 & 185 & 0.17
\end{tabular}

\begin{tabular}{|c|c|c|c|c|c|c|}
\hline \multirow[b]{3}{*}{ Average } & \multicolumn{2}{|c|}{ Altimetry } & \multicolumn{4}{|c|}{ interval $A_{3}-A_{4}$ versus } \\
\hline & $\mathrm{ADCP}$ & $\mathrm{NA}$ & $\mathrm{ADCP}$ & $\mathrm{NE}$ & $\mathrm{ADCP}$ & $\mathrm{NB}$ \\
\hline & $\mathrm{N}$ & $\mathrm{R}$ & $\mathrm{N}$ & $\mathrm{R}$ & $\mathrm{N}$ & $\mathrm{R}$ \\
\hline 1 day: & 6297 & 0.20 & 2729 & 0.55 & 5762 & 0.52 \\
\hline 7 days: & 886 & 0.26 & 384 & 0.68 & 824 & 0.63 \\
\hline 29 days: & 200 & 0.29 & 87 & 0.77 & 185 & 0.75 \\
\hline
\end{tabular}

\begin{tabular}{|c|c|c|c|c|c|c|}
\hline \multirow[b]{3}{*}{ Average } & \multicolumn{2}{|c|}{ Altimetry } & \multicolumn{4}{|c|}{ interval $A_{4}-A_{5}$ versus } \\
\hline & $\mathrm{ADCP}$ & $\mathrm{NE}$ & ADCP & $\mathrm{NB}$ & $\mathrm{ADCP}$ & NG \\
\hline & $\mathrm{N}$ & $\mathrm{R}$ & $\mathrm{N}$ & $\mathrm{R}$ & $\mathrm{N}$ & $\mathrm{R}$ \\
\hline 1 day: & 2729 & 0.12 & 5762 & 0.52 & 4423 & 0.43 \\
\hline 7 days: & 384 & 0.16 & 824 & 0.64 & 620 & 0.53 \\
\hline 29 days: & 87 & 0.40 & 185 & 0.74 & 140 & 0.58 \\
\hline
\end{tabular}

In order to expect high correlations between altimetry and ADCPs, we have to assume that the measured ADCP velocities are representative, not only for the location of the ADCP, but also for the whole horizontal interval between the two altimetry points. For that assumption to be valid, we have to require high correlations between eastward velocities from two ADCPs that are in the same altimetry interval, but that is not generally the case (Table 3.1.2).

Table 3.1.2 Correlations between surface or depth-averaged eastward velocities at ADCP pairs. Depth averaging is either over the full ADCP depth (max 600$)$ or over the $0-275 \mathrm{~m}$ interval. The table lists number of data values and correlation coefficients for daily, as well weekly, and 29-day averaged velocities.

\begin{tabular}{lrrrrrr}
\hline ADCP pair: & NA-NE & NA-NB & NA-NG & NE-NB & NE-NG & NB-NG \\
\hline Number daily averages (days): & 2728 & 5753 & 4423 & 2706 & 2727 & 4402 \\
Correlation daily surface: & 0.44 & -0.13 & -0.25 & 0.19 & -0.38 & -0.06 \\
Correlation daily 0-275m: & 0.53 & -0.14 & -0.30 & 0.20 & -0.40 & -0.05 \\
Correlation daily full depth: & 0.50 & -0.10 & -0.28 & 0.27 & -0.34 & -0.02 \\
\hline Number weekly averages (weeks): & 382 & 806 & 620 & 379 & 382 & 617 \\
Correlation weekly surface: & 0.45 & -0.14 & -0.37 & 0.40 & -0.45 & 0.05 \\
Correlation weekly 0-275m: & 0.57 & -0.13 & -0.45 & 0.39 & -0.48 & 0.05 \\
Correlation weekly full depth: & 0.51 & -0.13 & -0.44 & 0.45 & -0.43 & 0.05 \\
Number 29-day averages: & 87 & 183 & 140 & 85 & 88 & 138 \\
Correlation 29-day surface: & 0.29 & -0.12 & -0.30 & 0.63 & -0.27 & 0.17
\end{tabular}


To overcome this difficulty, we can instead of simple regression try multiple linear regression of altimetry derived surface velocities on more than one ADCP:

$$
U_{k}(0, t)=\sum_{i} \alpha_{i} \cdot u_{i}(0, t)
$$

where $U_{k}(0, t)$ is altimetry velocity for interval $\mathrm{A}_{\mathrm{k}}$ to $\mathrm{A}_{\mathrm{k}+1}$ and $u_{i}(0, t)$ is the eastward surface velocity of ADCP number i. In a traditional multiple regression, Eq. (3.1.1) would include an additional constant term (the offset), and the inclusion of such a term would give a better fit, but this would be misleading. When all the surface velocities measured by the ADCPs are zero, then the calibrated altimetry velocity should also be zero, which implies no offset in Eq. (3.1.1). Instead of traditional multiple linear regression analyses, we have therefore performed zero-offset regressions. To judge the quality of the regressions, we have used the two parameters: the "Mean square error" $\left(\Delta^{2}\right)$ and the variance $\left(\sigma^{2}\right)$, defined as:

$$
\Delta^{2}=\frac{\sum_{j}\left(U_{k}\left(0, t_{j}\right)-\sum_{i} \alpha_{i} \cdot u_{i}\left(0, t_{j}\right)\right)^{2}}{n} \quad \text { and } \quad \sigma^{2}=\frac{\sum_{j}\left(U_{k}\left(0, t_{j}\right)-\left\langle U_{k}(0, t)\right\rangle\right)^{2}}{n-1}
$$

An often used quality indicator is "the explained variance": $R^{2}=1-\Delta^{2} / \sigma^{2}$, which in a traditional regression analysis (no restrictions on offset) is always between 0 and 1 . In our case, the maximum value for $\mathrm{R}^{2}$ is still 1 , indicating a perfect fit, but negative values may also occur. This is indeed the case for some of the cases in Table 3.1.3, which is depressing but, perhaps, a bit misleading, since they do not take into account that all the series have high positive average values, as illustrated in Figure 3.1.2.
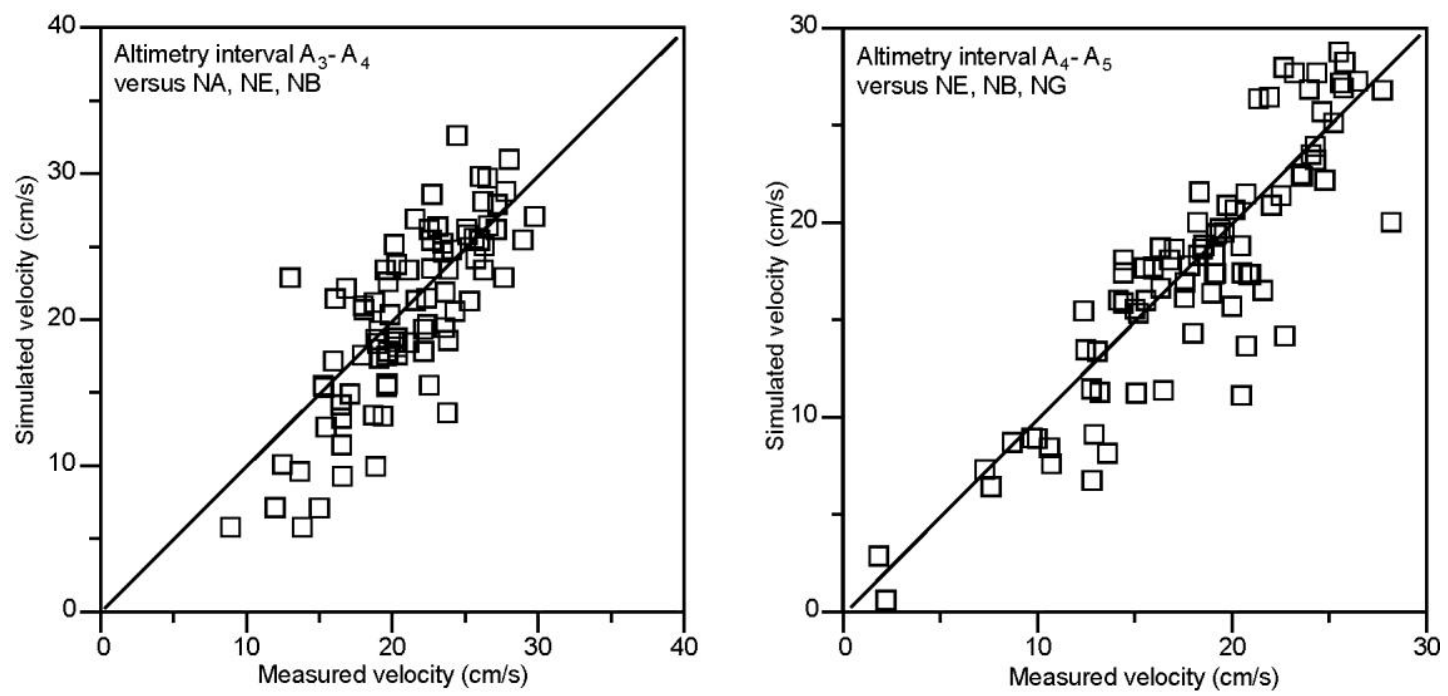

Figure 3.1.2 Twentynine-day averaged eastward surface velocity, simulated by multiple regression equations based on three ADCPs, plotted against the velocity measured by altimetry (calibrated). The diagonal lines indicate equality.

A more appropriate quality indicator is the "Relative error": Rerr $=\Delta /\left\langle U_{k}\right\rangle$, which may be compared to the "Coefficient of variation": $C V=\sigma /\left\langle U_{k}\right\rangle$. The negative values for $R^{2}$ occur when Rerr $>C V$. Even when regressed on three ADCPs and averaged over 29 days, the simulated velocities do not fit very convincingly (Figure 3.1.2). It does not seem very meaningful to regress an altimetric velocity on an ADCP outside the altimetry interval. Thus, the red columns in Table 3.1.3 are probably the most appropriate examples of the best fits and they do not indicate a very good correspondence between altimetry and ADCP velocities. This problem is further discussed in Chapter 8. 
Table 3.1.3 Multiple zero-offset regression of surface velocity from altimetry on two or three eastward ADCP surface velocities. Rerr is the rms deviation of the regression from the actual value divided by the average altimetry velocity and CV is the coefficient of variation (standard deviation divided by mean). The red columns indicate regressions where all ADCPs are within the altimetry interval.

\begin{tabular}{|c|c|c|c|c|c|c|c|c|c|c|}
\hline \multirow[b]{3}{*}{ Averaging } & \multirow[b]{3}{*}{$\mathrm{N}_{\operatorname{Min}}$} & \multicolumn{9}{|c|}{ Altimetry interval $A_{3}-A_{4}$} \\
\hline & & \multicolumn{3}{|c|}{$\mathrm{NA}+\mathrm{NE}$} & \multicolumn{3}{|c|}{$\mathrm{NE}+\mathrm{NB}$} & \multicolumn{3}{|c|}{$\mathrm{NA}+\mathrm{NE}+\mathrm{NB}$} \\
\hline & & $\mathrm{R}^{2}$ & Rerr & $\mathrm{CV}$ & $\mathrm{R}^{2}$ & Rerr & $\mathrm{CV}$ & $R^{2}$ & Rerr & $\mathrm{CV}$ \\
\hline 1 day : & 2706 & -2.56 & 0.51 & 0.27 & -1.51 & 0.43 & 0.27 & -0.99 & 0.38 & 0.27 \\
\hline 7 days: & 381 & -1.08 & 0.38 & 0.26 & -0.68 & 0.34 & 0.26 & -0.13 & 0.28 & 0.26 \\
\hline \multirow[t]{2}{*}{29 days: } & 85 & -0.49 & 0.25 & 0.20 & -0.41 & 0.24 & 0.21 & 0.20 & 0.18 & 0.21 \\
\hline & & \multicolumn{9}{|c|}{ Altimetry interval $A_{4}-A_{5}$} \\
\hline Averaging & $\operatorname{Min} . \mathrm{N}$ & $\mathrm{R}^{2}$ & Rerr & $\mathrm{CV}$ & $\mathrm{R}^{2}$ & Rerr & $\mathrm{CV}$ & $\mathrm{R}^{2}$ & Rerr & $\mathrm{CV}$ \\
\hline 1 day : & 2706 & -1.06 & 0.53 & 0.37 & -0.49 & 0.51 & 0.42 & 0.04 & 0.36 & 0.37 \\
\hline 7 days: & 381 & -0.57 & 0.45 & 0.36 & 0.08 & 0.39 & 0.41 & 0.49 & 0.26 & 0.36 \\
\hline 29 days: & 85 & -0.05 & 0.31 & 0.30 & 0.38 & 0.26 & 0.33 & 0.69 & 0.16 & 0.30 \\
\hline
\end{tabular}

\subsection{Vertical variation of the eastward velocity}
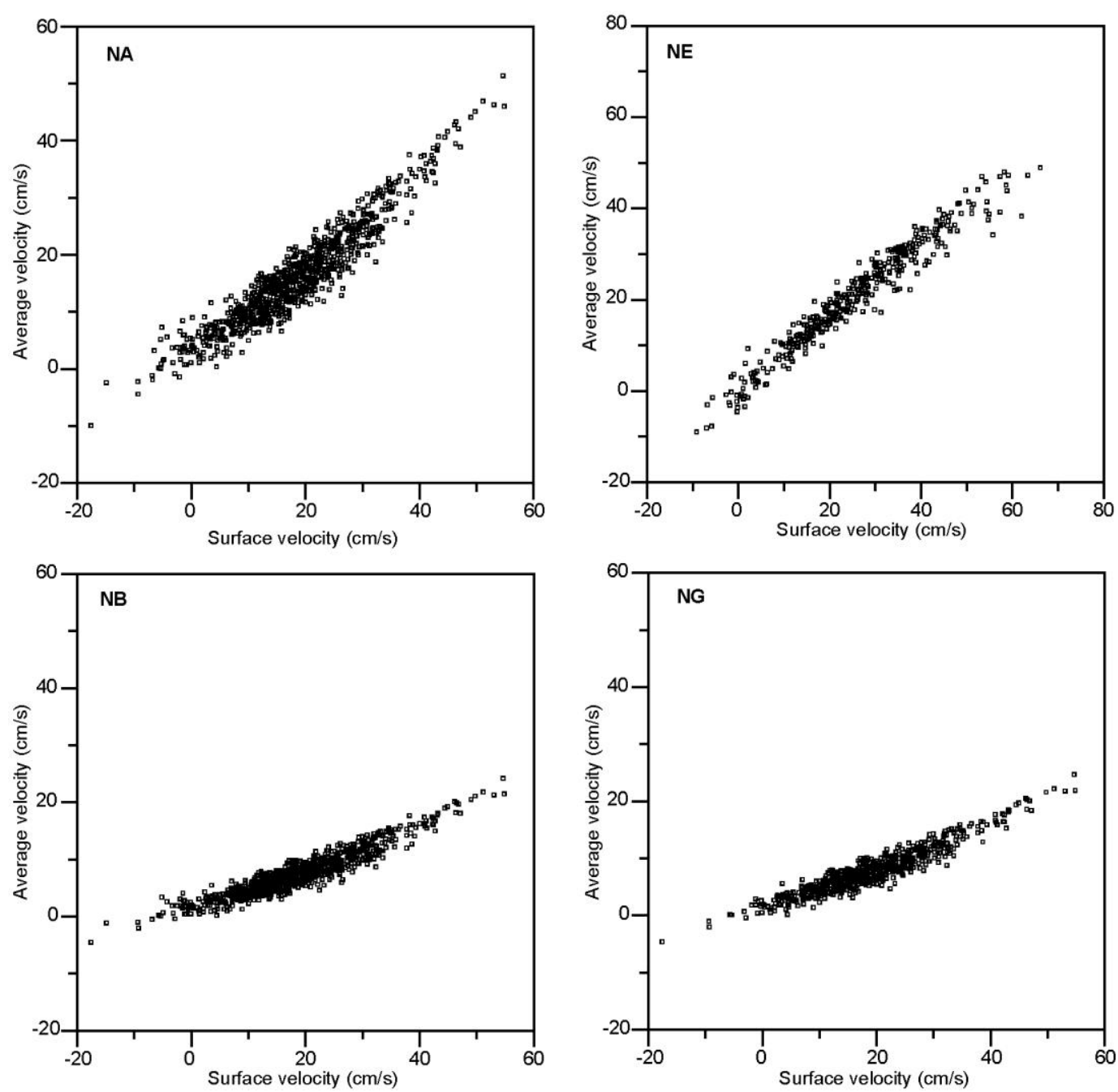

Figure 3.2.1 Seven day averaged values of depth-averaged (over full ADCP depth) eastward velocity plotted against extrapolated eastward surface velocity for the four long-term ADCPs. 

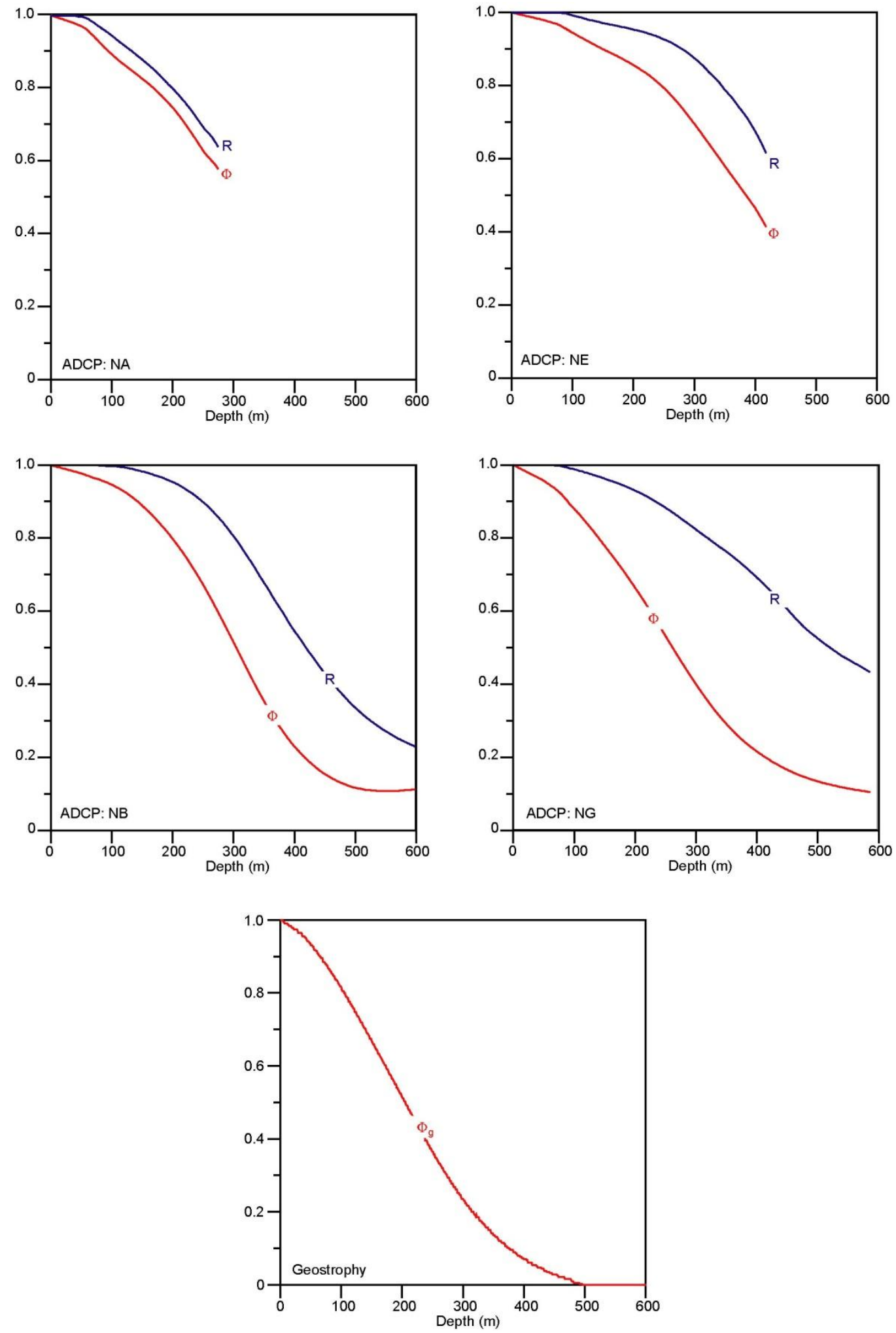

Figure 3.2.2 Relative profiles for eastward velocity. Uppermost four panels show the correlation coefficient between eastward velocity at depth and at surface (R, blue) and the average ratio between eastward velocity at depth and at surface $(\Phi(z)$, red) for the four long-term ADCP sites from a zero-offset regression analysis using Eq. (3.2.1). Lowest panel shows the ratio between eastward velocity at depth and at surface $\left(\Phi_{g}(z)\right)$ based on the average geostrophic profile. 
For each of the four long-term ADCP sites, we have correlated the extrapolated eastward surface velocities $u(0, t)$ with eastward velocity averaged over the full depth of the ADCP profile $u_{\text {avg }}(t)$ (Figure 3.2.1) and determined regression coefficients for the fit: $u_{\text {avg }}(t)=a \cdot u(0, t)+b$ (Table 3.2.1). We find high correlations both for daily and weekly averaged velocities, indicating that the velocity profile usually keeps a consistent shape, but in extreme cases, a small surface velocity combined with a sub-surface maximum may give the ratio $F(t)=u_{\text {avg }}(t) / u(0, t)$ an extremely high value as indicated by the $F_{\max }$ values in Table 3.2.1.

Table 3.2.1 Correlation and regression coefficients between eastward surface velocity and average eastward velocity down to maximum depth covered by the ADCP (column labeled Depth) for daily and 7-day averaged values. $F_{\max }$ is the maximum ratio of Average to Surface velocity.

\begin{tabular}{|c|c|c|c|c|c|c|c|c|c|c|c|}
\hline \multirow[b]{2}{*}{ Site } & \multirow[b]{2}{*}{$\begin{array}{c}\text { Depth } \\
\text { m }\end{array}$} & \multicolumn{5}{|c|}{ Daily averages } & \multicolumn{5}{|c|}{ 7-day averages } \\
\hline & & $\begin{array}{c}\mathrm{N} \\
\text { Days }\end{array}$ & $\mathrm{R}$ & a & $\begin{array}{c}\mathrm{b} \\
\mathrm{cm} / \mathrm{s}\end{array}$ & $\mathrm{F}_{\max }$ & $\mathrm{N}$ & $\mathrm{R}$ & a & $\begin{array}{c}\mathrm{b} \\
\mathrm{cm} / \mathrm{s}\end{array}$ & $\mathrm{F}_{\max }$ \\
\hline NA & 275 & 6310 & 0.937 & 0.747 & 2.5 & 86 & 881 & 0.945 & 0.751 & 2.4 & 42 \\
\hline $\mathrm{NE}$ & 418 & 2729 & 0.965 & 0.759 & 1.4 & 65 & 389 & 0.975 & 0.775 & 1.0 & 23 \\
\hline NB & 600 & 5775 & 0.933 & 0.349 & 1.1 & 40 & 806 & 0.939 & 0.351 & 1.0 & 16 \\
\hline NG & 588 & 4436 & 0.936 & 0.359 & 1.1 & 41 & 627 & 0.944 & 0.366 & 0.9 & 16 \\
\hline
\end{tabular}

For each of the long-term ADCP sites, we have determined a function $\Phi(z)$ that represents the average ratio between the eastward velocity at depth $z, u(z, t)$ and the extrapolatedeastward surface velocity $u(0, t)$ where $\Phi(z)$ for every value of $\mathrm{z}$ is determined by a regression analysis of $u(z, t)$ on $u(0, t)$ where we require zero offset:

$$
\Phi(z)=\frac{\sum_{t} u(z, t) \cdot u(0, t)}{\sum_{t} u(0, t) \cdot u(0, t)}
$$

Profiles of $\Phi(z)$ are plotted in Figure 3.2.2 together with the correlation coefficient between eastward velocity at surface and at depth. It is seen that the correlation coefficient remains above 0.2 at all depths for all the four long-term ADCP sites. 


\section{The temperature and salinity fields}

In Figure 4.1, the Temperature-Salinity relationship is illustrated for the best quality CTD data.
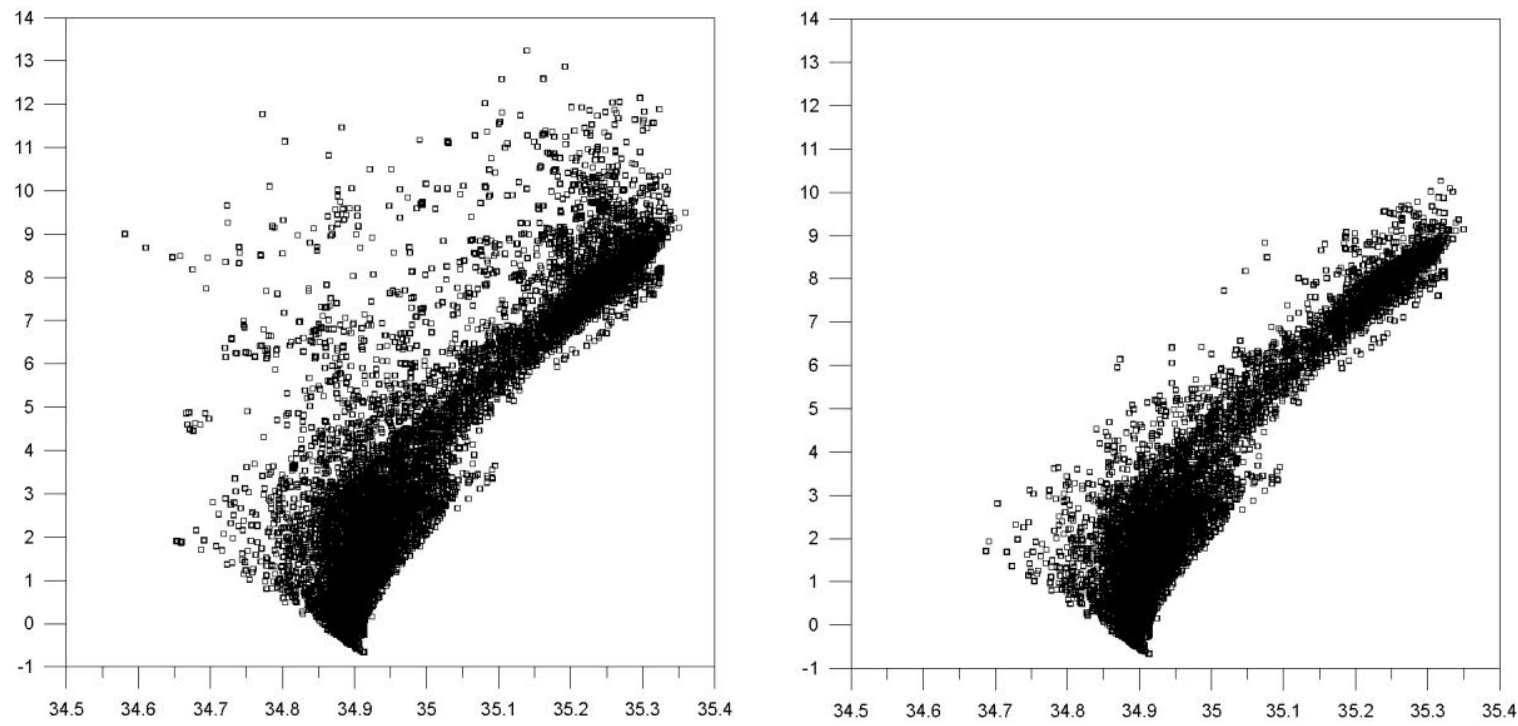

Figure 4.1 TS-diagram from CTD profiles between stations N01 and N11 from surface to 600m depth (left panel) and from $125 \mathrm{~m}$ to $600 \mathrm{~m}$ (right panel). One square is plotted for every $25 \mathrm{~m}$ depth. Based on 66 CTD cruises 1997-2013.

\subsection{Average temperature and salinity fields}

The CTD data set contains 66 cruises from the main ADCP period with complete coverage of the section from N02 to N11. The average distributions of temperature and salinity on the section (Figure 4.1.1) demonstrates that the warm and saline Atlantic water typically is found in a wedge-shaped region, which is south of station N09 in the surface and slopes downwards to hit the bottom of the Faroe Plateau at depths of around $400 \mathrm{~m}$.
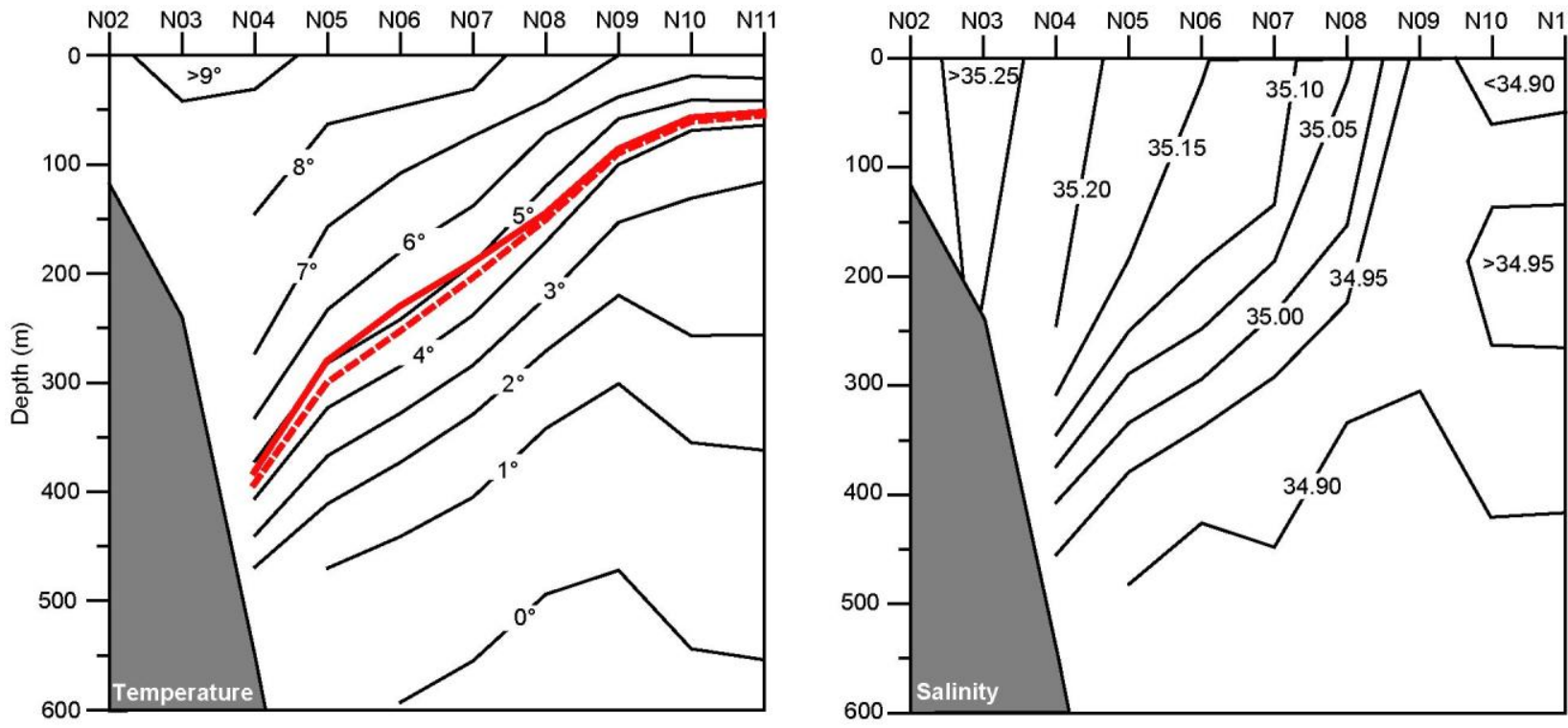

Figure 4.1.1 Average temperature (left panel) and salinity (right panel) based on 66 complete CTD sections 1997-2013. The red lines on the left panel show average simulated depths of the $4^{\circ} \mathrm{C}$ isotherm. The full red line is averaged over the whole altimetry period. The dashed red line is averaged over the dates of the 66 cruises. 
Table 4.1.1 Average depth (m) of isolines based on 66 complete CTD sections 1997-2013.

\begin{tabular}{|c|c|c|c|c|c|c|c|c|c|}
\hline Isoline & N03 & $\mathrm{N04}$ & N05 & N06 & N07 & N08 & N09 & N10 & N11 \\
\hline Isotherm $0^{\circ} \mathrm{C}$ : & & & & 593 & 555 & 494 & 472 & 544 & 554 \\
\hline Isotherm $1{ }^{\circ} \mathrm{C}$ : & & & 470 & 441 & 405 & 342 & 301 & 355 & 362 \\
\hline Isotherm $2{ }^{\circ} \mathrm{C}$ : & & 469 & 411 & 373 & 329 & 271 & 220 & 257 & 256 \\
\hline Isotherm $3^{\circ} \mathrm{C}$ : & & 440 & 367 & 328 & 284 & 222 & 153 & 131 & 116 \\
\hline Isotherm $4{ }^{\circ} \mathrm{C}$ : & & 406 & 323 & 285 & 238 & 171 & 100 & 69 & 64 \\
\hline Isotherm $5^{\circ} \mathrm{C}$ : & & 372 & 282 & 242 & 191 & 120 & 58 & 41 & 42 \\
\hline Isotherm $6^{\circ} \mathrm{C}$ : & & 332 & 233 & 180 & 138 & 72 & 38 & 19 & 21 \\
\hline Isotherm $7^{\circ} \mathrm{C}$ : & & 273 & 157 & 108 & 74 & 42 & & & \\
\hline Isotherm $8^{\circ} \mathrm{C}$ : & & 145 & 63 & 47 & 31 & & & & \\
\hline Isotherm $9^{\circ} \mathrm{C}$ : & 42 & 31 & & & & & & & \\
\hline Isohaline 34.90: & & & 482 & 426 & 448 & 334 & 305 & & \\
\hline Isohaline 34.95: & & 455 & 379 & 338 & 292 & 224 & & & \\
\hline Isohaline 35.00 : & & 407 & 334 & 294 & 234 & 153 & & & \\
\hline Isohaline 35.05: & & 374 & 289 & 248 & 186 & 21 & & & \\
\hline Isohaline 35.10: & & 345 & 250 & 187 & 134 & & & & \\
\hline Isohaline 35.15: & & 308 & 184 & 22 & & & & & \\
\hline Isohaline 35.20 : & & 245 & & & & & & & \\
\hline
\end{tabular}

\subsection{The depth of the $4^{\circ} \mathrm{C}$ isotherm}

In order to calculate time series of Atlantic water transport, we need the temporal variation of the boundary between Atlantic and other water masses on the section. Here, we represent that with the $4^{\circ} \mathrm{C}$ isotherm, but observations of this isotherm are only available from the CTD cruises. As shown by Hátún et al. (2004), the temperature (and salinity) field is, however, linked to the velocity field. Thus, some of the variation in isotherm depth may be explained by other parameters, such as the ADCP velocities or the altimetry data. The bottom temperature measured by ADCP NE could also be important.
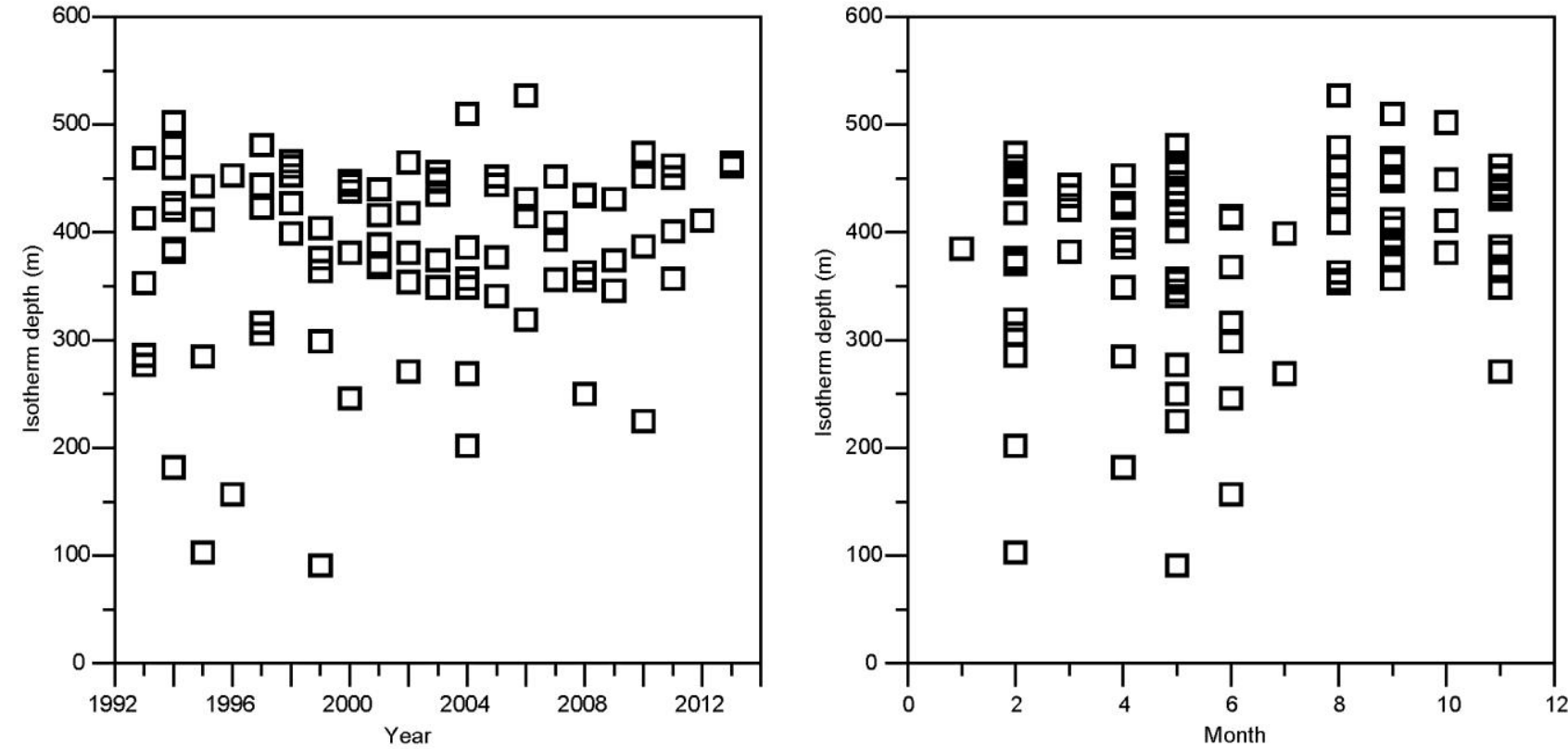

Figure 4.2.1 Depth of the $4^{\circ} \mathrm{C}$ isotherm at station N04 for 94 CTD profiles from 1993-2013 plotted against year and month.

To investigate this, all CTD profiles since 1993 between $62^{\circ} \mathrm{N}$ and $64^{\circ} \mathrm{N}$ and between $6^{\circ} 00^{\prime} \mathrm{W}$ and $6^{\circ} 10^{\prime} \mathrm{W}$ were analyzed to find the depth of the $4^{\circ} \mathrm{C}$ isotherm at stations N04 to N11. No clear trend or seasonal variation were evident, at least for station N04 (Figure 4.2.1). These depth values were then correlated with 
the parameters that might be considered to influence isotherm depth. For the ADCP at site NB, we made an EOF analysis of the velocity profile and correlated the first two principal components with isotherm depth, but neither this, nor correlations with NB velocities at various depths explained more than $20 \%$ of the variance and less than correlations with other parameters.

Table 4.2.1 Main characteristics and explained variance $\left(\mathrm{R}^{2}\right)$ of $4^{\circ} \mathrm{C}$ isotherm depth at stations N04-N11 by various variables. The first four columns indicate the station number, the number of observations $(\mathrm{N})$, the average depth (Avg), and its standard deviation (Std). The remaining columns, except for the second to last, list $\mathrm{R}^{2}$ for either single or multiple (2 independent variables) regression of isotherm depth on: bottom temperature at $\mathrm{NE}\left(T_{N E}\right)$, and the following parameters based on altimetry: surface velocity in altimetry interval $\mathrm{A}_{\mathrm{k}}$ to $\mathrm{A}_{\mathrm{k}+1}\left(U_{k}\right)$, and principal components $\left(P C_{l}\right.$ and $\left.P C_{2}\right)$. For station $\mathrm{N} 04$, brackets around $\mathrm{N}$ indicate that there were fewer (47) data with values for $T_{N E}$. The second to last column lists the interval (k: $\mathrm{A}_{\mathrm{k}}$ to $\left.\mathrm{A}_{\mathrm{k}+1}\right)$, in which the surface velocity $U_{k}$ together with $P C_{l}$ gave the best fit (last column).

\begin{tabular}{|c|c|c|c|c|c|c|c|c|c|c|c|c|c|}
\hline$\overline{\text { St. }}$ & $\mathrm{N}$ & Avg & Std & $\mathrm{T}_{\mathrm{NE}}$ & $\mathrm{T}_{\mathrm{NE}}+\mathrm{U}_{3}$ & $\mathrm{PC}_{1}$ & $\mathrm{PC}_{2}$ & $\mathrm{PC}_{1+2}$ & $\mathrm{U}_{3}$ & $\mathrm{U}_{6}$ & $\mathrm{U}_{3}+\mathrm{U}_{6}$ & $\mathrm{k}$ & $\mathrm{U}_{\mathrm{k}}+\mathrm{PC}_{1}$ \\
\hline$\overline{\mathrm{NO}} 4$ & $(94)$ & 387 & 85 & 0.50 & 0.58 & 0.13 & 0.04 & 0.17 & 0.12 & 0.11 & 0.13 & 5 & 0.30 \\
\hline N05 & 97 & 285 & 114 & 0.00 & 0.49 & 0.31 & 0.00 & 0.31 & 0.49 & 0.39 & 0.52 & 5 & 0.56 \\
\hline N0 6 & 86 & 244 & 106 & 0.08 & 0.38 & 0.30 & 0.03 & 0.33 & 0.37 & 0.50 & 0.51 & 6 & 0.58 \\
\hline N07 & 87 & 194 & 105 & 0.04 & 0.17 & 0.51 & 0.06 & 0.59 & 0.27 & 0.36 & 0.37 & 4 & 0.65 \\
\hline N0 8 & 85 & 145 & 95 & 0.01 & 0.02 & 0.55 & 0.02 & 0.60 & 0.10 & 0.09 & 0.11 & 5 & $\overline{0.62}$ \\
\hline N09 & 85 & 86 & 70 & 0.00 & 0.02 & 0.52 & 0.01 & 0.54 & 0.07 & 0.02 & 0.07 & 5 & 0.58 \\
\hline $\mathrm{N} 10$ & 84 & 58 & 50 & 0.00 & 0.05 & 0.46 & 0.00 & 0.46 & 0.07 & 0.05 & 0.07 & 5 & $\overline{0.47}$ \\
\hline N11 & 51 & 52 & 41 & 0.03 & 0.00 & 0.37 & 0.00 & 0.37 & 0.03 & 0.07 & 0.07 & 5 & 0.42 \\
\hline
\end{tabular}

The remaining parameters are: bottom temperature at $\mathrm{NE}\left(T_{N E}\right)$, and the following parameters based on altimetry: surface velocity in altimetry interval $\mathrm{A}_{\mathrm{k}}$ to $\mathrm{A}_{\mathrm{k}+1}\left(U_{k}\right)$, and principal components $\left(\mathrm{PC}_{1}\right.$ and $\left.\mathrm{PC}_{2}\right)$. We did both simple regressions with one independent variable and multiple regressions with two independent variables. The combinations that explained most of the variance in isotherm depth at each station are underlined in Table 4.2.1. When the isotherm outcropped above the surface, its depth was set to zero. We also tried to ignore these cases, but that gave worse fits.

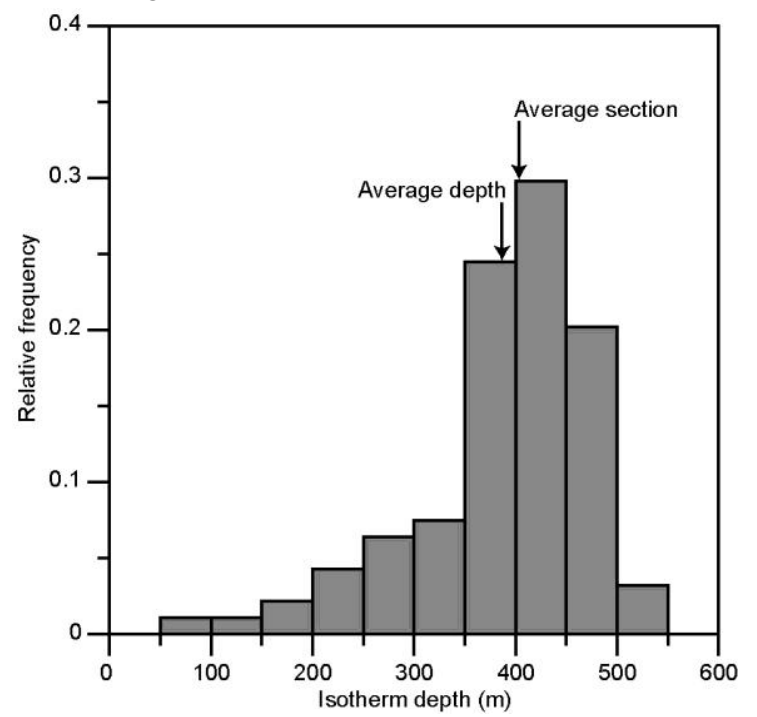

Figure 4.2.2 Relative distribution of the depth of the $4^{\circ} \mathrm{C}$ isotherm at station N04 for 94 CTD profiles from 1993-2013. The arrow labeled "Average depth" indicates the average of all the isotherm depths in the histogram. The arrow labeled "Average section" is the depth of the isotherm on the average section shown in Figure 4.1.1 
The regression equations that gave the best fits (maximized $\mathrm{R}^{2}$ ) are listed in Table 4.2.2. Using these, we can calculate simulated isotherm depths for the whole altimetry period. Figure 4.2.3 compares simulated and observed depths of the $4^{\circ} \mathrm{C}$ isotherm. Generally, the simulated isotherm depths vary less than the observed depths.
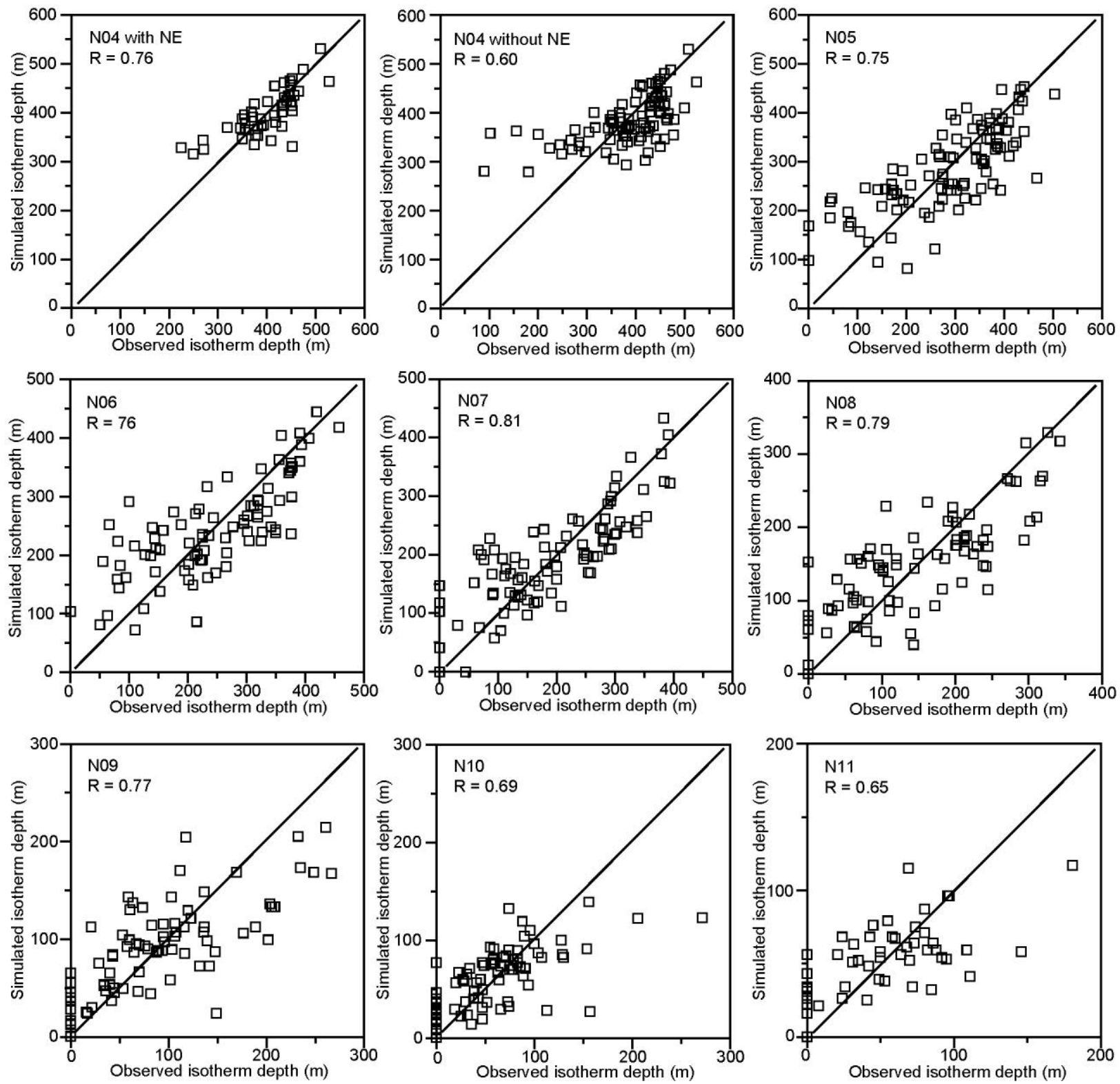

Figure 4.2.3 Comparison of observed and simulated depth of the $4{ }^{\circ} \mathrm{C}$ isotherm at standard stations N04 to N11. For station N04, simulations are shown both with temperature at NE and without.

Averaging the simulated depths of the $4^{\circ} \mathrm{C}$ isotherm over the whole altimetry period, we get the full red line in Figure 4.1.1, left panel, which is seen to be shallower than the observed $4^{\circ} \mathrm{C}$ average isotherm and closer to the $5^{\circ} \mathrm{C}$ average isotherm over much of the section. Averaging only over the dates of the 66 cruises, on which Figure 4.1.1 is based, (dashed red line in the figure), we find a better resemblance, but the simulated isotherm is still too shallow.

Likely explanations for this bias may be the tendency for the simulated isotherm depth to vary less than the observed one (Figure 4.2.3) and the skewness of the distribution (Figure 4.2.2), but whether that is so or 
not, it seems appropriate to correct for this bias, which is done in the right hand side of Table 4.2 .2 by adding the difference between the observed average isotherm depth and the average simulated depth.

Table 4.2.2 Regression equations for the depth $(\mathrm{m})$ of the $4^{\circ} \mathrm{C}$ isotherm. The biased equations are the regressions that give the best fits (underlined bold in Table 4.2.1). The unbiased equations are the same, except that the offset has been changed so that the average simulated depth for the dates of the 66 cruises (dashed red curve in Figure 4.1.1) fits the average observed isotherm depth.

\begin{tabular}{c|c}
\hline Biased equations & Unbiased equations \\
\hline $\mathrm{D}_{\mathrm{N} 04}=31.95 \cdot \mathrm{T}_{\mathrm{NE}}-2.76 \cdot \mathrm{U}_{3}+343$ & $\mathrm{D}_{\mathrm{N} 04}=31.95 \cdot \mathrm{T}_{\mathrm{NE}}-2.76 \cdot \mathrm{U}_{3}+355$ \\
$\mathrm{D}_{\mathrm{N} 04}=5.97 \cdot \mathrm{U}_{5}-3033 \cdot \mathrm{PC}_{1}+321$ & $\mathrm{D}_{\mathrm{N} 04}=5.97 \cdot \mathrm{U}_{5}-3033 \cdot \mathrm{PC}_{1}+333 \quad\left(\mathrm{~T}_{N E}\right.$ unavailable $)$ \\
$\mathrm{D}_{\mathrm{N} 05}=9.92 \cdot \mathrm{U}_{5}-5986 \cdot \mathrm{PC}_{1}+173$ & $\mathrm{D}_{\mathrm{N} 05}=9.92 \cdot \mathrm{U}_{5}-5986 \cdot \mathrm{PC}_{1}+195$ \\
$\mathrm{D}_{\mathrm{N} 06}=10.91 \cdot \mathrm{U}_{6}-3105 \cdot \mathrm{PC}_{1}+122$ & $\mathrm{D}_{\mathrm{N} 06}=10.91 \cdot \mathrm{U}_{6}-3105 \cdot \mathrm{PC}_{1}+153$ \\
$\mathrm{D}_{\mathrm{N} 07}=-6.48 \cdot \mathrm{U}_{4}-4704 \cdot \mathrm{PC}_{1}+307$ & $\mathrm{D}_{\mathrm{N} 07}=-6.48 \cdot \mathrm{U}_{4}-4704 \cdot \mathrm{PC}_{1}+340$ \\
$\mathrm{D}_{\mathrm{N} 08}=-4.33 \cdot \mathrm{U}_{5}-6333 \cdot \mathrm{PC}_{1}+192$ & $\mathrm{D}_{\mathrm{N} 08}=-4.33 \cdot \mathrm{U}_{5}-6333 \cdot \mathrm{PC}_{1}+211$ \\
$\mathrm{D}_{\mathrm{N} 09}=-2.97 \cdot \mathrm{U}_{5}-4397 \cdot \mathrm{PC}_{1}+118$ & $\mathrm{D}_{\mathrm{N} 09}=-2.97 \cdot \mathrm{U}_{5}-4397 \cdot \mathrm{PC}_{1}+127$ \\
$\mathrm{D}_{\mathrm{N} 10}=-0.94 \cdot \mathrm{U}_{5}-3062 \cdot \mathrm{PC}_{1}+68$ & $\mathrm{D}_{\mathrm{N} 10}=-0.94 \cdot \mathrm{U}_{5}-3062 \cdot \mathrm{PC}_{1}+75$ \\
$\mathrm{D}_{\mathrm{N} 11}=-1.69 \cdot \mathrm{U}_{5}-2228 \cdot \mathrm{PC}_{1}+72$ & $\mathrm{D}_{\mathrm{N} 11}=-1.69 \cdot \mathrm{U}_{5}-2228 \cdot \mathrm{PC}_{1}+80$
\end{tabular}

\subsection{Bottom temperature at ADCP site NE}

The ADCP site NE with an average bottom depth of $455 \mathrm{~m}$ is located close to the boundary between Atlantic and non-Atlantic water masses as it hits the bottom. Variations of the bottom temperature at this site show no clear seasonal variation and no clear trend (Figure 4.3.1).
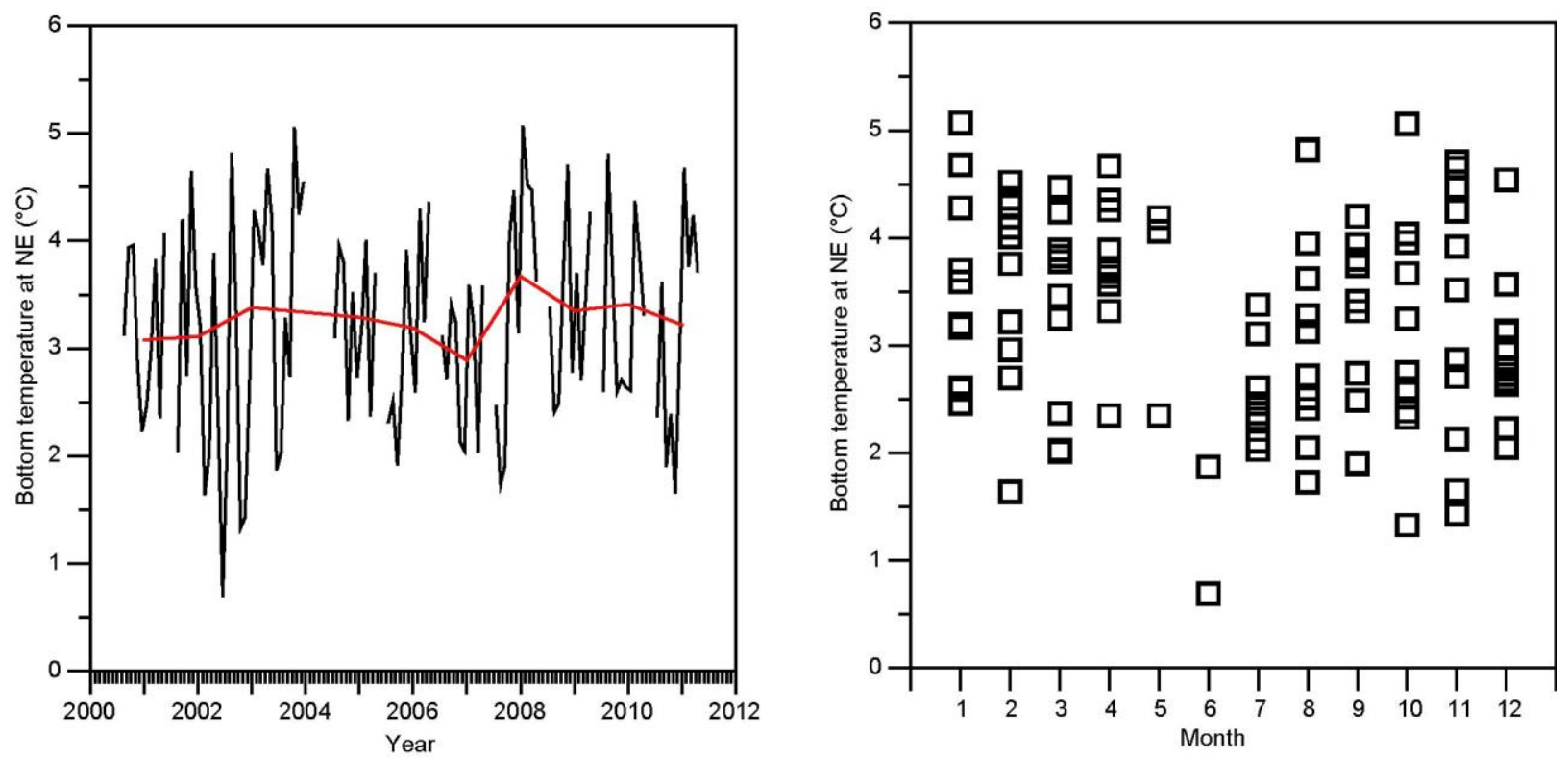

Figure 4.3.1 Bottom temperature at ADCP site NE: $T_{N E}(t)$. Left panel: Monthly averaged (black curve) and August-April averaged (red curve). Right panel: seasonal variation.

The bottom temperature at NE may be used to estimate where the $4^{\circ} \mathrm{C}$ isotherm hits the bottom. In Table 4.2.1 it is shown that the simple regression of $D_{N 04}$ on $T_{N E}$ gave a good fit $\left(\mathrm{R}^{2}=0.50\right)$. The associated regression equation: $D_{N 04}=29 \cdot T_{N E}+300$ implies that $D_{N 04}=416 \mathrm{~m}$ when $T_{N E}=4^{\circ} \mathrm{C}$, i.e. when the $4^{\circ} \mathrm{C}$ isotherm hits bottom at the depth of NE, which on average was $455 \mathrm{~m}$. In this case, the isotherm, thus, deepens by 39m from N04 until it hits the bottom at NE a small distance south of N04. 
If we extrapolate the average $4^{\circ} \mathrm{C}$ isotherm in Figure 4.1 .1 from N05 (depth 323m) to N04 (depth $406 \mathrm{~m}$ ) linearly to NE, it would deepen by $20 \mathrm{~m}$ to give a depth of $426 \mathrm{~m}$. On average, the $4^{\circ} \mathrm{C}$ isotherm should thus hit bottom inside of NE, consistent with the fact that the average bottom temperature at $\mathrm{NE}$ was $3.15^{\circ} \mathrm{C}$, i.e. colder than $4^{\circ} \mathrm{C}$. We, therefore, will assume that the we can extrapolate the depth of the $4^{\circ} \mathrm{C}$ isotherm from N04 southwards by using the slope of it from N05 to N04, but will limit the depth change from N04 southwards to $39 \mathrm{~m}$.

\subsection{The northern surface boundary of Atlantic water}

At depth, temperature may be used to distinguish between Atlantic and non-Atlantic water masses on the section but close to the surface, seasonal heating makes that futile. Instead, determination of the northern boundary of the Atlantic water close to the surface has to be based on salinity. On average, this boundary is located between stations N08 and N09, where the isohalines for 34.95, 35.00, and 35.05 all outcrop (Figure 4.1.1 (right panel). One could hope that the temporal variation of the surface-near salinity could be explained by altimetry and for the stations close to the boundary, there is some indication of this (Table 4.4.1). At most about one third of the variance is, however, explained in this way.

Table 4.4.1 Explained variance $\left(\mathrm{R}^{2}\right)$ of average salinity in top $50 \mathrm{~m}$ column in regressions on one or two variables being either a principal component or surface velocity determined from altimetry. For each station, the table shows the variables (for N10 just one) that gave the highest value for $\mathrm{R}^{2}$ and this value. CTD data from 1997-2013 were used.

\begin{tabular}{|c|c|c|c|c|c|c|c|c|c|c|}
\hline Station: & N02 & N03 & No 4 & N05 & N06 & N07 & N08 & N09 & N10 & N11 \\
\hline Variables: & $\mathrm{PC} 1+\mathrm{U} 4$ & $\mathrm{PC} 2+\mathrm{U} 4$ & $\mathrm{PC} 1+\mathrm{U} 2$ & $\mathrm{PC} 2+\mathrm{U} 5$ & $\mathrm{PC} 2+\mathrm{U} 6$ & $\mathrm{PC} 2+\mathrm{U} 7$ & $\mathrm{PC} 2+\mathrm{U} 5$ & $\mathrm{PC} 2+\mathrm{U} 5$ & PC2 & $\mathrm{PC} 1+\mathrm{U} 4$ \\
\hline Exp.var.: & 0.11 & 0.07 & 0.06 & 0.19 & 0.35 & 0.37 & 0.35 & 0.24 & 0.25 & 0.23 \\
\hline
\end{tabular}

South of station N08, the depth of the $4^{\circ} \mathrm{C}$ isotherm follows closely the depth of the 35.00 isohaline and we choose this isohaline as the Atlantic water boundary also close to the surface. For the 66 CTD cruises from 1997-2013, the latitude at which the average 0-50m salinity fell below 35.00 was determined for each cruise and this latitude was regressed on the altimetry parameters (principal components and surface velocities). As in Table 4.4.1, the best fit was when using PC2 and surface velocity interval $\mathrm{A}_{7}-\mathrm{A}_{8}$, but this only explained $23 \%$ of the variance.

Among the CTD cruises from the section, one sometimes sees a relatively thin layer of low-salinity water above the Atlantic water in the southern part of the section, which may perhaps help explain the irregular character of the surface-near salinity. It may therefore be more appropriate to consider the salinity at somewhat larger depth, e.g. $100 \mathrm{~m}$. Indeed, we find that the latitude at which the salinity at $100 \mathrm{~m}$ depth falls below 35.00 may be represented by a regression equation:

$$
D_{35.00,100 m}(t)=-52.2 \cdot P C_{1}(t)+0.18 \cdot U_{7}(t)+6.62
$$

which explains $44 \%$ of the variance in $D_{35.00,100 m}(t)$. The unit for $D_{35.00,100 m}(t)$ in this equation is the distance between standard stations (10 nautical miles), so that 6.62 mean a bit more than half way between N06 and N07. The quality of this fit is illustrated in Figure 4.4.1. At $100 \mathrm{~m}$ depth, the 35.00 isohaline should usually be somewhat south of its surface outcrop (Figure 4.1.1) and the average value of $D_{35.00,100 m}(t)$ (7.42) was about 1 unit less than the average surface outcrop. We can therefore get an expression for location of the 35.00 isohaline for the whole 0 to $100 \mathrm{~m}$ layer by adding 0.5 to Eq. (4.4.1) to get:

$$
D_{35.00}(t)=-52.2 \cdot P C_{l}(t)+0.18 \cdot U_{7}(t)+7.12
$$




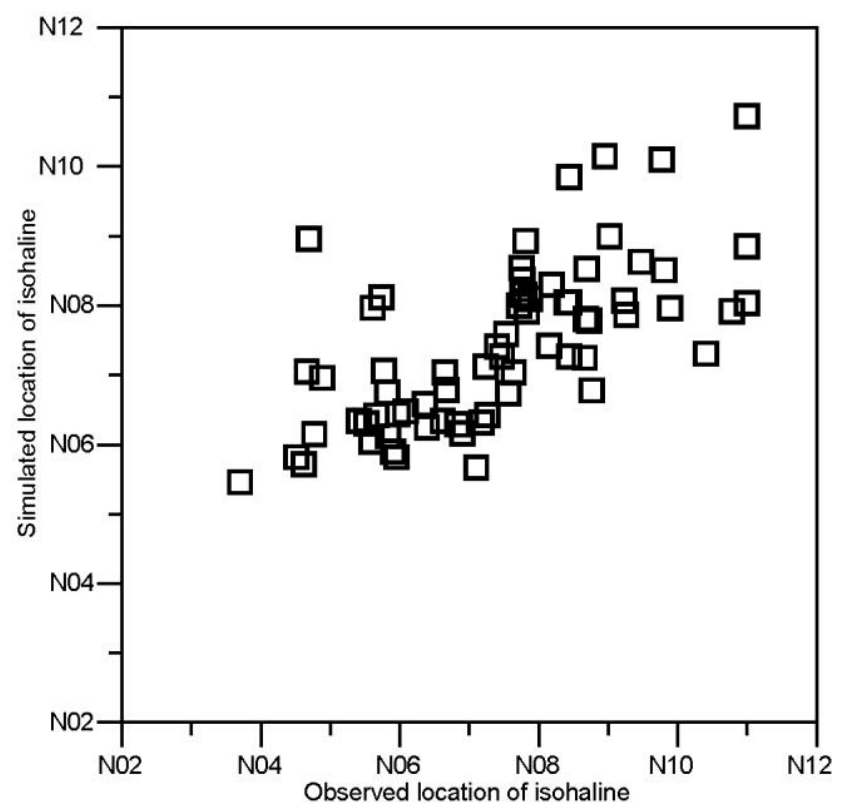

Figure 4.4.1 Location of the 35.00 isohaline at $100 \mathrm{~m}$ depth as simulated by Eq. (4.4.1) plotted against the observed location.

\subsection{Atlantic water temperature}

The water on the section is a mixture of Atlantic water and other water masses of Arctic origin. To determine the temporal variations of the Atlantic water temperature on the section, we can use two sets of observations: data from CTD cruises and temperature from the ADCP located on the bottom at site NA with a bottom depth of $300 \mathrm{~m}$. The bottom temperature at NA has the benefit of being a continuous time series although with gaps during servicing periods in the summer. From 1996 to 2014, there were 6328 days with observations during at least 12 hours of the day.
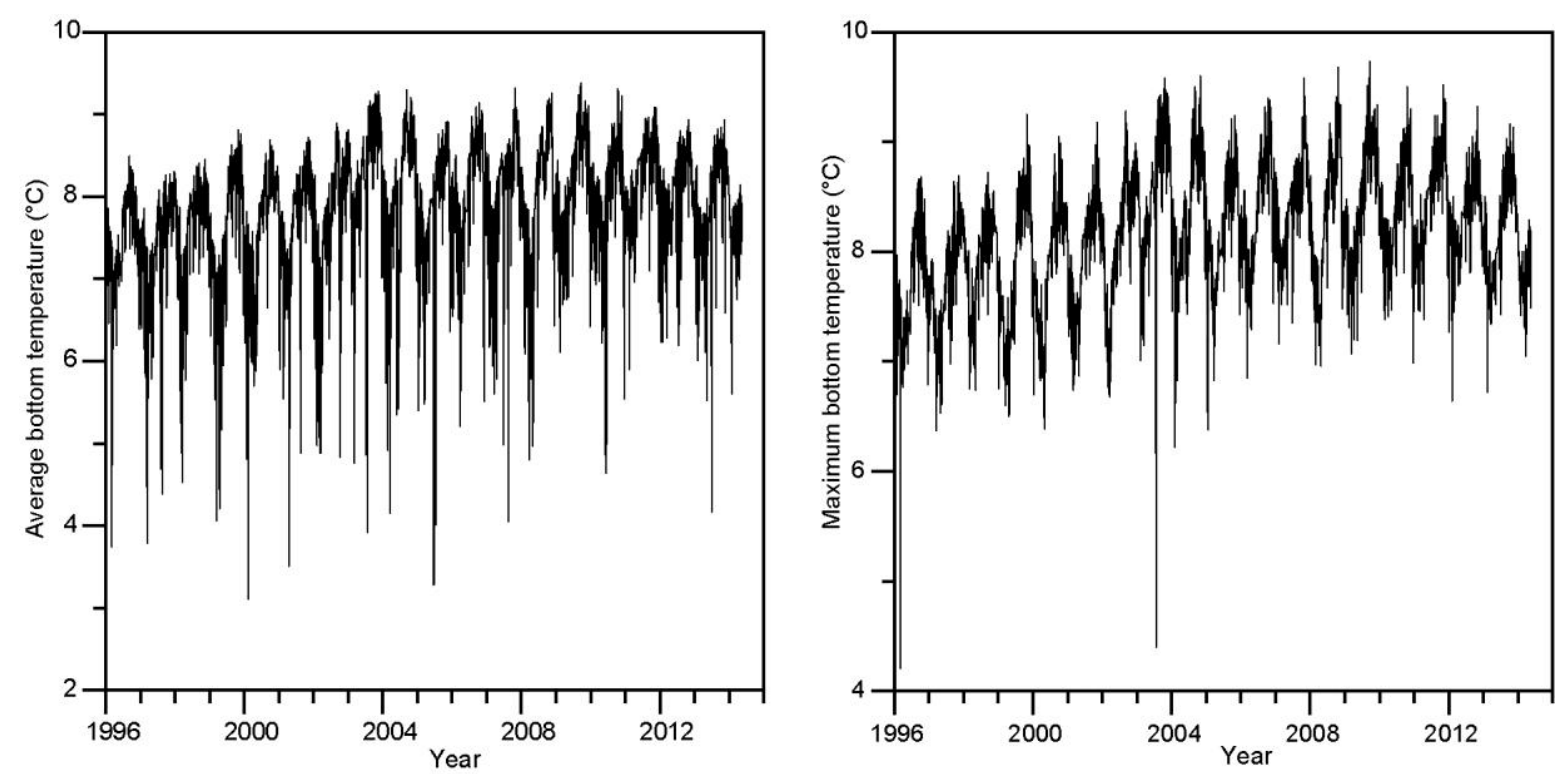

Figure 4.5.1 Left panel: Daily averaged bottom temperature at site NA. Right panel: Daily maximum bottom temperature at site NA, restricted to days when the maximum did not exceed the daily average by more than $0.5^{\circ} \mathrm{C}$. 
The daily averaged bottom temperature at NA (Figure 4.5.1, left panel) has a clear seasonal variation with an amplitude of $0.62^{\circ} \mathrm{C}$ and we see the Atlantic inflow warming from the mid-1990s to the early 2000s, but there are several very cold days, which clearly implies that NA is not always surrounded by Atlantic water. These incursions of cold water are probably affected by the tides, which implies that the maximum temperature of a day may be more representative of Atlantic water than the average.

We can further restrict the data to days when the daily maximum did not exceed the daily average by more than $0.5^{\circ} \mathrm{C}$. This reduced the number of days by about $16 \%$ and gave a much cleaner series (Figure 4.5.1, right panel), but it is clearly still contaminated by non-Atlantic water.

The data from CTD cruises is restricted to the dates of the cruises, but allows better identification of Atlantic water. The traditional parameter is the "Atlantic core temperature", which is designed to represent the purest Atlantic water during each cruise as defined by having the highest salinity. For each cruise with complete coverage from station N02 to N07, we find that 50m depth layer, from 50m downwards, that has the highest average salinity. This layer is the Atlantic core and the average temperature of this layer is the Atlantic core temperature. For details, consult Larsen et al. (2012).

From 1991 to 2013, there were 90 cruises with complete coverage from station N02 to N07. When these values are compared with simultaneous measurements of bottom temperature at NA (Figure 4.5.2, left panel), we find that the bottom temperature at NA may be more than a degree lower than the Atlantic core temperature, even when using the daily maximum bottom temperature. When combined with the low accuracy of the ADCP temperature sensor, this argues against using the bottom temperature at NA to represent the temperature of the Atlantic water.
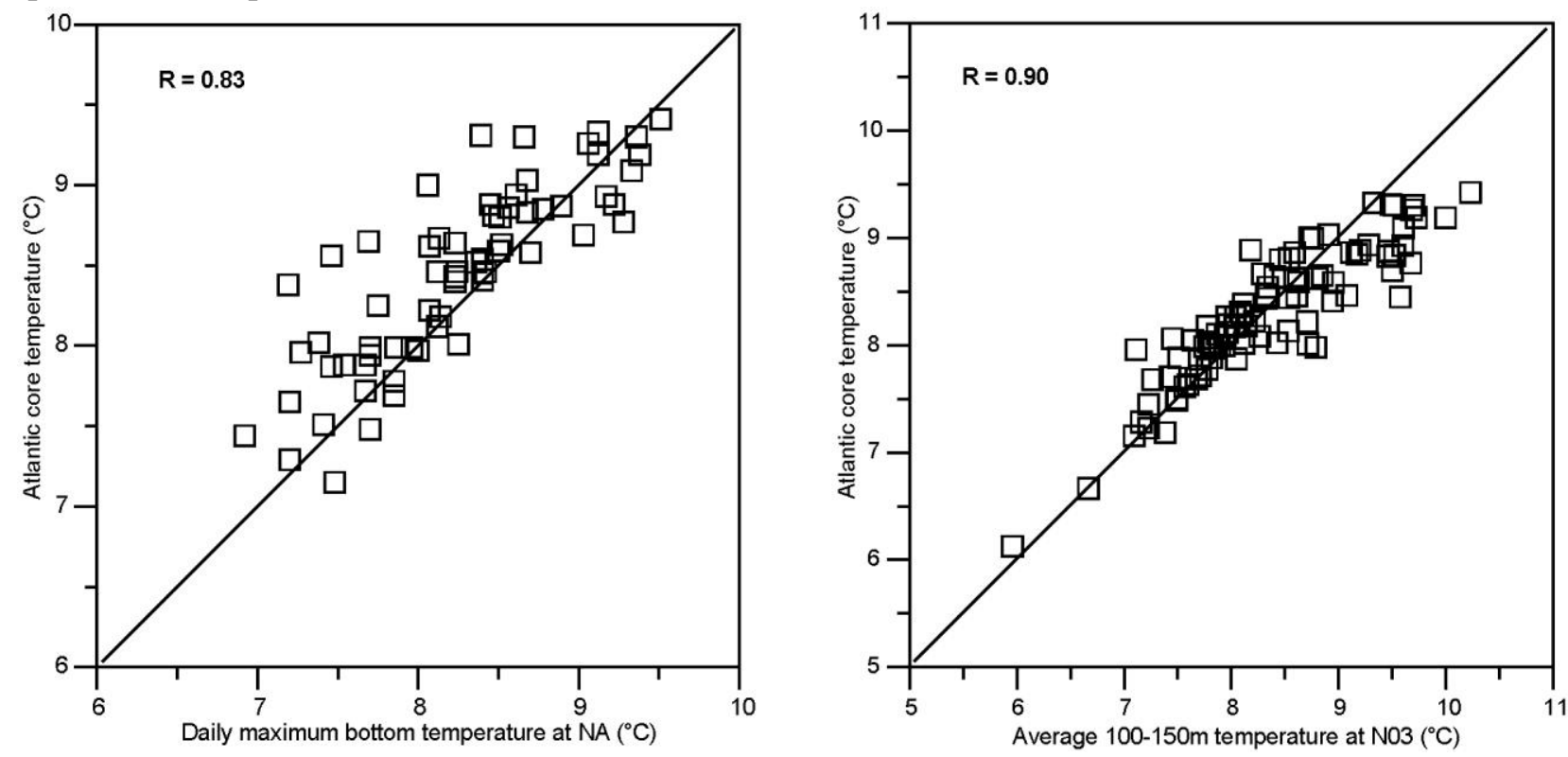

Figure 4.5.2 Atlantic core temperature plotted against daily maximum bottom temperature at NA (left panel) and against the average $100-150 \mathrm{~m}$ temperature at $\mathrm{N} 03, T_{\mathrm{NO} 3}(t)$, (right panel). Correlation coefficients are indicated.

The Atlantic core temperature is probably the most appropriate parameter to describe Atlantic water on the section, but the core may be located at different depths and different stations, which makes its use less appropriate for some purposes. We therefore also consider an additional time series, which is generated by averaging temperature between $100 \mathrm{~m}$ and $150 \mathrm{~m}$ depth at station N03. This time series is termed: $T_{N O 3}(t)$ and it is highly correlated with the Atlantic core temperature (Figure 4.5.2, right panel). 
The main characteristics of the two time series are listed in Table 4.5.1. To determine both the seasonal and the long-term variations for each parameter, we ran an iterative analysis, as described in appendix B. During the iteration, the maximum correlation coefficient with a sinusoidal seasonal signal increased from 0.82 to 0.92 for $T_{N 03}(t)$ and from 0.71 to 0.86 for the Atlantic core temperature.

Table 4.5.1 Characteristics of the two selected time series for Atlantic water temperature based on 90 cruises 1991-2013, listing average (Avg), standard deviation (Std), maximum correlation coefficient of seasonal fit (R), seasonal amplitude (Amp), and day number of maximum temperature (Max).

\begin{tabular}{lccccc}
\hline Parameter & $\begin{array}{c}\text { Avg } \\
{ }^{\circ} \mathrm{C}\end{array}$ & $\begin{array}{c}\text { Std } \\
{ }^{\circ} \mathrm{C}\end{array}$ & $\begin{array}{r}\mathrm{R} \\
{ }^{\circ} \mathrm{C} p\end{array}$ & $\begin{array}{r}\text { Max } \\
\text { Day }\end{array}$ \\
\hline Average temperature 100-150m at $\mathrm{N03:}$ & 8.36 & 0.83 & 0.92 & 0.91 & 264 \\
Atlantic core temperature: & 8.30 & 0.62 & 0.86 & 0.61 & 245
\end{tabular}
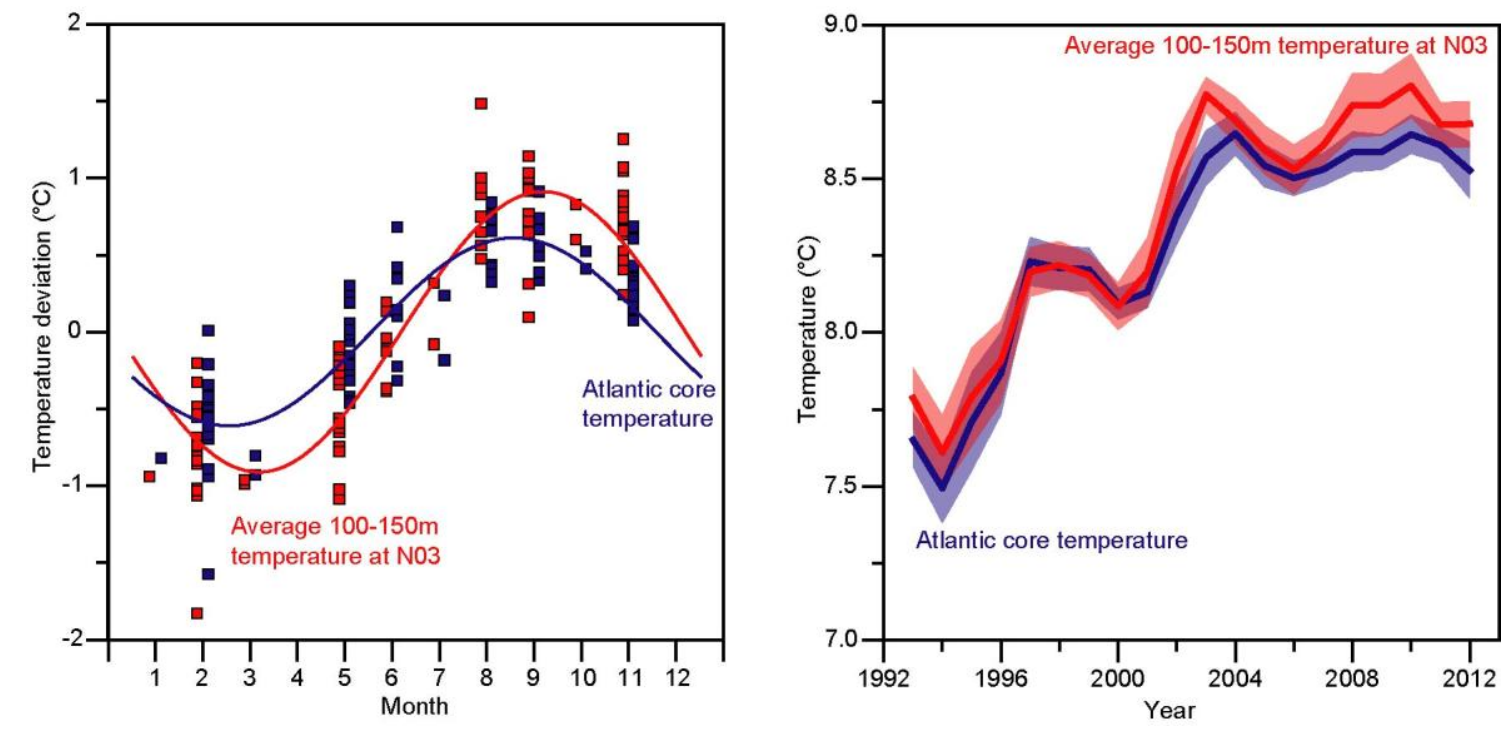

Figure 4.5.3 Temporal variations of the Atlantic core temperature (blue) and the average 100-150m temperature at station N03 (red). Left panel: Temperature deviation from the 3-year running mean (squares) and fitted sinusoidal variation (curves). Right panel: 3-year running mean of deseasoned temperature (thick curves) with semitransparent background colours indicating \pm the standard error.

The seasonal variation is considerably larger and the time of maximum is delayed for $T_{N 03}(t)$ as compared to the Atlantic core temperature (Table 4.5.1 and Figure 4.5.3, left panel). For the 3-year running mean, each year was based on between 9 and 15 individual cruises. This allows calculation of the standard error, which is indicated by the semitransparent background colours on Figure 4.5.3, right. $T_{N 03}(t)$ is generally a bit warmer than the Atlantic core temperature, but both series are fairly similar and show the $1{ }^{\circ} \mathrm{C}$-warming from the mid-1990s to the early 2000s.

\subsection{Simulating the temperature distribution}

We now want to generate an algorithm that will allow us to simulate the temperature distribution on the section at any given time in the observational period 1993 - 2013. To do this, we first express the temperature as a sum of the average, the seasonal variation, and a residual:

$$
T\left(k, i, t_{m}\right)=T_{A v}(k, i)+T_{A m p}(k, i) \cdot \cos \left(2 \pi \cdot\left(t_{m}-D_{M a x}(k, i) / 365\right)\right)+T_{\operatorname{Res}}\left(k, i, t_{m}\right)
$$


where $T\left(k, i, t_{m}\right)$ is the temperature at depth $i(1-600)$ at standard station $k(2-11)$ at time $t_{m}$, which is the time in years since 1 January $1993 . T_{A v}(k, i)$ is the average, $T_{A m p}(k, i)$ is the amplitude, and $D_{\operatorname{Max}}(k, i)$ is the day number of the year with maximum temperature. $T_{R e s}\left(k, i, t_{m}\right)$ is the residual.

To determine these fields, we use 78 CTD cruises from 1993 to 2013 with full coverage of the section from station $\mathrm{N} 02$ to $\mathrm{N} 11$. After subtracting the average field from the original observed temperature distributions, the seasonal variation in each point $(k, i)$ of the section was determined by regression on a sinusoidal seasonal variation and varying the phase lag to give maximum correlation.

As expected, the maximum correlation coefficient is high in the surface layer, but it is also high over the shallower stations N02 and N03 (Figure 4.6.1, top left). At larger depths on the outer stations, the maximum correlation coefficients are low, indicating that the seasonal signal is not very clear. Also, the maximum temperature occurs later in the year (Figure 4.6.1, bottom right). We have therefore set the amplitude to be zero for depth more than $100 \mathrm{~m}$ from station N04 to N11 (Figure 4.6.1, bottom left).
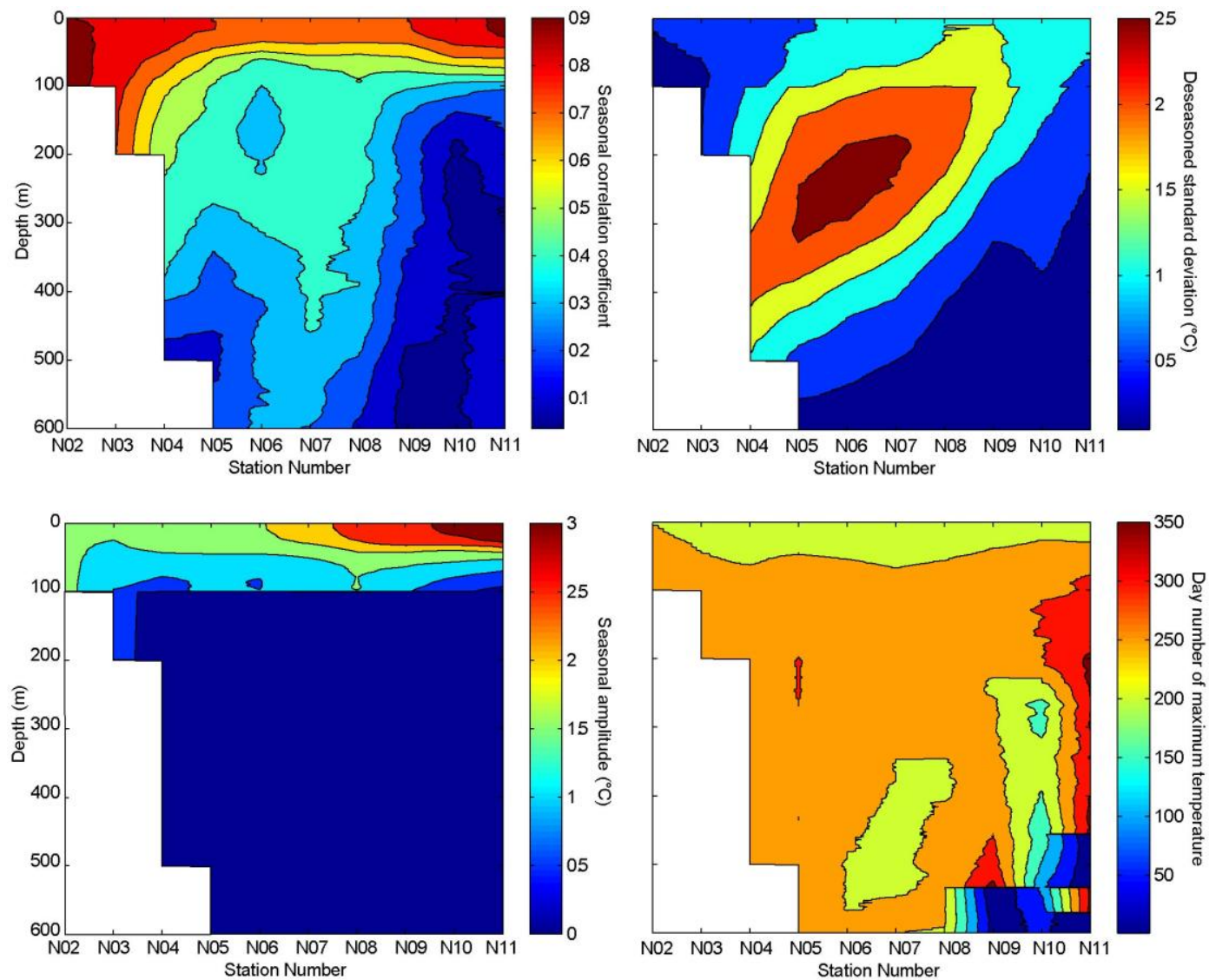

Figure 4.6.1 Seasonal variation of the temperature field based on 78 CTD sections from 1993 - 2013. Top left: Maximum correlation coefficient with sinusoidal seasonal variation. Top right: Standard deviation of the temperature field after deseasoning. Bottom left: Amplitude of the seasonal temperature variation (set to 0 where the correlation coefficient is low). Bottom right: Day number of the year with maximum temperature.

Once the average temperature and the seasonal variation have been determined, they may be subtracted from the original observed temperature distributions to give the residual temperature distribution for each cruise $T_{R e s}\left(k, i, t_{m}\right)$. The standard deviation of the residual (Figure 4.6.1, top right) shows that most of the variance is associated with movement of the thermocline. 
It therefore seems reasonable to link the variations of the residual temperature to the depth of the $4^{\circ} \mathrm{C}$ isotherm, $d_{4}\left(k, t_{m}\right)$. In addition to this, we expect the distribution to depend on the temperature of the Atlantic water. As discussed in Part 4.5, there are different ways to represent that but, after some experimentation, we found the average temperature between $100 \mathrm{~m}$ and $150 \mathrm{~m}$ at station $\mathrm{N03}: T_{\mathrm{NO} 3}(t)$ to give the best fit.

For stations N04 to N11, where the $4^{\circ} \mathrm{C}$ isotherm is well defined, $T_{R e s}\left(k, i, t_{m}\right)$ was therefore simulated by multiple regression for each point $(k, i)$ :

$$
T_{\mathrm{Re} s}\left(k, i, t_{m}\right)=a(k, i) \cdot\left(T_{N 03}\left(t_{m}\right)-\left\langle T_{N 03}\right\rangle\right)+b(k, i) \cdot d_{4}\left(k, t_{m}\right)+c(k, i)
$$

For the two stations $\mathrm{N} 02$ and N03, we use the first altimetry principal component $P C_{I}(t)$ instead of the $4^{\circ} \mathrm{C}$ isotherm depth:

$$
T_{\mathrm{Re} s}\left(k, i, t_{m}\right)=a(k, i) \cdot\left(T_{N 03}\left(t_{m}\right)-\left\langle T_{N 03}\right\rangle\right)+b(k, i) \cdot P C_{1}\left(t_{m}\right)+c(k, i)
$$
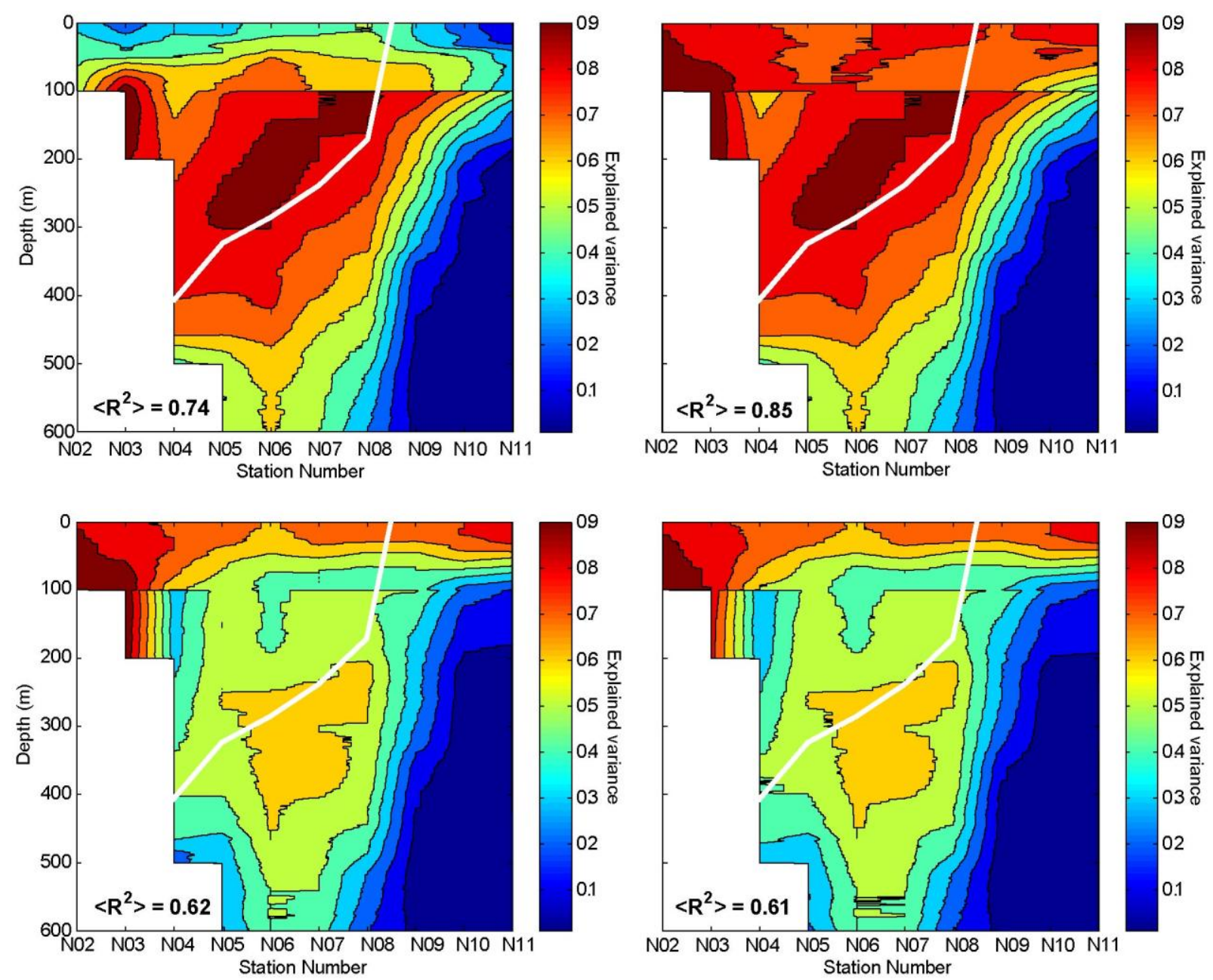

Figure 4.6.2 Explained variance $\left(\mathrm{R}^{2}\right)$ of the temperature field. Top left: Explained variance of the residual temperature field (where the seasonal variation has been subtracted) by Eqs. (4.6.2) and (4.6.3) with observed $D_{j}(t)$ and $T_{N O 3}(t)$. Top right: Explained variance of the original observed temperature field with observed $D_{j}(t)$ and $T_{N 03}(t)$. Bottom left: Explained variance of the original observed temperature field with simulated $D_{j}(t)$ and observed $T_{N 03}(t)$. Bottom right: Explained variance of the original observed temperature field with simulated $D_{j}(t)$ and simulated $T_{N 03}(t)$. The value given for $\left\langle\mathrm{R}^{2}\right\rangle$ on each panel is the average over the average Atlantic water extent, which is bounded by the thick white line on each panel. 
The multiple regression explained a large fraction of the variance for points dominated by Atlantic water (Figure 4.6.2, top left). Averaging over the "average Atlantic water extent", bounded by the bottom or the $4{ }^{\circ} \mathrm{C}$ isoline north to station N08, the explained variance $\left(\mathrm{R}^{2}\right)$ of the residual temperature distributions was 0.74. Combining the three Eq. (4.6.1), Eq. (4.6.2), and Eq. (4.6.3), an even larger fraction of the original temperature distribution is explained (Figure 4.6.2, top right). Averaging over the average Atlantic water extent, the explained variance $\left(\mathrm{R}^{2}\right)$ of the original temperature distributions was 0.85 .

The fact that we can explain $85 \%$ of the variance in the temperature field by these three equations is very encouraging. To some extent, the good correspondence is, however, because the values used for $d_{4}\left(k, t_{m}\right)$ and $T_{\mathrm{NO} 3}(t)$ in Eq. (4.6.2) and Eq. (4.6.3) were determined from the observed CTD data for each of the 78 cruises. To simulate the temperature field for a day when there were no CTD data, $d_{4}\left(k, t_{m}\right)$ and $T_{N O 3}(t)$ would have to be simulated as well. Algorithms for doing that were discussed in Part 4.2 (Table 4.2.2) and Part 4.5.

The bottom panels of Figure 4.6.2 show the explained variance when only $d_{4}\left(k, t_{m}\right)$ was simulated (bottom left) and when both $d_{4}\left(k, t_{m}\right)$ and $T_{\mathrm{NO} 3}(t)$ were simulated (bottom right). Averaging over the average Atlantic water extent, the explained variance $\left(\mathrm{R}^{2}\right)$ of the original temperature distributions was 0.62 in the first case (bottom left) and 0.61 in the second (bottom right).

\subsection{Atlantic water salinity}

As for temperature, there are different possibilities for describing the salinity of "pure" Atlantic water on the section. Here, we use the average salinity of the 100-150 m layer at station N03. As elaborated in appendix $\mathrm{B}$, we may iteratively separate the temporal salinity variations of the Atlantic water into a long-term variation + a seasonal variation + short-term variations. After iteration, the correlation coefficient with the fitted sinusoidal was $R_{\max }=0.49$ and the seasonal amplitude 0.020 with maximum salinity on day number 209 .
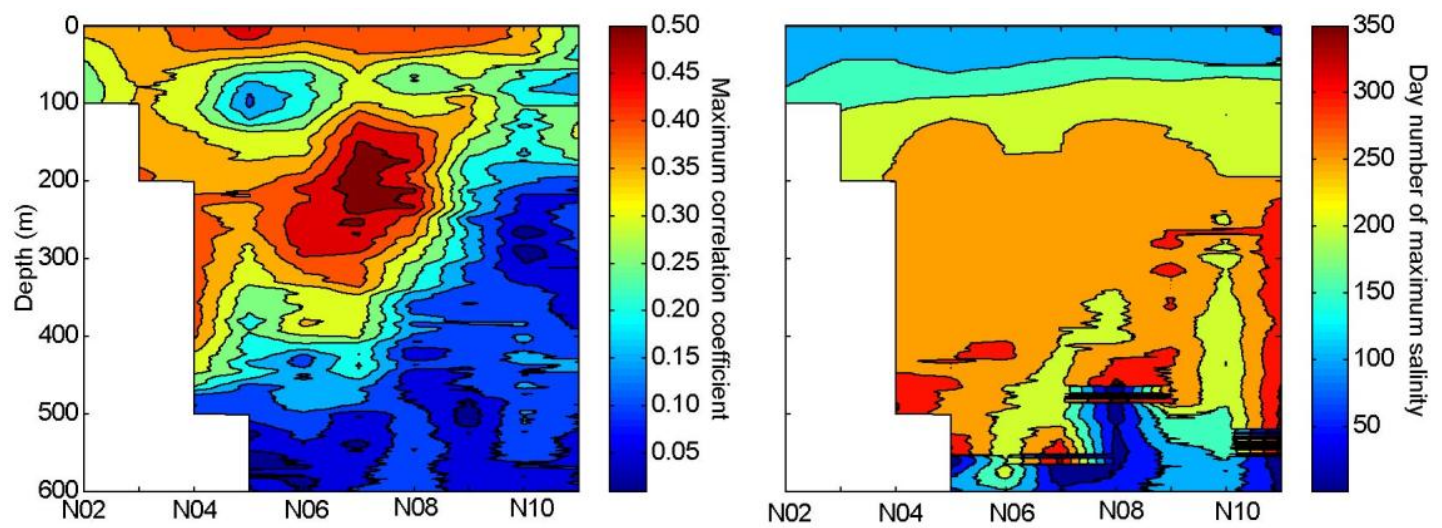

Figure 4.8.1 Seasonal salinity variation on section N based on 78 CTD cruises 1993-2013. Left panel: Maximum correlation coefficient of fit between salinity and sinusoidal seasonal variation. Right panel: Day number of maximum salinity from best fit with sinusoidal seasonal variation.

\subsection{Simulating the salinity distribution}

In order to derive a continuous time series for salt transport, we need to be able to estimate the salinity distribution on the section for any given period; not only for the cruises when CTD observations are available. To investigate this, we use the 78 CTD sections from 1993-2013, previously discussed. Fitting a sinusoidal seasonal variation to salinity at various points on the section (without accounting for long-term variation iteratively), we do not find high maximum correlation coefficients (Figure 4.8.1, left panel) and the day of maximum salinity varies considerably with depth. The best fit (highest correlation coefficient) is for 
the pycnocline region and no doubt caused by the seasonal variation of the velocity field (Figure 3.1.1 and Figure 5.4.3).

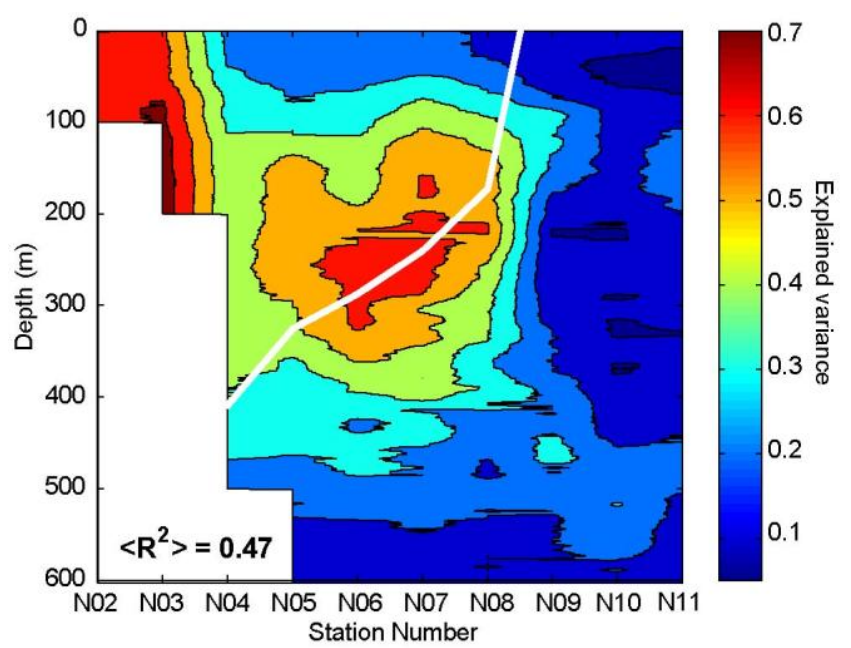

Figure 4.8.2 Explained variance $\left(\mathrm{R}^{2}\right)$ of the observed salinity field by Eqs. (4.8.1) and (4.8.2) with $S_{A t l}(t)$ and simulated $d_{4}\left(k, t_{m}\right)$. The value given for $\left\langle\mathrm{R}^{2}\right\rangle$ is the average over the average Atlantic water extent, which is bounded by the thick white line.

We therefore ignore the seasonal salinity variation and fit the salinity $S\left(k, i, t_{m}\right)$ at point $(k, i)$ on the section and at time $t_{m}$ in a slightly different manner than temperature. For stations N04 to N11, where the $4^{\circ} \mathrm{C}$ isotherm is well defined, $S\left(k, i, t_{m}\right)$ was simulated by multiple regression for each point $(k, i)$ :

$$
S\left(k, i, t_{m}\right)=a_{S}(k, i) \cdot\left(S_{A t l}\left(t_{m}\right)-\left\langle S_{A t l}\right\rangle\right)+b_{S}(k, i) \cdot d_{4}\left(k, t_{m}\right)+c_{S}(k, i)
$$

where $S_{A t l}\left(t_{m}\right)$ is the 3-year running mean salinity of the Atlantic water for the year of $t_{m}$. For the two stations $\mathrm{N} 02$ and N03, we use the first altimetry principal component $P C_{I}(t)$ instead of the $4^{\circ} \mathrm{C}$ isotherm depth:

$$
S\left(k, i, t_{m}\right)=a_{S}(k, i) \cdot\left(S_{A t l}\left(t_{m}\right)-\left\langle S_{A t l}\right\rangle\right)+b_{S}(k, i) \cdot P C_{1}\left(k, t_{m}\right)+c_{S}(k, i)
$$

As might have been expected, the simulated salinity fields explains considerably less of the observed variance than for temperature (compare Figure 4.8.2 with Figure 4.6.2, bottom right). We have tried other alternatives than Eqs. (4.8.1) and 4.8.2), but without improvement. It seems that it is especially for the top $100 \mathrm{~m}$ layer from station N04 northwards that the simulation fails. 


\section{Volume transport}

\subsection{Combining altimetry surface velocity with ADCP velocity profile}

Once calibrated, the altimetry data provide us with a time series of horizontally averaged surface velocity $U_{k}(0, t)$ for each altimetry interval $\mathrm{A}_{\mathrm{k}}$ to $\mathrm{A}_{\mathrm{k}+1}$. To allow calculation of volume transport, this has to be combined with information on the vertical variation of the velocity field so that we can find the horizontally averaged velocity $U_{k}(z, t)$ for interval $\mathrm{k}$ at depth $z$. To do this we multiply the surface velocity $U_{k}(0, t)$ by a function $\varphi_{k}(z, t)$ :

$$
U_{k}(z, t)=U_{k}(0, t) \cdot \varphi_{k}(z, t)
$$

If, in a certain period, there is one ADCP that is considered to represent the altimetry interval $k$, then for most of the period, we may assume that:

$$
\varphi_{k}(z, t)=u_{A D C P}(z, t) / u_{A D C P}(0, t)
$$

If, however, the ADCP has a low surface velocity and a subsurface maximum, this may produce extremely high velocities at depth $\left(F_{\max }\right.$ in Table 3.2.1). So, when the maximum ADCP velocity exceeds the surface velocity by a factor of 1.5 , we use instead the average (time-independent) function for $\varphi_{k}(z, t): \varphi_{k}(z, t)=\Phi_{k}(z)$ in Figure 3.2.2.
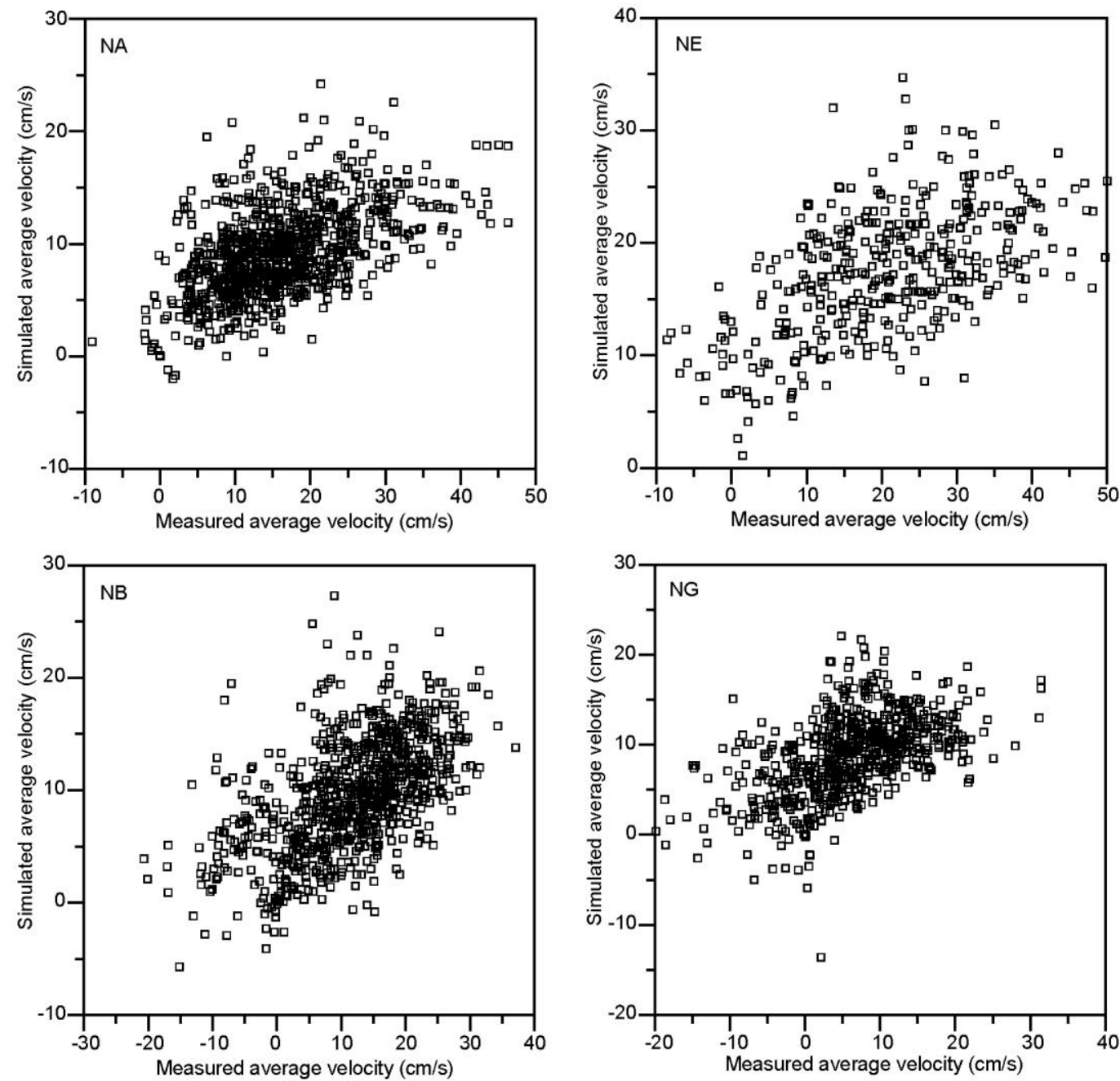

Figure 5.1.1 Weekly and depth averaged velocity, simulated by Eq. (5.1.1), plotted against weekly and depth averaged ADCP velocity. Depth averaging is over the whole ADCP depth range (Table 3.2.1). For NA, altimetry interval $A_{2}-A_{3}$ was used in the simulation. For $N E$, interval $A_{3}-A_{4}$ was used, and for $N B$ and $N G$, interval $\mathrm{A}_{4}-\mathrm{A}_{5}$ was used. 
To test this procedure, Eq. (5.1.1) was used to calculate a simulated depth-averaged (full depth or 0-275m layer) velocity for every day with $\mathrm{ADCP}$ coverage, using either $\varphi_{k}(z, t)$ or $\Phi_{k}(z)$, depending on the ratio $u_{A D C P, \max }(t) / u_{A D C P}(0, t)$. For daily averages, between $10 \%$ and $19 \%$ of days had this ratio exceeding 1.5 , so that $\Phi_{k}(z)$ was used instead of $\varphi_{k}(z, t)$ (Table 5.1.1). For weekly averages, this percentage ("f" in Table 5.1.1) decreased to between $4 \%$ and $14 \%$. The correlation coefficients are not impressive, but they are generally consistent with Table 3.1.1. We also see large differences between the averages, which was to be expected, since the values calculated by Eq. (5.1.1) are horizontally averaged in contrast to the ADCP values. The differences are generally consistent with Figure 2.4.4. Comparing the two sets of weekly averaged velocities (Figure 5.1.1), we see no irregularities at low velocities that might be associated with the swap between $\varphi_{k}(z, t)$ and $\Phi_{k}(z)$.

Table 5.1.1 Comparison between depth-averaged eastward velocity calculated from Eq. (5.1.1) and depthaveraged eastward velocity measured by an ADCP for daily and weekly averaged data. "R" is the correlation coefficient. " $\mathrm{f}$ " is the relative occurrence of a subsurface maximum in the ADCP profile that necessitates the use of $\Phi_{k}(z)$ instead of $\varphi_{k}(z, t)$ in Eq (5.1.1), which by experimentation was found to be when the maximum ADCP velocity exceeds the surface velocity by a factor of 1.5 . "Dif" is the average velocity $\left(\mathrm{cm} \cdot \mathrm{s}^{-1}\right)$ over the whole period as calculated by Eq. (5.1.1) minus the average measured by the ADCP.

\begin{tabular}{|c|c|c|c|c|c|c|c|c|c|c|}
\hline \multirow[b]{2}{*}{ Depth avg. } & \multirow[b]{2}{*}{ Site } & \multirow[b]{2}{*}{ Altim. } & \multicolumn{4}{|c|}{ Daily averages } & \multicolumn{4}{|c|}{ Weekly averages } \\
\hline & & & $\mathrm{N}$ & $\mathrm{R}$ & $\mathrm{f}$ & Dif & $\mathrm{N}$ & $\mathrm{R}$ & $\mathrm{f}$ & Dif \\
\hline Full depth & NA & $\mathrm{A}_{2}-\mathrm{A}_{3}$ & 6297 & 0.57 & 0.19 & -7.4 & 901 & 0.53 & 0.14 & -6.8 \\
\hline Full depth & $\mathrm{NE}$ & $\mathrm{A}_{3}-\mathrm{A}_{4}$ & 2729 & 0.57 & 0.15 & -3.7 & 390 & 0.55 & 0.08 & -3.2 \\
\hline Full depth & NB & $A_{4}-A_{5}$ & 5762 & 0.57 & 0.18 & $-2 \cdot 2$ & 824 & 0.56 & 0.10 & $-2 \cdot 0$ \\
\hline Full depth & NG & $A_{4}-A_{5}$ & 4423 & 0.45 & 0.17 & 2.0 & 633 & 0.53 & 0.11 & 2.7 \\
\hline $0-275 m$ & NA & $\mathrm{A}_{2}-\mathrm{A}_{3}$ & 6297 & 0.57 & 0.19 & -7.4 & 901 & 0.53 & 0.14 & -6.8 \\
\hline $0-275 m$ & $\mathrm{NE}$ & $\mathrm{A}_{3}-\mathrm{A}_{4}$ & 2729 & 0.57 & 0.11 & -4.2 & 390 & 0.56 & 0.06 & -3.8 \\
\hline $0-275 m$ & NB & $A_{4}-A_{5}$ & 5762 & 0.54 & 0.10 & $-4 \cdot 3$ & 824 & 0.54 & 0.04 & -4.0 \\
\hline $0-275 m$ & NG & $\mathrm{A}_{4}-\mathrm{A}_{5}$ & 4423 & 0.50 & 0.14 & 3.5 & 633 & 0.58 & 0.09 & 4.2 \\
\hline
\end{tabular}

\subsection{Combining altimetry surface velocity with geostrophic velocity profile}

North of altimetry point $\mathrm{A}_{5}$, the only ADCP site is $\mathrm{NC}$, for which it was difficult to extrapolate the profile all the way to the surface. Thus, we have no reliable ADCP observations, from which to derive the vertical variation of the eastward velocity. We find, however, a similar shape of the average NC profile and the average geostrophic profile between stations N05 and N07 (Figure 2.4.3). We therefore use a timeindependent function $\Phi_{g}(z)$ to represent the vertical variation, so that the eastward velocity at depth $\mathrm{z}$ for altimetry interval from $A_{k}$ to $A_{k+1}$ is given by:

$$
U_{k}(z, t)=U_{k}(0, t) \cdot \Phi_{g}(z)
$$

The function $\Phi_{g}(z)$ is determined from the average geostrophic velocity profile $\Psi_{\text {Avg }}(z)$. The three intervals N06-N07, N07-N08, and N08-N09 had very similar average geostrophic profiles, each of which was based on 84-85 CTD casts (Table 2.4.3). The average geostrophic profile $\Psi_{\text {Avg }}(z)$ was therefore derived by averaging the average profiles from these three intervals and the relative profile derived from that:

$$
\Phi_{g}(z)=\frac{\Psi_{A v g}(z)-\Psi_{A v g}(500)}{\Psi_{A v g}(0)-\Psi_{A v g}(500)}
$$




\subsection{Total volume transport}

The total volume transport (ignoring the origin of water masses) is here defined as the total transport between station $\mathrm{N} 02$ and altimetry point $\mathrm{A}_{7}$, from the surface down to $500 \mathrm{~m}$ depth. It is derived as:

$$
Q_{T o t}(t)=\sum_{k=2}^{6} \sum_{z=0}^{500} U_{k}(z, t) \cdot W_{k}(z)=\sum_{k=2}^{6} \sum_{z=0}^{500} U_{k}(0, t) \cdot \varphi_{k}(z, t) \cdot W_{k}(z)
$$

where $U_{k}(z, t)$ as before is the eastward velocity at depth z, horizontally averaged over the altimetry interval from $A_{k}$ to $A_{k+1}$, and $W_{k}(z)$ is the width of the interval at depth $z$, which for intervals $A_{2}-A_{3}$ and $A_{3}-A_{4}$ decreases as $\mathrm{z}$ approaches the bottom and is zero below it.

In the last sum in Eq. (5.3.1), we have used Eq. (5.1.1) to express $U_{k}(z, t)$ as the product of the horizontally averaged surface velocity in each altimetry interval $U_{k}(0, t)$ and the relative profile $\varphi_{k}(z, t)$ in that interval. We start the integration from standard station N02 at a bottom depth of $118 \mathrm{~m}$. This is in the middle of the altimetry interval $\mathrm{A}_{2}-\mathrm{A}_{3}$, and there we used the ADCP velocity from NA: $\varphi_{2}(z, t)=\varphi_{N A}(z, t)$, although NA is outside the interval, since the surface velocity at NA was fairly well correlated with the altimetry surface velocity for $\mathrm{A}_{2}-\mathrm{A}_{3}$ (Table 3.1.1).

Table 5.3.1 Relative profile functions used in each altimetry interval for calculation of velocity at depth and transport. $\varphi_{k}(z, t)$ is the temporally variable relative profile for interval $\mathrm{A}_{\mathrm{k}}$ to $\mathrm{A}_{\mathrm{k}+1}$, whereas $\Phi_{k}(z)$ is the fixed relative profile. $\Phi_{g}(z)$ is the average geostrophic profile.

\begin{tabular}{llll}
\hline Interval & Depth range & Variable relative profile & Fixed relative profile \\
\hline $\mathrm{A}_{2}-\mathrm{A}_{3}$ & $z=0$ to $600 \mathrm{~m}:$ & $\varphi_{2}(z, t)=\varphi_{N A}(z, t)$ & $\Phi_{2}(z)=\Phi_{N A}(z)$ \\
$\mathrm{A}_{3}-\mathrm{A}_{4}$ & $z=0$ to $275 \mathrm{~m}:$ & $\varphi_{3}(z, t)=1 / 2 \cdot\left(\varphi_{N A}(z, t)+\varphi_{N E}(z, t)\right)$ & $\Phi_{3}(z)=1 / 2 \cdot\left(\Phi_{N A}(z)+\Phi_{N A}(z)\right)$ \\
& $z=276$ to $418 \mathrm{~m}:$ & $\varphi_{3}(z, t)=1 / 2 \cdot\left(\varphi_{N E}(z, t)+\varphi_{N B}(z, t)\right)$ & $\Phi_{3}(z)=1 / 2 \cdot\left(\Phi_{N E}(z)+\Phi_{N B}(z)\right)$ \\
& $z=419$ to $600 \mathrm{~m}:$ & $\varphi_{3}(z, t)=\varphi_{N B}(z, t)$ & $\Phi_{3}(z)=\Phi_{N B}(z)$ \\
$\mathrm{A}_{4}-\mathrm{A}_{5}$ & $z=0$ to $600 \mathrm{~m}:$ & $\varphi_{4}(z, t)=1 / 2 \cdot\left(\varphi_{N B}(z, t)+\varphi_{N G}(z, t)\right)$ & $\Phi_{4}(z)=1 / 2 \cdot\left(\Phi_{N B}(z)+\Phi_{N G}(z)\right)$ \\
$\mathrm{A}_{5}-\mathrm{A}_{6}$ & $z=0$ to $600 \mathrm{~m}:$ & & $\Phi_{5}(z)=\Phi_{g}(z)$ \\
$\mathrm{A}_{6}-\mathrm{A}_{7}$ & $z=0$ to $600 \mathrm{~m}:$ & & $\Phi_{6}(z)=\Phi_{g}(z)$ \\
$\mathrm{A}_{7}-\mathrm{A}_{8}$ & $z=0$ to $600 \mathrm{~m}:$ & & $\Phi_{7}(z)=\Phi_{g}(z)$
\end{tabular}

For altimetry interval $\mathrm{A}_{3}-\mathrm{A}_{4}$, there are two ADCPs, NA and NE, inside the interval, but the surface velocity at $\mathrm{NB}$, which is slightly outside the interval, was also well correlated with the altimetry velocity (Table 3.1.1). This interval deepens from $194 \mathrm{~m}$ at $\mathrm{A}_{3}$ to $700 \mathrm{~m}$ at $\mathrm{A}_{4}$, whereas NA only has measurements down to $275 \mathrm{~m}$ and NE down to $418 \mathrm{~m}$. We therefore use different combinations in different depth intervals (Table 5.3.1). Altimetry interval $A_{4}-A_{5}$ has two ADCPs, NB and NG, which should be equally representative and we have to rely on the geostrophic profiles north of $\mathrm{A}_{5}$ (Table 5.3.1).

From Table 3.1.1, daily averaged eastward surface velocities from ADCPs and from altimetry are not well correlated and the assumption of geostrophic balance is doubtful on a daily time scale. We therefore will not attempt to calculate daily averaged volume transport, but use a week as the shortest averaging period. From 1 January 1993 to 1 May 2014, there are 1113 weeks for which we have altimetry data. During 232 of those weeks, all four long-term ADCPs (NA, NE, NB, and NG) were in operation and none of the weekly averaged ADCP profiles had a subsurface maximum higher than 1.5 times the surface velocity, which would have necessitated the use of the average vertical variation given by Eq. (3.2.1) instead of the instantaneous variation given by Eq. (5.1.2) for $\varphi_{k}(z, t)$ in Eq. (5.3.1).

These 232 weeks form the most complete dataset for the total volume transport, based on both altimetry and instantaneous data from all four ADCPs. We can, however, compute volume transport values also for the 
rest of the altimetry period by using the average vertical variation at each ADCP site $\Phi(z)$. These values may be expected to be less accurate than the values that are based on full ADCP coverage, but their quality may be estimated by re-calculating the volume transport for the 232 high-quality weeks, using the average vertical variation at each ADCP site $\Phi(z)$, and comparing the two data sets. This is done in Table 5.3.2 and Figure 5.3.1.

Table 5.3.2 Comparison of total volume transport calculated by Eq. (5.3.1) in two different ways. $Q_{\text {Tot }}(t)$ is calculated using $\varphi_{k}(z, t)$ determined from ADCP data every day. $Q^{\prime}{ }_{T o t}(t)$ is calculated using the average $\Phi(z)$. $\mathrm{R}$ is the correlation coefficient, $\alpha$ and $\beta$ are regression coefficients: $Q_{T o t}^{\prime}(t)=\alpha \cdot Q_{T o t}(t)+\beta$. $\mathrm{R}_{0}$ is the zero-offset correlation coefficient with $\alpha_{0}$ the zero-offset regression coefficient: $Q_{T o t}^{\prime}(t)=\alpha_{0} \cdot Q_{T o t}(t)$. Dif is the difference between averages, Err is the rms deviation of the zero-offset regression from the actual value and Rerr is Err divided by the average value of $Q_{T o t}(t)$.

\begin{tabular}{lrrrrrrrrr}
\hline Averaging & $\mathrm{N}$ & $\mathrm{R}$ & $\mathrm{R}_{0}$ & $\alpha$ & $\beta$ & $\alpha_{0}$ & Dif & Err & Rerr \\
\hline 1 week: & 232 & 0.92 & 0.996 & 0.73 & 1.21 & 0.974 & -0.06 & 0.43 & 0.09 \\
4 weeks: & 30 & 0.94 & 0.998 & 0.74 & 1.18 & 0.987 & -0.03 & 0.28 & 0.06
\end{tabular}
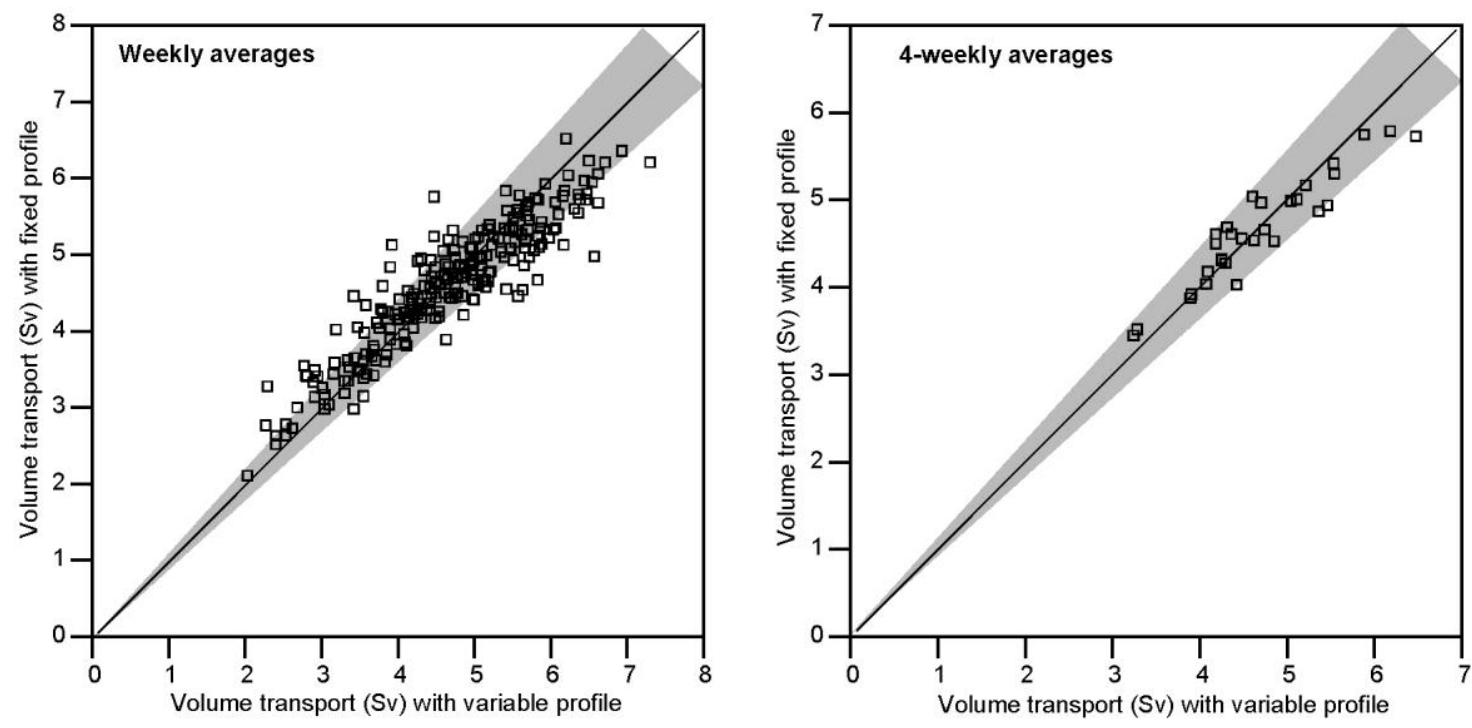

Figure 5.3.1 Comparison of total volume transport calculated by Eq. (5.3.1) in two different ways. The abscissa is calculated using variable profiles $\varphi_{k}(z, t)$ determined from ADCP data every day. The ordinate is calculated using the fixed profiles $\Phi_{k}(z)$. Left panel shows weekly, right panel 4-week averages. Points within the grey area deviate less than $10 \%$ from equality (diagonal line).

Both weekly and 4-week averaged data are well correlated with negligible difference in average transport (column "Dif" in Table 5.3.2) and with relative rms-error 9\% and 6\%, respectively (column "Rerr" in Table 5.3.2). The zero-offset regression factor $\alpha_{0}$ is very close to 1 and, for 4 -week averages, only few values have relative deviation more than $10 \%$ (grey areas in Figure 5.3.1).

Taking into account other uncertainties in the transport estimate, the added uncertainty in $\mathrm{Q}^{\prime}{ }_{\text {Tot }}(\mathrm{t})$ seems small and we can therefore produce estimates of total volume transport for the whole altimetry period although we expect (without proof) higher quality when all four long-term ADCPs are in operation. 


\subsection{Volume transport of Atlantic water}

The Atlantic water on the section is warmer and more saline than the other water masses. Using this to identify the Atlantic water and calculating its transport can be accomplished in different ways. The easiest method is to choose an isoline of either temperature or salinity as the boundary of Atlantic water wherever it is shallower than the bottom. With that method, Eq. (5.3.1) can be used directly by choosing $W_{k}(z)=L \cdot r_{k}(z)$ where $L$ is the distance between grid points and $r_{k}(z)$ is the fraction (between 0 and 1) of the width of altimetry interval $k$ that is above the boundary at depth $z$.

For altimetry interval $\mathrm{A}_{2}$ to $\mathrm{A}_{3}, W_{k}(z)$ is determined solely from bottom depth. For $\mathrm{A}_{3}$ to $\mathrm{A}_{4}, W_{k}(z)$ is determined from bottom depth northwards to the point where the selected isoline intersect the bottom. From this point northwards, the depth of the selected isoline is determined by linear interpolation between standard stations and $W_{k}(z)$ calculated for the four altimetry intervals from $\mathrm{A}_{4}$ to $\mathrm{A}_{8}$. This method, thus, just requires the depth of the selected isoline to be known at each standard station. The average hydrographic conditions are illustrated in Figure 4.1.1 and depths of various isolines based on that are listed in Table 4.1.1. Using those values, we can get a first estimate of the volume transport of Atlantic water, depending on the choice of isoline (Table 5.4.1).

Table 5.4.1 Volume transport between $\mathrm{N} 02$ and $\mathrm{A}_{8}$ above either a fixed depth of $500 \mathrm{~m}$, a selected fixed isotherm, or a selected fixed isohaline in the average hydrographic field (Figure 4.1.1).

\begin{tabular}{|c|c|c|c|c|c|c|c|c|c|}
\hline & $\mathrm{D}=500 \mathrm{~m}$ & $\mathrm{~T}=2^{\circ} \mathrm{C}$ & $\mathrm{T}=3^{\circ} \mathrm{C}$ & $\mathrm{T}=4^{\circ} \mathrm{C}$ & $\mathrm{T}=5^{\circ} \mathrm{C}$ & $\mathrm{T}=6^{\circ} \mathrm{C}$ & $\mathrm{T}=7^{\circ} \mathrm{C}$ & $S=34.9$ & $S=35.0$ \\
\hline ransport & & 19 & & 4.05 & & & 70 & & \\
\hline
\end{tabular}

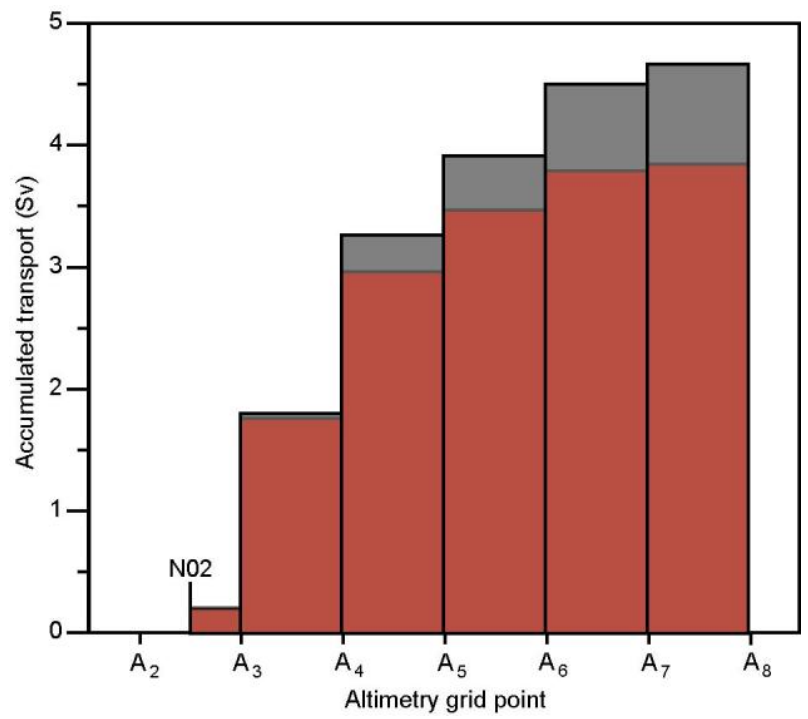

Figure 5.4.1 Average accumulated total volume transport in altimetry intervals down to $500 \mathrm{~m}$ (grey bars in back) and Atlantic water transport (red bars in front).

The choice of isotherm to act as Atlantic water boundary is to some extent arbitrary and represents a main uncertainty in the average value for atlantic water transport. We choose the $4^{\circ} \mathrm{C}$-isotherm, which is intermediate between the core of Atlantic water around $8^{\circ} \mathrm{C}$ and the cold water masses around $0^{\circ} \mathrm{C}$. This isotherm is also located in the middle of the thermocline over much of the section. From Table 5.4.1, a choice of $5^{\circ} \mathrm{C}$ or $3^{\circ} \mathrm{C}$, instead, would have decreased or increased the transport by $0.2-0.3 \mathrm{~Sv}$, respectively. To illustrate the contributions from individual altimetry intervals, Figure 5.4.1 shows the accumulated average transport down to $500 \mathrm{~m}$ as we go from N02 to $\mathrm{A}_{8}$ (grey bars). 
Using the average $4^{\circ} \mathrm{C}$ isotherm depth as a fixed lower boundary for Atlantic water will not give realistic variations of the Atlantic transport and may also affect the average value. Since observed isotherm depths are only available as snapshots from the CTD cruises, we use the simulated isotherm depths discussed in part 4.2. These are simulated for the whole altimetry period, although the values at station N04 are more reliable when bottom temperature is also available. As argued in part 4.2, we use the unbiased equations in Table 4.2.2. To implement this into the transport calculation, we adapt Eq. (5.3.1) to have a time-variable width $W_{k}(z, t)$ at each depth and extend the integration to $600 \mathrm{~m}$ :

$$
Q_{A t l}(t)=\sum_{k=2}^{7} \sum_{z=0}^{600} U_{k}(0, t) \cdot \varphi_{k}(z, t) \cdot W_{k}(z, t)
$$

We have used an isotherm instead of an isohaline to define the lower boundary of Atlantic water since we have more high-quality data for temperature than salinity and the temperature distribution on the section is simpler (Figure 4.1.1), but as we approach the surface, temperature is no longer a good indicator of water mass origin. Between the surface and $100 \mathrm{~m}$, we therefore use the northern surface boundary, discussed in Part 4.4 in the form of Eq. (4.4.2) to determine the northern limit of integration. With this procedure, we have calculated weekly averaged Atlantic water transport for the whole altimetry period (Figure 5.4.2).

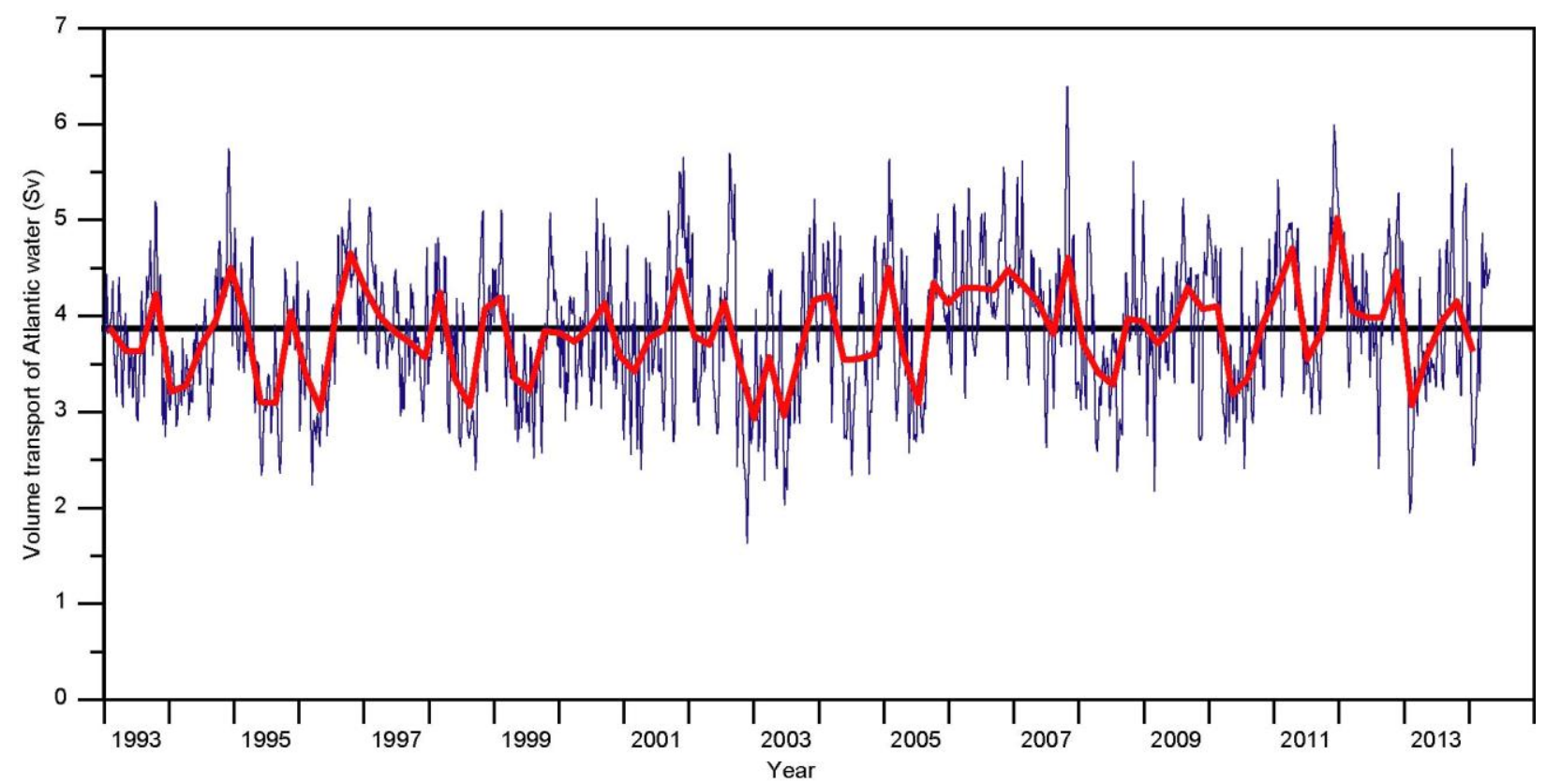

Figure 5.4.2 Long-term variation of Atlantic water transport averaged over 1 week (thin blue curve) and 12 weeks (thick red curve). Thick black line indicates average Atlantic water transport.

Averaging the weekly values, we find that the average transport of Atlantic water 1993-2013 was: 3.84 Sv. This value is lower by $0.2 \mathrm{~Sv}$ than the corresponding value in Table 5.4.1, which was calculated assuming fixed isotherm depths. To some extent, this will be due to the antiphase in the seasonal variations of velocity (Figure 5.4.3a) and the cross-sectional area covered by Atlantic water on the section (Figure 5.4.3b). This introduces a negative correlation between these two parameters (Figure 5.4.3c) such that the seasonal variation of the Atlantic water transport (Figure 5.4.3d) is relatively small. The value in Table 5.4.1 was also integrated all the way out to $A_{8}$, whereas the average cited above was integrated only out to the simulated surface 35.0 isohaline. The red bars in Figure 5.4.1 show that on average most of the Atlantic water transport occurs between $\mathrm{A}_{3}$ and $\mathrm{A}_{5}$. 
If we base the overall average on monthly, instead of weekly, values, we get a slightly different value: $3.82 \mathrm{~Sv}$, but the difference is small. This is an indication that the system is sufficiently linear so that the end result is not very sensitive to averaging periods.
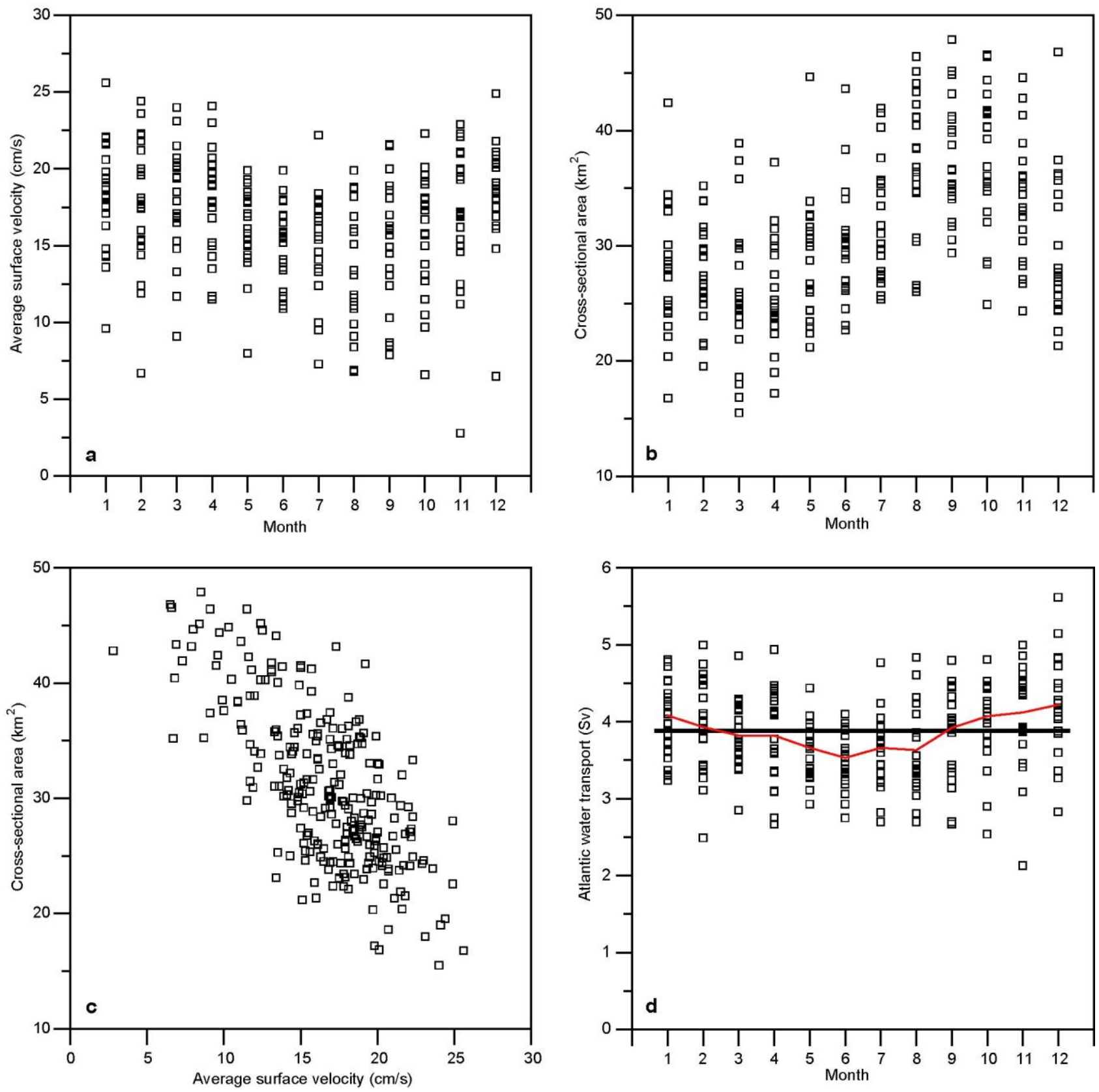

Figure 5.4.3 Panels $a, b$, and d show monthly averages of a: the surface velocity averaged over altimetry intervals $A_{3}$ to $A_{6}$, b: the cross-sectional area covered by Atlantic water, and d: Atlantic water volume transport. In panel $\mathrm{c}$, the cross-sectional area is plotted against the average surface velocity. The red line in panel $\mathrm{d}$ shows the overall monthly average transport.

\subsection{Comparison of old and new transport estimates}

The overall average Atlantic water transport for 1993-2013, calculated from weekly averages, the "new" estimate $(3.84 \mathrm{~Sv})$ is somewhat higher than the average transport reported previously, the "old" estimate, 
based only on in-situ data (Hansen et al., 2003), (3.5 $\pm 0.5 \mathrm{~Sv}$ ), but within the uncertainty. If we compare monthly averages from the new estimate with the 158 full months (at least 28 days) that were in the old data set, we find that the difference between averages persists and that the new estimate varies less than the old estimate (Table 5.5.1).

Table 5.5.1 Comparison of old and new estimates for Atlantic water transport for the 158 full months (at least 28 days) that were in the old data set and for only the (57) months with all 4 long-term ADCPs in operation. $\mathrm{N}$ is the number of months, $\mathrm{R}$ the correlation coefficient, and Err the root mean square difference.

\begin{tabular}{|c|c|c|c|c|c|c|c|}
\hline \multirow[b]{3}{*}{ Al1: } & \multirow[b]{2}{*}{$\mathrm{N}$} & \multirow[b]{2}{*}{$\mathrm{R}$} & \multirow[b]{2}{*}{ Err } & \multicolumn{2}{|c|}{ Old estimate } & \multicolumn{2}{|c|}{ New estimate } \\
\hline & & & & Average & St. dev. & Average & St. dev. \\
\hline & 158 & 0.55 & $0.49 \mathrm{~Sv}$ & $3.51 \mathrm{~Sv}$ & $0.77 \mathrm{~Sv}$ & $3.90 \mathrm{~Sv}$ & $0.59 \mathrm{~Sv}$ \\
\hline 4 ADCPS : & 57 & 0.58 & $0.46 \mathrm{~Sv}$ & $3.73 \mathrm{~Sv}$ & $0.62 \mathrm{~Sv}$ & $4.00 \mathrm{~Sv}$ & $0.57 \mathrm{~Sv}$ \\
\hline
\end{tabular}

A correlation analysis gives a correlation coefficient of only 0.55 and individual points may diverge considerably from equality (Figure 5.5.1). If the comparison is confined to the 57 months with all four longterm ADCPs in operation (red squares in Figure 5.5.1), the correlation coefficient increases to 0.58 (Table 5.5.1) and the most extreme outliers are removed (Figure 5.5.1).
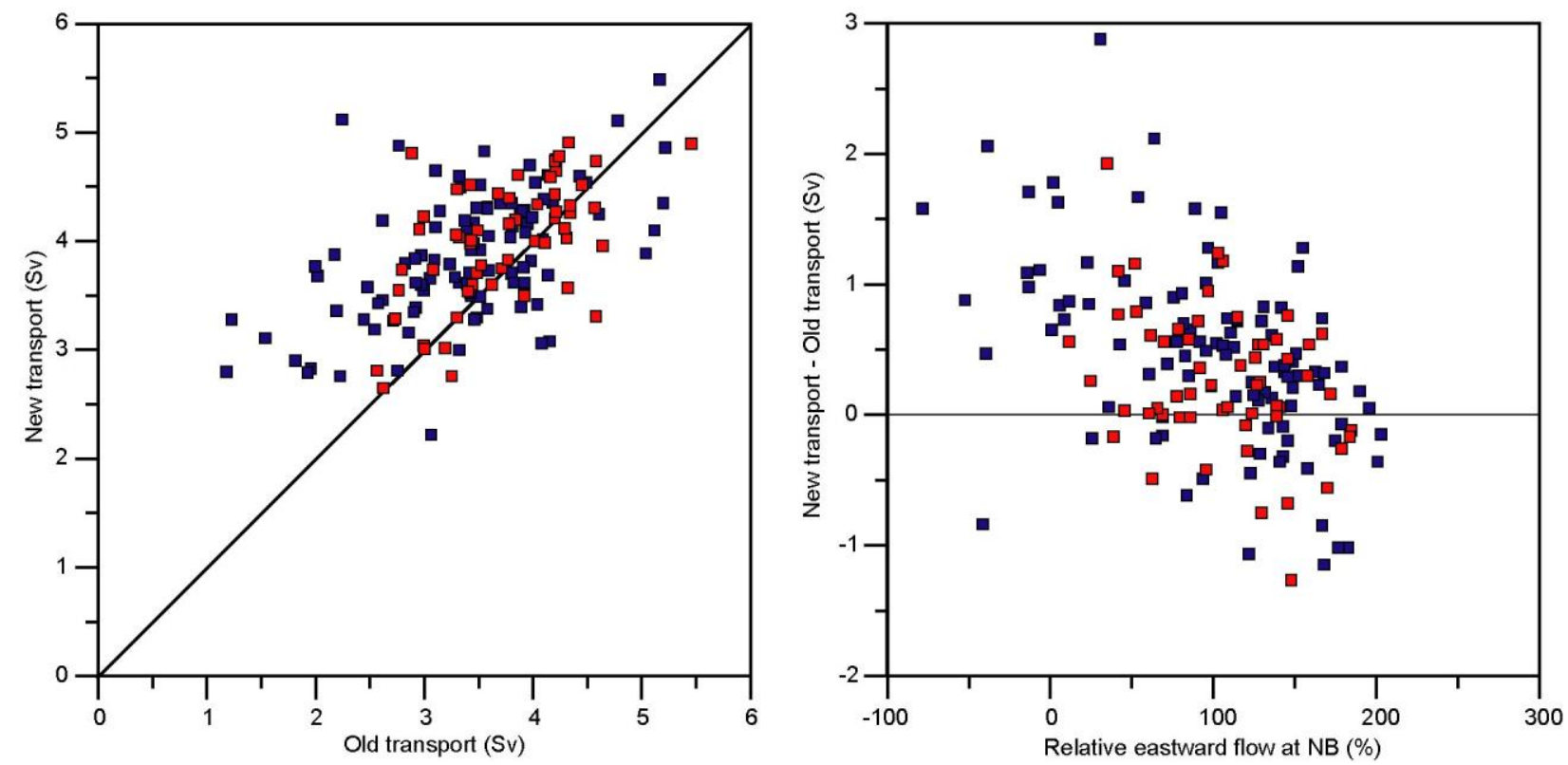

Figure 5.5.1 Comparison between monthly averaged Atlantic water transport calculated as described in this report (new) and the old estimates, which did not use altimetry data. Left panel: New transport plotted against old transport. Right panel: Difference between new and old transport estimates plotted against the relative eastward flow at site NB, defined as the depth-averaged ( 0 to $400 \mathrm{~m}$ ) eastward velocity divided by its average for all months. In both panels, red squares are for months with all four long-term ADCPs (NA, NE, $\mathrm{NB}$, and NG) in operation whereas blue squares are for months when one or more ADCPs were missing.

In order to explore the conditions under which the new estimate deviates strongly from the old estimate, we compared the difference between the two estimates with various parameters. One conclusion was that the eastward velocity at site NB is important (right panel in Figure 5.5.1). The large positive deviations occurred while this velocity was low compared to its average. When the ADCP at site NE was missing, in the old method the velocity at this site was simulated by multiple regression equations with eastward velocities at 
$\mathrm{NA}$ and NB as independent variables. This regression was found to give a good fit in the test period from summer 2000 to summer 2001 (Hansen et al., 2003) but, apparently, it breaks down when the eastward velocity at NB is abnormally low (Figure 5.5.1, right panel).

The monthly values in the old data set for periods when site NE was unoccupied are therefore suspect but, more generally, the horizontal interpolation also introduces uncertainties. The old method was based solely on the ADCP measurements with linear interpolation between them. For optimal results, this requires fairly high positive correlations between neighbouring ADCP sites. As seen in Table 3.1.2, this is generally not the case. In the new method, the surface velocities derived from altimetry should be better horizontal averages, since sea level change from one altimetry point to another depends on the horizontally averaged surface velocity.

A further problem with the old transport estimate is that, after 2000 (before which NE was unoccupied), there have been no ADCPs north of altimetry point $A_{5}$ (Figure 2.1) and transport north of site NG has been extrapolated. In the new time series, the transport of Atlantic water north of altimetry point $\mathrm{A}_{5}$ has an average value of $0.9 \mathrm{~Sv}$ with a standard deviation of $0.4 \mathrm{~Sv}$. These variations will not have been well captured in the old data set. 


\section{Transport of heat and salt}

\subsection{Relative heat transport}

The heat delivered by any inflow branch to the Arctic Mediterranean depends on the temperature of the water when it returns back to the Atlantic Ocean, either as overflow, or as surface outflow in the East Greenland Current or through the Canadian Archipelago. Thus, the heat transport of the IF-inflow is only well defined if we know the average outflow temperature. The detailed pathways of the various inflow branches are not well known, but most likely the average outflow temperature of the water that entered in the IF-inflow is close to $0^{\circ} \mathrm{C}$ (Hansen et al., 2008). Following tradition, we therefore calculate heat transport relative to this reference temperature, $T_{\text {Ref }}=0^{\circ} \mathrm{C}$, and term this "Relative heat transport".

To implement this, we modify Eq. (5.3.1) by multiplying each term in the volume transport by the temperature at depth $z$ and time $t$, horizontally averaged between altimetry grid points $\mathrm{A}_{\mathrm{k}}$ and $\mathrm{A}_{\mathrm{k}+1}, T_{k}(z, t)$ :

$$
Q_{\text {Heat }}(t)=\rho \cdot C \cdot \sum_{k=2}^{7} \sum_{z=0}^{600} U_{k}(0, t) \cdot \varphi_{k}(z, t) \cdot\left[T_{k}(z, t)-T_{\operatorname{Re} f}\right] \cdot W_{k}(z, t)
$$

where $\rho \cdot C$ is the heat capacity per cubic metre $\left(4.1 \cdot 10^{6} \mathrm{~J} /\left({ }^{\circ} \mathrm{C} \cdot \mathrm{m}^{3}\right)\right)$. From direct observations, we only know $T_{k}(z, t)$ for times of CTD cruises, but in Part 4.6, we showed that the temperature distribution may be simulated for other periods as well with a fair degree of accuracy (Figure 4.6.2), using as input the average 100-150m temperature at N03 (Figure 4.5.3, right panel) and the simulated depth of the $4^{\circ} \mathrm{C}$ isotherm (Table 4.2.2). From this, $T_{k}(z, t)$ is easily calculated at any given time.

When calculating the volume transport of Atlantic water, we have used the $4^{\circ} \mathrm{C}$ isotherm to define the Atlantic water extent on the section. This means that some of the water that crossed the IFR from the Atlantic may not be included in the estimate. Some of the water that is included may, on the other hand, have been admixed with Arctic water. Since $4^{\circ} \mathrm{C}$ is approximately midways between the temperatures of Atlantic $\left(\sim 8^{\circ} \mathrm{C}\right)$ and Arctic $\left(\sim 0^{\circ} \mathrm{C}\right)$ waters, this seems to be a reasonable combination of loss and gain for volume transport, although it contributes heavily to the uncertainty.

The Atlantic water that is lost in the volume transport estimate will, however, have a higher heat content than the Arctic water that is gained (except possibly for the surface layer in summer). For relative heat transport, the $4^{\circ} \mathrm{C}$ isotherm is therefore not very appropriate as a boundary for Atlantic water extent on the section. Instead, we should choose a colder boundary temperature, $T_{\text {Bound }}$. To see the effect of this, we calculated monthly averaged relative heat transport using different boundary temperatures to define the Atlantic water extent and compared the overall 1993-2013 average (Table 6.1.1).

Table 6.1.1 Average relative (to $0^{\circ} \mathrm{C}$ ) heat transport of the IF-inflow 1993-2013 using different boundary temperatures to define the Atlantic water extent and its trend with $95 \%$ confidence interval based on annual averages. The average temperature listed is averaged in terms of the average volume transport $(3.82 \mathrm{~Sv})$.

\begin{tabular}{lccccccc}
\hline Boundary temperature $\left({ }^{\circ} \mathrm{C}\right):$ & 5 & 4 & 3 & 2 & 1 \\
\hline Relative heat transport $(\mathrm{TW}):$ & 114 & 119 & 122 & 123 & 124 \\
Average temperature $\left({ }^{\circ} \mathrm{C}\right):$ & 7.3 & 7.6 & 7.8 & 7.9 & 7.9 & 7.9 \\
Trend (TW/year): & & $1.1 \pm 0.4$ & $1.1 \pm 0.5$ & $1.0 \pm 0.5$ & $1.0 \pm 0.5$ & $1.0 \pm 0.5$ & $1.0 \pm 0.5$
\end{tabular}

As could be expected, the relative heat transport is not very sensitive to the choice of boundary temperature, as long as it is low. In the following, we therefore use $0^{\circ} \mathrm{C}$ as boundary temperature. With this choice, we may possibly be including some Arctic water, but it will not contribute much. The monthly averaged relative heat transport by this definition varies by more than a factor of two (Figure 6.1.1).

When both the average relative heat transport $\left\langle Q_{\text {Heat }}(t)\right\rangle$ and the average volume transport of Atlantic water $\left\langle Q_{A t l}(t)\right\rangle$ have been determined, we can derive a transport averaged temperature $T_{A v g}=\left\langle Q_{\text {Heat }}(t)\right\rangle$ 
$/\left(C \cdot \rho \cdot<Q_{A t l}(t)>\right)$. Using the average value for volume transport based on the $4{ }^{\circ} \mathrm{C}$ isotherm $(3.82 \mathrm{~Sv})$, the relative heat transport values give average temperatures between $7.3^{\circ} \mathrm{C}$ and $7.9^{\circ} \mathrm{C}$ (Table 6.1.1), which seems reasonable.

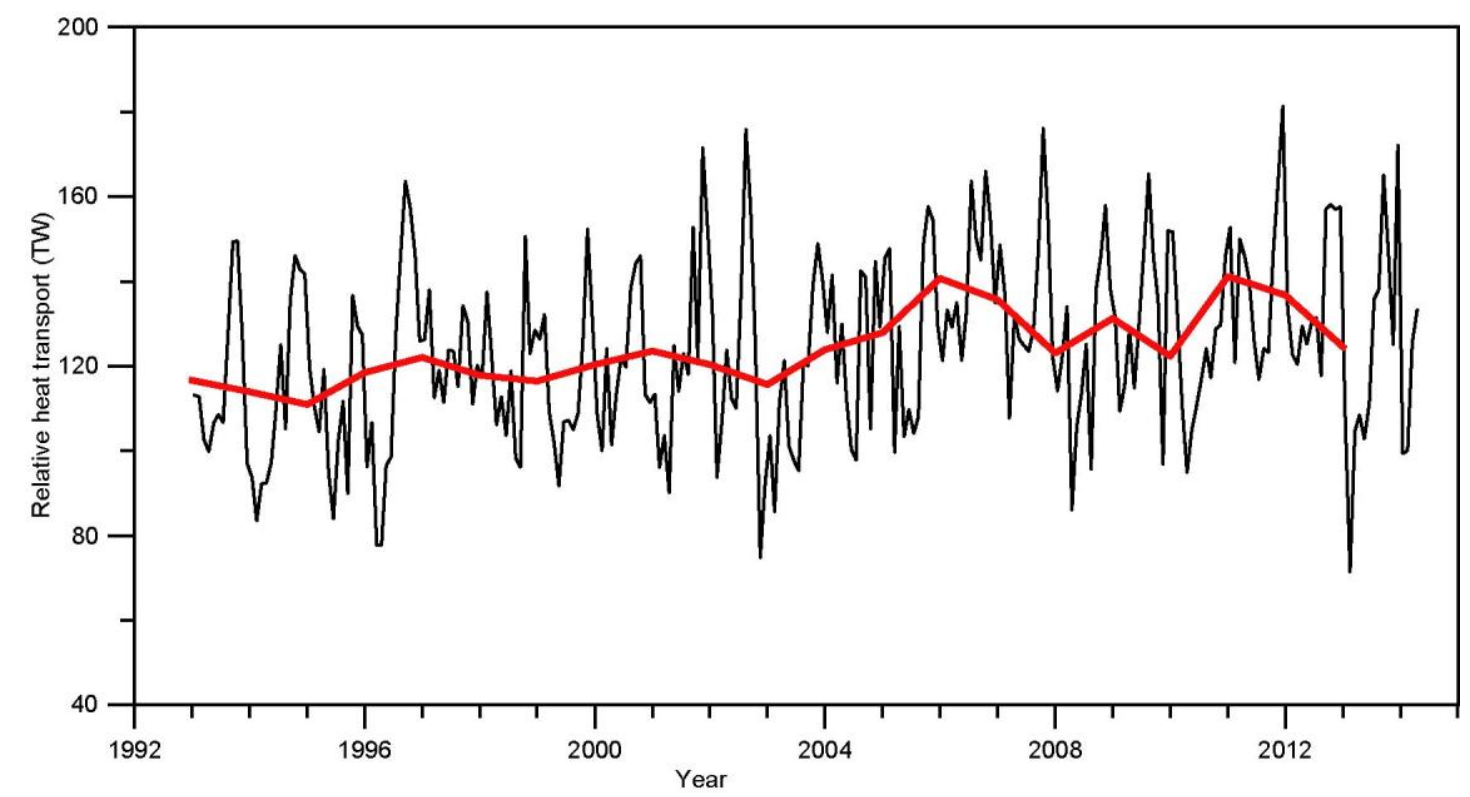

Figure 6.1.1 Monthly (black) and annually (red) averaged relative heat transport. The heat transport is relative to a reference temperature $T_{R e f}=0^{\circ} \mathrm{C}$ and is integrated over a simulated extent bounded by the temperature $T_{\text {Bound }}=0^{\circ} \mathrm{C}$, except for the surface layer, which is bounded by the simulated location of the 35.0 isohaline (Part 4.4).

The seasonal variation of the relative heat transport was determined iteratively (Appendix B). The seasonal fit to the relative heat transport had a maximum on day number 307 (red curve on Figure 6.1.2, left panel), which is 2 months before the maximum of the volume transport, but 1-2 months after the maximum of the Atlantic water temperature (Figure 4.5.3, left panel).
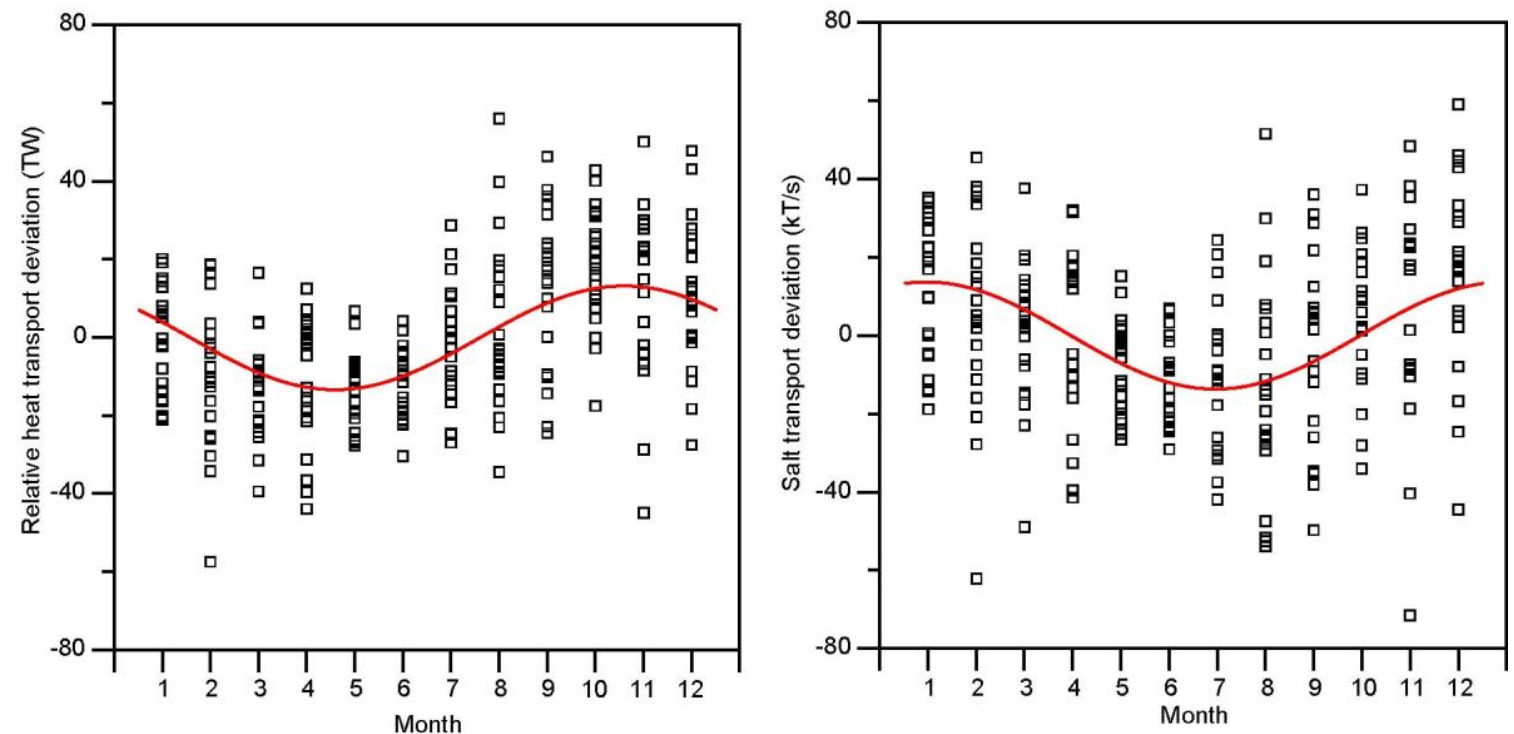

Figure 6.1.2 Seasonal variations of relative heat $\left(T_{r e f}=0^{\circ} \mathrm{C}, T_{B o u n d}=0^{\circ} \mathrm{C}\right.$, left panel $)$ and absolute salt $\left(S_{\text {ref }}=\right.$ $0, S_{\text {Bound }}=34.95$, right panel) transports 1992-2013. Each square represents iteratively highpassed transport deviation for one month. The red lines represent the iteratively determined sinusoidal seasonal fits. 


\subsection{Salt transport}

The salt transport through section $\mathrm{N}$ by Atlantic water is well defined in an absolute sense. Every cubic metre passing across the IFR with a salinity $S$, represents an input of salt to the Arctic Mediterranean equal to $1.03 . S \mathrm{~kg}$. Eventually, this salt is returned to the Atlantic by the overflows and surface outflows, but the returning water has been diluted by added freshwater and the low-salinity Pacific inflow through the Bering Strait. A rough budget estimate indicates that the salinity is reduced by about 1 psu on average (Hansen et al., 2008), but the overflows, which will return a large fraction of the IF-inflow, are more saline. In addition to the absolute salt transport, it may therefore be appropriate to consider the transport relative to some reference salinity $S_{\text {Ref: }}$ :

$$
Q_{\text {Salt }}(t)=1.03 \cdot \sum_{k=2}^{7} \sum_{z=0}^{600} U_{k}(0, t) \cdot \varphi_{k}(z, t) \cdot\left[S_{k}(z, t)-S_{\operatorname{Re} f}\right] \cdot W_{k}(z, t)
$$

where $S_{k}(z, t)$ is the salinity at depth $z$ and time $t$ averaged horizontally over the altimetry interval from $\mathrm{A}_{\mathrm{k}}$ to $\mathrm{A}_{\mathrm{k}+1}$. If we choose $S_{\text {Ref }}$ to be zero, we get the absolute salt transport. Otherwise, we get a relative salt transport. In Part 4.8, we demonstrated how to simulate the salinity at each point of the section based on data on the salinity of the Atlantic water and altimetry data. The salinity simulation did not explain as large a fraction of the variance as the temperature simulation, but still, it did explain $47 \%$ of the salinity variance within the typical Atlantic water extent (Figure 4.8.2). The basic unit for salt transport will be $\mathrm{kg} / \mathrm{s}$ but we use also $\mathrm{T} / \mathrm{s}=10^{3} \mathrm{~kg} / \mathrm{s}$ and $\mathrm{kT} / \mathrm{s}=10^{6} \mathrm{~kg} / \mathrm{s}$.

As for volume and heat transport, one problem with determining salt transport is to distinguish between the Atlantic water and other water masses. So far, we have grouped these other water masses into one group termed Arctic water, but there are several different types with different characteristics and origin and the Atlantic water mixes with waters with highly variable salinities. We can use the same strategy as for heat transport by defining a boundary salinity $S_{\text {Bound, }}$ which should represent the boundary of Atlantic water extent on the section at any time, but it is difficult to choose the most appropriate value for $S_{\text {Bound }}$. To get an impression of the sensitivity, Table 6.2.1 lists average transports for some different combinations of $S_{R e f}$ and $S_{\text {Bound. }}$

Table 6.2.1 Average (1993-2013) salt transport, average inflow salinity, and salt transport trend with 95\% confidence interval for different reference salinities and boundary salinities.

\begin{tabular}{l|ccc|cc|cc}
\hline & \multicolumn{3}{|c|}{$S_{\text {Ref }}=0$} & \multicolumn{2}{c}{$S_{\text {Ref }}=34.0$} & $S_{R e f}=34.95$ \\
$S_{\text {Bound }}:$ & 34.9 & 34.95 & 35.0 & 34.9 & 35.0 & 34.9 & 35.0 \\
\hline Salt transp.(kT/s) : & 149 & 138 & 127 & 4.83 & 4.23 & 0.807 & 0.798 \\
Average salinity: & 37.9 & 35.1 & 32.3 & 35.23 & 35.08 & 35.16 & 35.15 \\
Trend (T/s/year): & $1468 \pm 643$ & $1789 \pm 741$ & $2313 \pm 773$ & $71 \pm 22$ & $94 \pm 27$ & $32 \pm 7$ & $32 \pm 7$
\end{tabular}

Once the average salt transport $\left\langle Q_{\text {Salt }}(t)\right\rangle$ has been determined, we can estimate the average salinity of the Atlantic water as $S_{A v g}=\left\langle Q_{\text {Salt }}(t)\right\rangle /\left(1.03 \cdot\left\langle Q_{A t l}(t)\right\rangle\right)+S_{R e f}$. For absolute salt transport $\left(S_{R e f}=0\right)$, the result becomes critically dependent on the boundary salinity used, and we easily get some very unrealistic values, but choosing $S_{\text {Bound }}=34.95$, the average salinity looks reasonable (Table 6.2.1). Figure 6.1.2 (right panel) shows the seasonal variation of the absolute salt transport for this case. The relative salt transport is much less sensitive to the choice of $S_{B o u n d}$, especially for high values of $S_{R e f}$ and quite realistic values for the average salinity are obtained for $S_{R e f}=34.95$ (Table 6.2.1).

The absolute salt transport is highly correlated with volume transport, $\mathrm{R}=0.91$, for monthly averages and its seasonal variation has maximum close to the time of maximum volume transport. A linear regression of annually averaged salt transport on time yields trends that are positive and significantly different from zero for all choices of $S_{R e f}$ and $S_{\text {Bound }}$ that were tested (Table 6.2.1) and most significant, the higher the $S_{\text {Ref }}$ value, as might have been expected. 


\section{References}

Hansen, B. and Østerhus, S.: North Atlantic-Nordic Seas exchanges, Prog. Oceanogr., 45, 2, 109-208, 2000.

Hansen, B., Østerhus, S., Hátún, H., Kristiansen, R., and Larsen, K. M. H.: The Iceland-Faroe inflow of Atlantic water to the Nordic Seas, Prog. Oceanogr., 59, 4, 443-474, doi:10.1016/j.pocean.2003.10.003, 2003.

Hansen, B. and Østerhus, S.: Faroe Bank Channel overflow 1995-2005, Prog. Oceanogr., 75, 4, 817-856, doi:10.1016/j.pocean.2007.09.004, 2007.

Hansen, B., Østerhus, S., Turrell, W. R., Jónsson, S., Valdimarsson, H., Hátún, H., and Olsen, S. M.: The Inflow of Atlantic Water, Heat, and Salt to the Nordic Seas Across the Greenland-Scotland Ridge, in: Arctic-Subarctic Ocean Fluxes: Defining the Role of the Northern Seas in Climate, edited by: Dickson, R. R., Meincke, J., and Rhines, P., Chap. 1, 15-43, Springer Science + Business Media B. V., 2008.

Hansen, B., Hátún, H., Kristiansen, R., Olsen, S. M., and Østerhus, S.: Stability and forcing of the Iceland-Faroe inflow of water, heat, and salt to the Arctic, Ocean Sci., 6, 4, 1013-1026, doi:10.5194/os-6-1013-2010, 2010.

Hansen, B., Larsen, K. M. H., Hátún, H., Kristiansen, R., Mortensen, E., and Østerhus, S.: Increasing transports of volume, heat, and salt towards the Arctic in the Faroe Current 1993-2013, submitted to Ocean Science, 2015.

Hátún, H. and McClimans, T. A.: Monitoring the Faroe Current using altimetry and coastal sea-level data, Cont. Shelf Res., 23, 9, 859-868, doi:10.1016/S0278-4343(03)00059-1, 2003.

Hátún, H., Hansen, B., and Haugan, P.: Using an "inverse dynamic method" to determine temperature and salinity fields from ADCP measurements, J. Atmos. Oceanic Tech., 21, 3, 527-534, 2004.

Larsen, K. M. H., Hansen, B., and Svendsen, H.: Faroe Shelf Water, Cont. Shelf Res., 28, 1754-1768, doi:10.1016/j.csr.2008.04.006, 2008.

Larsen, K. M. H., Hátún, H., Hansen, B., and Kristiansen, R.: Atlantic water in the Faroe area: sources and variability, ICES J. Mar. Sci., 69, 5, 802-808, doi:10.1093/icesjms/fss028, 2012. 
Appendix A: Latitudes $\left({ }^{\circ} \mathrm{N}\right)$ and depths of observational points on section $\mathrm{N}$

\begin{tabular}{|c|c|c|c|}
\hline Altimetry point & A1 & 62.13 & \\
\hline CTD station & N01 & 62.33 & 88 \\
\hline Altimetry point & A2 & 62.38 & 92 \\
\hline CTD station & N02 & 62.50 & 118 \\
\hline Altimetry point & A3 & 62.63 & 194 \\
\hline CTD station & N03 & 62.67 & 240 \\
\hline ADCP site & $\mathrm{NA}$ & 62.70 & 300 \\
\hline ADCP site & $\mathrm{NE}$ & 62.79 & 455 \\
\hline CTD station & NO 4 & 62.83 & 550 \\
\hline Altimetry point & A4 & 62.88 & 700 \\
\hline ADCP site & $\mathrm{NF}$ & 62.88 & 700 \\
\hline ADCP site & NB & 62.92 & 925 \\
\hline ADCP site & ND & 62.96 & $>1000$ \\
\hline CTD station & N05 & 63.00 & $>1000$ \\
\hline ADCP site & NG & 63.10 & $>1000$ \\
\hline Altimetry point & A5 & 63.13 & $>1000$ \\
\hline CTD station & N0 6 & 63.17 & $>1000$ \\
\hline ADCP site & $\mathrm{NC}$ & 63.27 & $>1000$ \\
\hline CTD station & N07 & 63.33 & $>1000$ \\
\hline Altimetry point & A6 & 63.38 & $>1000$ \\
\hline CTD station & N0 8 & 63.50 & $>1000$ \\
\hline Altimetry point & A7 & 63.63 & $>1000$ \\
\hline CTD station & N09 & 63.67 & $>1000$ \\
\hline CTD station & N10 & 63.83 & $>1000$ \\
\hline Altimetry point & A8 & 63.88 & $>1000$ \\
\hline
\end{tabular}




\section{Appendix B: Iterative splitting of time series into seasonal and long-term variations}

Several of the time series considered in this report may be seen as superpositions of slowly varying signals + seasonal signals + short-term variations. The seasonal variation generally has a roughly sinusoidal shape and a simple analysis may be made by regressing the time series on a sinusoidal seasonal variation where the phase lag is varied to give maximum correlation. The long-term variation may since be calculated as a running mean of deseasoned values.

In this analysis, the seasonal variation is, however, often contaminated by the long-term variation and vice versa. To overcome this, we may use a more refined iterative procedure. First, we fit a sinusoidal seasonal variation to the raw series. This seasonal signal is subtracted from the raw series to produce a deseasoned signal, which is averaged over 3 years. The 3 -year running mean is subtracted from the raw series and the process repeated iteratively until it converges, which it does rapidly. In this way, we get a seasonal signal that is not so much contaminated by long-term variations and we get a time series of 3-year running mean, which is the average of all the deseasoned values within each 3 -year period. This also allows us to calculate the standard error of each 3-year mean value. 